\title{
Áreas de proveniencia de meta-sedimentos e interpretación geoquímica de ambientes tectónicos de deposición de la Formación Puncoviscana: Cordillera Oriental y Sierras Pampeanas, Argentina
}

\author{
Provenance of the Puncoviscana Formation meta-sediments and \\ geochemical interpretation of its tectonic-setting in Cordillera \\ Oriental and Sierras Pampeanas, Argentina
}

\author{
Alejandro J. Toselli ${ }^{1}$, Florencio G. AceñolazA ${ }^{1}$, Hubert MilleR ${ }^{2}$, Juana N. Rossi ${ }^{1}$ \\ 1 Instituto Superior de Correlación Geológica (INSUGEO). Miguel Lillo 205, (4000) Tucumán, Argenti- \\ na. ajtoselli@yahoo.com.ar; facenolaza@gmail.com; juanitarossi@gmail.com. \\ 2 Department für Geo-Unweltwissenschaften. München. Luisenstr. 37, 80333. Manchen. Germany. \\ hubert.miller@iaag.uni-muenchen.de.
}

> Resumen - La Formación Puncoviscana s.l. constituye una importante secuencia litoestratigráfica constituida dominantemente por psamitas y pelitas, con intercalaciones subordinadas de conglomerados, carbonatos y vulcanitas, depositadas en una cuenca somera, entre el Neo-Proterozoico y el Terreneuviano sobre el borde occidental de Gondwana, el cual se habría comportado, para algunos autores, como cuenca de antepaís y para otros, como borde continental pasivo, tesituras que nosotros combinamos, como secuencias de un mismo proceso evolutivo. En la Formación Puncoviscana s.l. se encuentran ichnofósiles agrupados en dos asociaciones con diferentes distribuciones: una zona con la asociación de Nereites saltensis, que correspondería a los niveles más altos del Ediacarano y otra con la asociación de Oldhamia radiata, que se ubicaría en niveles del Terreneuviano. Por otra parte los circones detríticos, dan una amplia gama de edades, que indican proveniencias desde terrenos Paleo-Proterozoicos, Meso-Proterozoicos y Neo-Proterozoicos a los que se suman los del Terreneuviano. Estos valores radiométricos corresponden a las diferentes áreas cratónicas reconocidas en el continente Sudamericano, con edades desde 2300 a 950 Ma. Aunque también se detectan edades entre 850 y $580 \mathrm{Ma}$, que indicarían actividad ígnea entre el final del Ciclo Sunsás y el comienzo del Ciclo Pampeano, que denominamos Ciclo Ancajano. Las secuencias clásticas de la Formación Puncoviscana, cuya base se inicia con el Ciclo Ancajano, constituye una secuencia continua formada desde meta-sedimentos a sucesiones metamórficas en Facies Esquistos Verdes a Anfibolitas, desarrolladas durante el Ciclo Pampeano y cuya culminación corresponde a la orogenia Tilcárica acaecida a los $520 \mathrm{Ma}$, evidenciada por la discordancia que la separa del Grupo Mesón. El desarrollo de la cuenca en un ambiente marginal distensivo entre los 580 y $540 \mathrm{Ma}$, dio lugar al desarrollo del magmatismo ultrabásico, a básico alcalino y a toleítico; mientras que la culminación de la secuencia sedimentaria, ya en un ambiente compresivo, entre los 540 y $520 \mathrm{Ma}$, genera el importante magmatismo calco-alcalino y meta- a per-aluminoso en la Cordillera Oriental y en las Sierras Pampeanas de Catamarca, Santiago del Estero y Córdoba. Los análisis geoquímicos realizados en los afloramientos representativos de los diferentes niveles de metamorfismo, permitió utilizar diagramas de elementos mayores, menores y trazas, para caracterizar ambientes de deposición de los sedimentos, que en general corresponden a «Margen Continental Activo» y «Arcos de Islas Oceánicas y Continentales». Por otra parte pudo establecerse que los detritos sedimentarios aportados a la cuenca de Puncoviscana, corresponde esencialmente a sedimentos cuarzosos y a rocas ígneas félsicas, que son típicas de Corteza Continental Superior (UCC), siendo los procesos sedimentarios muy similares en la totalidad de las rocas estudiadas, como lo demuestra la composición geoquímica global y el comportamiento de las tierras raras.

Palabras clave: Formación Puncoviscana, Ambiente tectónico, Proveniencia Corteza Continental Superior, Discriminación geoquímica. 
> Abstract - "Provenance of the Puncoviscana Formation meta-sediments and geochemical interpretation of its tectonic-setting in Cordillera Oriental and Sierras Pampeanas, Argentina". The Puncoviscana Formation sl. is an important lithostratigraphic sequence consisted of dominantly psammites and mudstones, interbedded with subordinate conglomerate, carbonates and volcanics deposited in a shallow basin between the Neo-Proterozoic and Terreneuvian on the western edge of Gondwana, which for some authors would have behaved as foreland basin and for others as a passive continental margin, a thesis we interpret like sequences of one same evolutionary process. In Puncoviscana formation sl. ichnofóssils are grouped into two associations with different distributions: an area with Nereites saltensis, which correspond to the highest levels of the Ediacaran and another one with Oldhamia radiata, which would fit on Terreneuvian levels. On another side, detrital zircons giving a wide range of ages, indicate provenances from Paleo-Proterozoic, Meso-Proterozoic and Neo-Proterozoic terranes to which are summoned those of Terreneuvian. The available radiometric values correspond to different cratonic areas recognized in the South American continent from 2,300 to 950 Ma. There are also detected zircon ages between 850 and $600 \mathrm{Ma}$, which indicate igneous activity between the end of the Sunsas and the beginning of the Pampean cycle. We propose the name of Ancajano Complex for this interval. Clastic sequences of the Puncoviscana formation, begin over the Ancajan Complex and comforms a continuous sequence from meta-sediments to Greenschists and Amphibolites metamorphic facies developed within the Pampean cycle and it ends with the Tilcaric orogeny occurred at $520 \mathrm{Ma}$, evidenced by the unconformity that separates the Puncoviscana Formation from Meson Group. The development of an extensional marginal basin between 580 and $540 \mathrm{Ma}$, led to the extrusion of basic alkaline, ultrabasic to a tholeiitic magmatism; whereas the culmination of the sedimentary sequence, and in a subduction environment, between 540 and $520 \mathrm{Ma}$, it generates significant calc-alkaline and a per-aluminous magmatism in the Eastern Cordillera and Precordillera of Catamarca, Santiago del Estero and Córdoba provinces. Geochemical analyzes on representative outcrops of different metamorphic levels, allowed us to use major, minor and trace element diagrams to characterize environments of deposition of sediments, which generally correspond to "Active Continental Margin" and "Oceanic and Continental Arc Islands". In addition, it could be shown that sedimentary debris which contributed to the Puncoviscana basin, essentially correspond to siliceous sediments and igneous felsic, which are typical of Upper Continental Crust (UCC), being very similar sedimentary processes in all the studied samples, as evidenced by the overall chemical composition and behavior of the Rare Earth Elements.

Keywords: Puncoviscana formation, Tectonic setting, Upper Continental Crust source, Geochemical discrimination.

\section{INTRODUCCIÓN}

Desde el sur de Bolivia y continuando en el noroeste de Argentina, hasta Córdoba y San Luis, se desarrollaron una serie de cuencas de carácter intra- a pericratónicas en el borde de Gondwana occidental, con desarrollo de depósitos clásticos heterogéneos de importante significación regional, entre el Ediacarano y el Terreneuviano, conocida como cuenca de Puncoviscana. Estas estuvieron controladas por los núcleos cratónicos denominados «Amazónico Occidental o Guaporé», «Mara», «Río Apa - Río de La Plata», «Arequipa - Antofalla» y «Margen activo Meso-Proterozoico superior», con edades superiores a los $2 \mathrm{Ga}$.

Básicamente, las rocas que afloran en territorio argentino, se asignan a la Formación
Puncoviscana s.l. que tiene varias unidades equivalentes con afloramientos en el borde andino desde el sur de Bolivia (Formación San Cristóbal), en localidades de Sierras Pampeanas (formaciones Suncho, Negro Peinado, San Luis, etc.) hasta el norte de la Patagonia (Formación Jagüelito) sensu Aceñolaza y Aceñolaza (2005).

Por otra parte el desarrollo de esta cuenca o sub-cuencas, han tenido distintas interpretaciones geotectónicas, ya sea como formada en un margen pasivo relacionada a extensión por rift (Aceñolaza y Miller, 1982; Ježek et al., 1985; Willner et al., 1983; Do Campo y Riveiro Guevara, 2005); o la propuesta dada por Kraemer et al. (1995), Keppie y Bahlburg (1998) y Zimmermann (2005), que sostienen que el desarrollo de la cuenca de 
antepaís se produjo por deformación cortical debido a la carga sedimentaria, al oeste del orógeno Pampeano. Ambas hipótesis han sido presentadas y discutidas en numerosos trabajos, utilizando distintos tipos de argumentos.

Nosotros sostenemos que la secuencia sedimentaria se ha iniciado en una cuenca distensiva desarrollada con dirección NNESSO, siguiendo una de las ramas de la estructura aulacogénica (Aceñolaza y Durand, 1986), que evoluciona desde el «Triple Punto Boliviano», en el este de Bolivia, que ya fue enunciada por Kroner (1981) y posteriormente desarrollada por Litherland et al. (1986) y Suarez Soruco $(1989,2000)$. Este Punto Triple habría sido el responsable de la ruptura de los núcleos antiguos de Guaporé, Arequipa-Antofalla y Río de La Plata, que controló el desarrollo de las cuencas que se desarrollaron en la región entre el Neo-Proterozoico y el Paleozoico inferior, que se extiende desde Bolivia hasta la región central de Argentina. Los trabajos de Tosdal (1996) y Lucassen et al. (2000) basados en datos geológicos, geocronológicos y geoquímicos establecieron la estrecha afinidad existente entre Arequipa-Antofalla y el Cratón Amazónico Occidental.

De dichos antecedentes y siguiendo a Litherland et al. (1986) consideramos la asignación del Ciclo San Ignacio-Sunsás como la referencia estratigráfica y cronológica más adecuada para constituir el basamento con edades del orden de 1400 a 950 Ma. Esta cuenca, que corresponde al orógeno Pampeano, está limitada al oeste, por el terreno de Arequipa-Antofalla y al este por los cratones de Guaporé y Rio de la Plata.

En la región norte de la Cuenca predominan las rocas sedimentarias que han sufrido procesos diagenéticos a bajo grado de metamorfismo, mientras que hacia el sur predominan áreas con rocas metamórficas de mediano grado. Algunos autores como Willner (1990) y Willner y Miller (1986) argumentan sobre la base de evidencias geoquímicas que las rocas más deformadas y con mayor metamorfismo, representarían niveles corticales más profundos y por ende más antiguos, de las sucesiones supra-corticales. Por otra parte Mon y Hongn (1991), interpretan las diferentes sucesiones metamórficas, como relacionadas a diferentes eventos tectono-metamórficos.

Debido a las diferentes interpretaciones ambientales sostenidas hemos seleccionado afloramientos representativos para los estudios geoquímicos de las rocas silico-clásticas, de las secuencias de la Quebrada de Humahuaca y sierras del Campo, Guasayán y San Javier, junto a localidades de bajo a mediano grado de metamorfismo de las sierras de Ancasti, Quilmes, Cumbres Calchaquíes, La Cébila y Famatina, con miras a relacionar los resultados con los obtenidos por otros autores que ya realizaron estudios similares en diferentes localidades Sierras Pampeanas, Sierras de Famatina, Cordillera Oriental y Puna, como von Gosen $(2009,2014)$, Zimmermann (2005) y en la sierra de Los Llanos (Verdecchia et al. 2014). Los análisis los hemos integrado con las bases de datos publicados por (Willner et al., 1983; Lottner, 1986; Rossi et al., 1997; von Gosen, 2009), que permiten caracterizar los ambientes en los que se produjo la deposición. Con esto pretendemos vincular los eventos tectónicos del Neo-Proterozoico-Cámbrico inferior en territorio argentino e identificar la base de la Formación Puncoviscana y las áreas de proveniencia del material sedimentario, para interpretar la evolución del margen del Gondwana occidental. Los resultados obtenidos serían complementarios, con las conclusiones obtenidas por los autores mencionados.

\section{ANTECEDENTES}

Los depósitos más antiguos reconocidos en el continente sudamericano y sus eventos magmáticos-metamórficos asociados, estarían relacionados con cuencas pericratónicas que corresponden a varios ciclos orogénicos cuya mayor expresión geológica se desarrolla en el borde amazónico boliviano-brasileño. Allí se reconoció la existencia de varios eventos que, según Litherland et al. (1986), se caracterizan bajo las denominaciones de 
Ciclo San Ignacio (1400-1280 Ma), Ciclo Sunsás (1280-950 Ma) y Ciclo Brasiliano (950-500 Ma) sensu Almeida et al. (1981). Con algunas diferencias autores brasileños como Colombo et al. (1999), a estos ciclos se los reconoce como Provincias Geocronológicas y que si bien se fundamentan en dataciones de rocas, las mismas presentan algunas variaciones en sus valores y se las denomina: Río Negro-Jurena (1800-1550 Ma); Cinturón Rondoniana-San Ignacio (1560-1300 Ma); Bloque Paraguá ( $>1700 \mathrm{Ma}$ ); Ventuarí-Tapajós (1950 - 1800 Ma); Escudo Amazónico (>2300 Ma); Cratón del Río de la Plata (2200 Ma) y Arequipa-Antofalla (1100 Ma) (Fig. 1), o sea valores correspondientes al
Paleo-Proterozoico, Meso-Proterozoico y Neo-Proterozoico.

Dataciones radimétricas realizadas sobre el llamado Cratón de Arequipa-Antofalla («Terrane») permiten identificar rocas con valores correlacionables al cratón Amazónico del área boliviano-brasileño, lo mismo ocurre con los estudios de afinidad geoquímica con el Cratón Amazónico occidental (Tosdal, 1995; Lucassen et al., 2000).

También en el borde occidental del Cratón del Río de la Plata, se reconocen rocas cronológicamente vinculadas con las del borde occidental amazónico (Gaucher, 2005, 2009; Aceñolaza y Toselli, 2009; Toselli et al. 2012), al igual que en el ámbito de las sie-

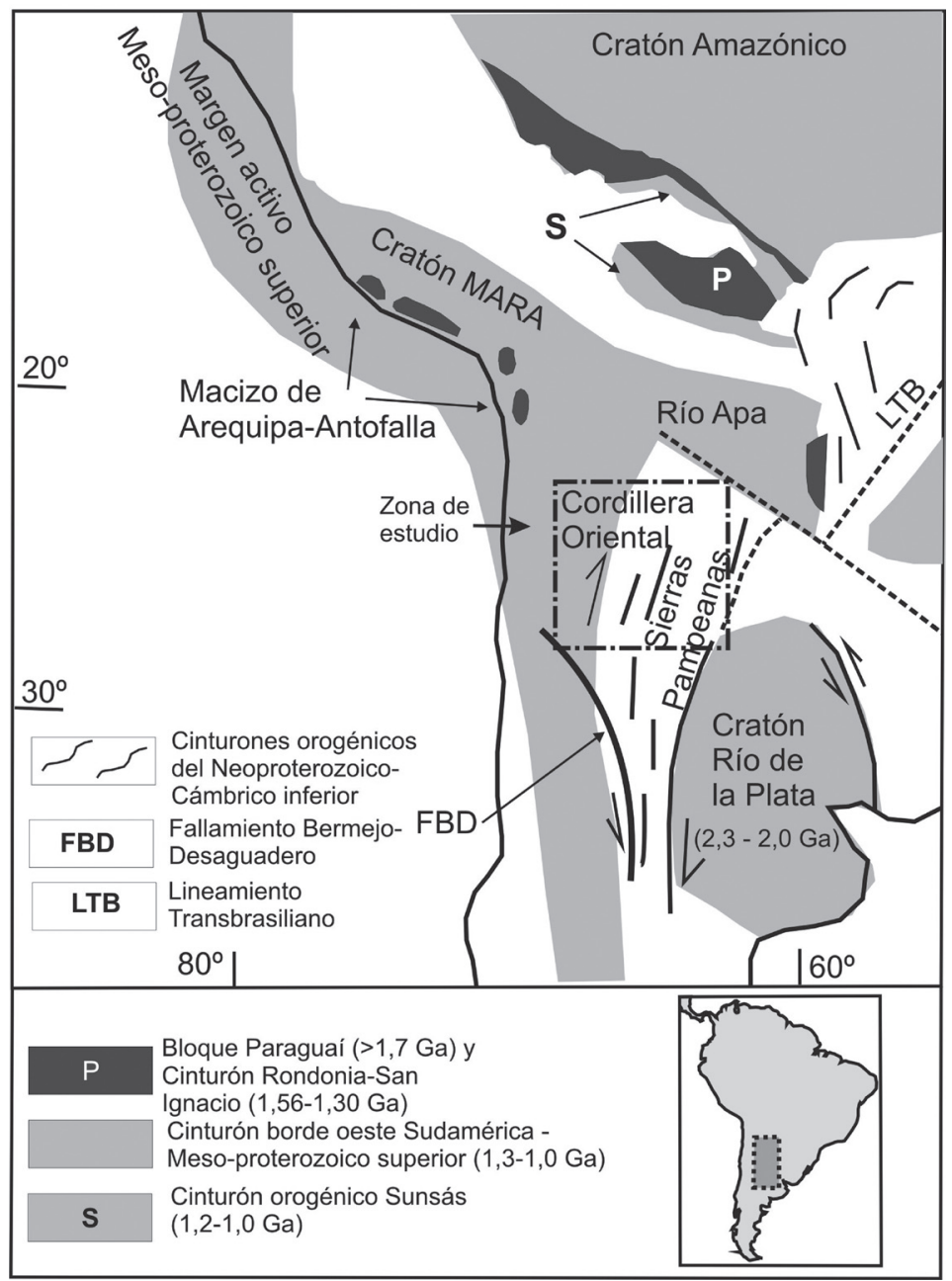

Figura 1. Esquema geotectónico con la ubicación de la región estudiada y su relación en el contexto de las principales unidades cratónicas de Sudamérica. 
rras de Córdoba, Santiago del Estero y provincia de Buenos Aires (Rapela et al., 2007; Sims et al., 1999).

Al referirnos a la Formación Puncoviscana s.l., es importante tener en cuenta su significado crono-estratigráfico, así como el marco regional en el que se desarrolló la sedimentación. Los datos cronológicos obtenidos de los circones detríticos, permiten interpretar el origen y procedencia de las rocas que la componen y sus relaciones con diferentes eventos orogénicos.

Con respecto a su ubicación estratigráfica en primer lugar se destaca que por su contenido paleontológico se asigna esta unidad al lapso Ediacarano-Terreneuviano. Trazas y cuerpos fósiles encontrados en distintas localidades del noroeste argentino, permiten asignar la icnofacies de Nereites saltensis a los niveles más altos del Ediacarano; mientras que los que contienen Oldhamia radiata forman parte de niveles del Terreneuviano (Cámbrico inferior) (Durand y Aceñolaza, 1990; Aceñolaza y Aceñolaza, 2005).

En los últimos años al intensificarse las dataciones isotópicas sobre circones detríticos presentes en diferentes afloramientos se comprueba que los datos obtenidos tienen un amplio rango cronológico. Las poblaciones de mayor edad presentan valores del orden de los $850 \mathrm{Ma}$, mientras que las rocas portadoras de icnofósiles se sitúan en los 540 - $525 \mathrm{Ma}$.

El techo de la Formación Puncoviscana se sitúa en los $\sim 520 \mathrm{Ma}$, posición cronológica que tiene a la Orogenia Tilcárica como responsable de la gran deformación tectónica que afectó a los afloramientos de la Formación Puncoviscana y unidades equivalentes, las cuales estuvieron acompañados por eventos ígneo-metamórficos. En discordancia angular, por sobre éstos, se dispone la sucesión siliciclástica de edad cámbrica correspondiente al Grupo Mesón (discordancia tilcárica).

Este buen conocimiento sobre el tope de esta unidad estratigráfica, es totalmente diferente con respecto a su base, de la que no se conoce fehacientemente ni su edad, ni sobre que terrenos se asienta, teniendo en cuenta el rol que le cupo a los núcleos proterozoicos de la región (Fig. 1). Como ya se dijo, por un lado estaba el Cratón Amazónico Occidental (Guaporé) mientras que por otro lo eran el de Arequipa-Antofalla y el del Río de la Plata con edades $>1500$ Ma y que en consecuencia debieron aportar a la cuenca sus detritos. Es conocido que en el margen del Macizo Guaporé se desarrolló una cuenca periférica cuyos datos cronológicos van desde 1280 a 950 Ma (Cuenca Sunsás). En este mismo lapso hay depósitos y rocas ígneo-metamórficas en el núcleo Arequipa-Antofalla y en el borde occidental del Río de La Plata.

Como se ve, en ese lapso temporal y constituyendo poblaciones de circones hay diversas agrupaciones que dan indicios de acontecimientos ígneos pre-Puncoviscana. En localidades de la sierra de Ancasti y de la quebrada de Humahuaca, es notable que la población de circones más jóvenes tienen valores mayores a los $900 \mathrm{Ma}$, lo que significa que éstos terrenos formarían parte del Ciclo Sunsás. Pero hay otros afloramientos cuyos picos más jóvenes tienen valores del orden de los 800 Ma., y otros aún más jóvenes con valores de 600 Ma. Dichas poblaciones son previas a las propias de Puncoviscana s.l. ( $\sim 540 \mathrm{Ma})$ (Aceñolaza et al., 2010. Esto implica interpretar que hay rocas correspondientes a otros ciclos entre Sunsás y Puncoviscana, sobre los cuales se apoyaría esta unidad. El problema de identificación, se da cuando se sospecha que la litología de Puncoviscana s.l. y las correspondientes a los ciclos previos parecen ser similares, lo que dificulta diferenciar las rocas que originaron y proveyeron los circones. Por otra parte no se han identificado fehacientemente macizos con edades entre 850 y 600 Ma.

En un trabajo anterior (Adams et al., 2011) hemos planteado un cuadro estratigráfico indicando que la posición de la base de Puncoviscana habría de posicionarse en el Criogeniano, sin descartar una edad algo más joven correspondiente al Ediacarano. Ello llevaría a suponer que habría ciclos orogénicos previos, no identificados, en la cuenca en la que se depositó la Formación Puncoviscana. 
En general las secuencias meta-sedimentarias de la Formación Puncoviscana s.l., están integradas esencialmente por rocas clásticas con bajo grado de metamorfismo, con caracteres de turbiditas (Ježek y Miller, 1986, 1987; Ježek, 1990). Los estudios sedimentológicos de (Ježek et al., 1985, 1986; Ježek, 1990; Durand, 1990) y con apoyo de datos químicos (Willner et al., 1985; Willner, 1987) describieron las litologías de dichas rocas meta-sedimentarias (Fig. 2). En general la secuencia geológica muestra importante deformación regional y metamorfismo de bajo a mediano grado. Con desarrollo restringido, se presentan niveles de conglomerados, carbonatos e intercalaciones volcánicas (Aceñolaza et al., 1988; Durand, 1990; Porto et al., 1990; Omarini et al., 1999a; Escayola et al., 2011).

La continuación de los afloramientos de la Formación Puncoviscana hacia el sur en las Sierras Pampeanas, con rocas de mayor grado metamórfico, es interpretada como una transición continua (Willner et al., 1987; Aceñolaza et al., 1988). No obstante uno de los mayores obstáculos para correlacionar las diferentes unidades, es la ausencia de fósiles en amplias regiones, que no permite subdivisiones dentro de las monótonas secuencias meta-clásticas. Asimismo, las sucesiones, litológicamente monótonas, están afectadas por importantes deformaciones y actividad magmática del Cámbrico medio al Ordovícico inferior (Rapela et al., 1998), que dificulta establecer correlaciones regionales o medir espesores reales.

Los datos de isótopos de $\mathrm{Nd}$ de las rocas meta-sedimentarias de bajo-grado obtenidos por Bock et al. (2000); así como los datos de medio- a alto-grado de metamorfismo (esquistos, gneises y calco-silicatos) obtenidos por Pankhurst et al. (1999); Pakhurst y Rapela (1998); Rapela et al. (1998); Lucassen et al. (2000), representan solo áreas restringidas, con edades de formación de corteza que varía entre 1,5 y 1,8 Ga, para los metasedimentos de bajo grado y de 1,5 a 2,1 Ga, para las rocas metamórficas de mediano- a alto grado.
Las edades de circones detríticos contenidos en las rocas, cubre un espectro de proveniencias de áreas continentales, con edades comprendidas entre el Paleo-Proterozoico, Meso-Proterozoico y Neo-Proterozoico temprano (entre 1900 a $850 \mathrm{Ma}$ ). También se determinan edades criogenianas y ediacaranas entre 850 y $541 \mathrm{Ma}$. La morfología de los circones encontrados en algunas secuencias silico-clásticas, tobáceas y volcánicas, evidencian la actividad magmática (volcánica y plutónica), que ocurre en el Terreneuviano, desarrollada en algunas áreas de deposición de la Formación Puncoviscana.

En general los sedimentos tienen su fuente en las diferentes áreas cratónicas, escudos y cinturones más antiguos ya mencionados, todos los cuales se consideran potenciales fuentes de sedimentos transportados por los ríos que fluyeron hacia el margen pasivo del océano paleo-Pacífico (Adams et al., 2005, 2008a, b, 2009, 2011; Aceñolaza et al., 2010). No debe olvidarse las edades Meso-Proterozoicas del terreno ArequipaAntofalla (1100 Ma), situado al oeste de la cuenca y cuyo aporte sólo fue explorado por Ježek (1990). En la figura 3 se sintetizan las edades y los limites temporales asignados a los diferentes ciclos.

Adicionalmente, deben considerarse los datos bio-estratigráficos y radiométricos que son consistentes con las edades de deposición de la Formación Puncoviscana, en el Ediacarano-Terreneuviano (Aceñolaza y Aceñolaza, 2005, y referencias allí citadas) y las edades $\mathrm{Rb} / \mathrm{Sr}$ de metamorfismo de 541, 540 y 504 Ma, en las provincias de Tucumán y Salta (Adams et al., 2005).

Autores como von Gosen (2009, 2014); Zimmermann (2005); Simpson et al. (2003); Schwartz y Gromet (2004); Rossi et al. (1997); Keppie y Bahlburg (1998) entre otros, fueron ajustando la interpretación de los depósitos silico-clásticos del Paleozoico, utilizando los datos geoquímicos como base de trabajo, logrando importantes resultados en regiones de las provincias de Catamarca, La Rioja, Salta, Santiago del Estero y Córdoba. 


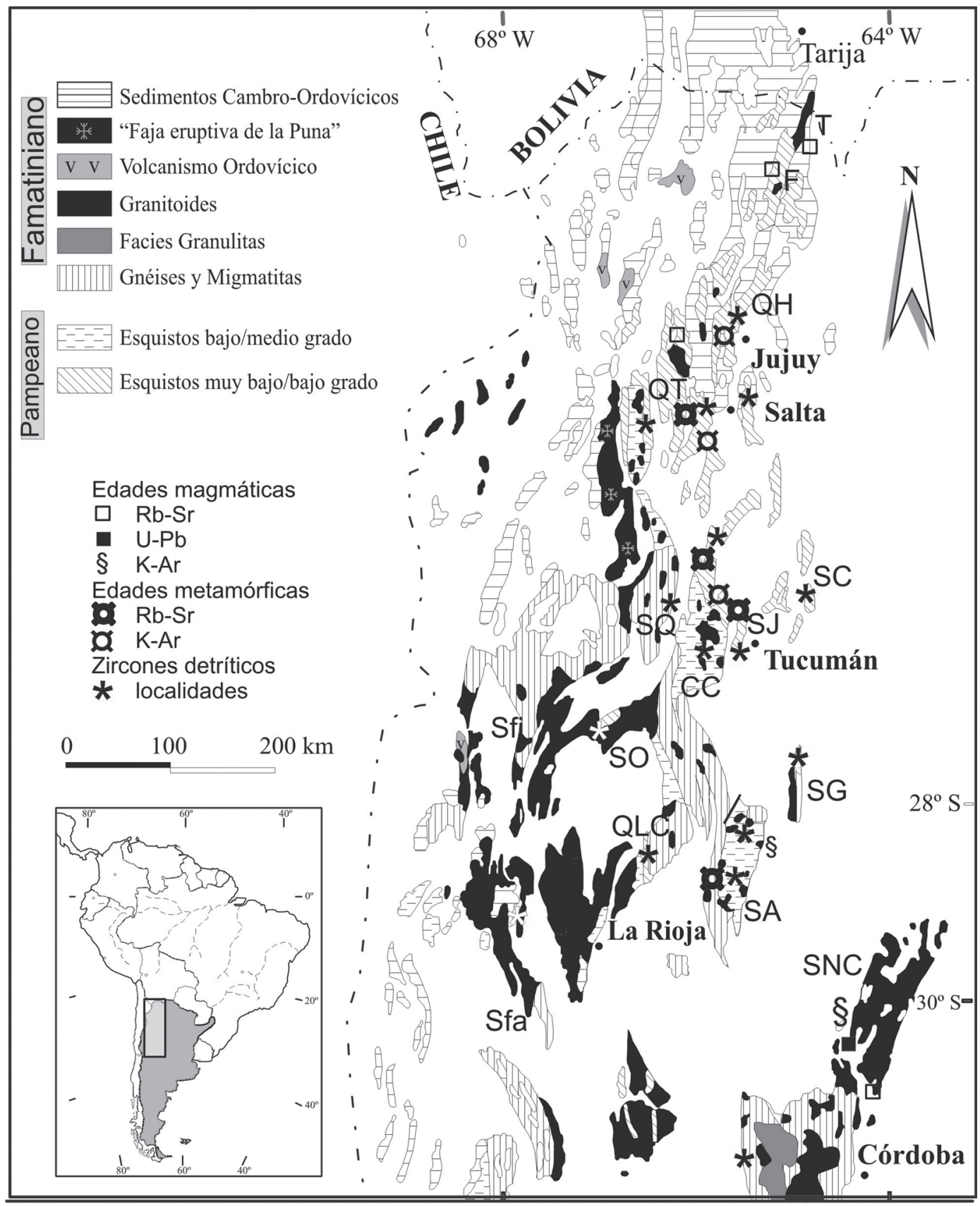

Figura 2. Mapa geológico del noroeste de Argentina, mostrando las áreas con dataciones conocidas. Los símbolos representan los isótopos utilizados para rocas ígneas y metamórficas. Las áreas datadas se identifican como sigue: QH: Quebrada de Humahuaca. QT: Quebrada del Toro. SQ: sierra de Quilmes. CC: Cumbres Calchaquíes. SJ: San Javier. SC: sierra del Campo. SG: sierra de Guasayán. SA: sierra de Ancasti. SFa: sierra de Famatina. SFi: sierra de Fiambalá. QC: Quebrada La Cébila. SNC: sierra Norte de Córdoba. Intrusivos graníticos: T: Tipayoc. C: Cañani. SR: Santa Rosa de Tastil. M: Mojotoro. AB: Albigasta. I: Icaño. 


\begin{tabular}{|c|c|c|c|c|c|c|}
\hline EON & ERA & EDAD: & PERIODOS & EDAD & CICLOS & OROGENIA \\
\hline \multirow{3}{*}{ 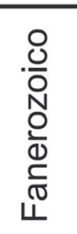 } & \multirow{3}{*}{ Paleozoico } & \multirow{8}{*}{ 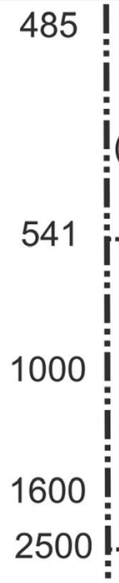 } & \multirow{3}{*}{$\begin{array}{c}\text { Ordovícico } \\
\text { (Furongiano) } \\
\text { Cámbrico } \\
\text { (Terreneuviano) }\end{array}$} & \multirow{3}{*}{520} & Famatiniano & \multirow{3}{*}{ Tilcárica } \\
\hline & & & & & & \\
\hline & & & & & Pampeano & \\
\hline \multirow{5}{*}{ 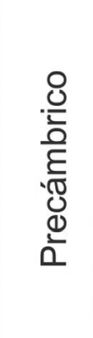 } & \multirow[t]{2}{*}{ Neo-proterozoico } & & & \multirow{2}{*}{$\begin{array}{l}580 \\
850\end{array}$} & Ancajano & \multirow[t]{2}{*}{ ¿? } \\
\hline & & & & & Sunsás & \\
\hline & Meso-proterozoico & & & \multirow{2}{*}{$\begin{array}{l}1200 \\
1520\end{array}$} & San Ignacio & \multirow[t]{3}{*}{ ¿? } \\
\hline & Paleo-proterozoico & & & & & \\
\hline & Arqueano & & & & & \\
\hline
\end{tabular}

Figura 3. Cuadro cronoestratigráfico con las edades propuestas por la IUGS (2015) y con los valores asignados a los ciclos y orogenias en Sudamérica.

\section{PETROGRAFÍA}

Las rocas sedimentarias clásticas que constituyen a la Formación Puncoviscana, son interpretadas por Ježek y Miller (1986) y Ježek (1990) como los protolitos de las secuencias metamórficas de bajo y mediano grado, que están formadas por rocas policíclicas depositadas en un margen continental pasivo, estando caracterizadas por cuarzo dominante, con feldespatos y litoclastos volcánicos y sedimentarios angulosos, así como por material limo-arcilloso, que indican baja selección, junto a relativamente corto transporte y rápido soterramiento.

Dichos caracteres petrográficos son interpretados por Zimmermann (2005) como correspondientes a una cuenca de antepaís, que no permiten en general, la maduración de los sedimentos y que corresponden a un ciclo sedimentario. Nosotros consideramos que dichos caracteres petrográficos son claramente correspondientes con este ambiente, que corresponde a la culminación de la evolución de la cuenca que se inició como ambiente distensivo y culminó como cuenca de antepaís, con la deposición de los sedimentos típicos que caracterizan a la Formación Puncoviscana.

Para caracterizar la distribución y caracteres petrográficos de las rocas de la Forma- ción Puncoviscana y términos equivalentes con mayor metamorfismo, se han seguido criterios de campo, junto a las evidencias geocronológicas. La petrografía, idealmente requiere para su clasificación, que las rocas sílico-clásticas tengan baja madurez y granulometría adecuada. La mayoría de las rocas de la Formación Puncoviscana son de grano medio a fino y están pobremente seleccionadas, con altos contenidos de matriz, que hacen difícil realizar la cuantificación de minerales por medio de un contador de puntos, por lo que las clasificaciones petrográficas son esencialmente cualitativas. Ante estas dificultades, se las clasificó utilizando diagramas geoquímicos, que se presentan más adelante. Las localidades estudiadas corresponden a las sierras de Famatina, San Javier, Nogalito, del Campo, Ancasti, Choromoro, Quilmes, Cumbres Calchaquíes, quebradas de Humahuaca, del Toro, de Purmamarca, y de La Cébila. En general se las clasifica como litarenistas y grauvacas que gradan a limolitas y pelitas, que habrían resultado de un transporte sedimentario relativamente breve sin procesos mayores de reciclaje, que no permitió maduración del material, ni alteración avanzada. Esto se observa en los clastos de feldespatos frescos, o con débil alteración. Esta aparente contradicción con las edades de los circones, indica que los 
materiales lábiles correspondientes a fuentes más distantes son degradados granulométricamente con el transporte y sólo los materiales provenientes de áreas más próximas son los que sobreviven para formar las rocas estudiadas. En diferentes localidades de la Formación Puncoviscana, se ha observado el desarrollo de pseudo-matriz, que se relaciona con la disolución de litoclastos poco estables, tales como sedimentarios de grano fino, o de componentes volcánicos.

En los ambientes modernos, la alteración está fuertemente condicionada por los ácidos orgánicos en ambientes tropicales húmedos. Considerando que no había vegetales que cubrieran los continentes en el Neo-Proterozoico - Terreneuviano, deducir la influencia de un control climático es difícil, pero se puede interpretar que durante el transporte se produjo la débil alteración de los minerales lábiles y de los litoclastos, en un ambiente de tipo cálido y húmedo como los postulan para esta época (Ramstein et al., 2004).

\section{OROGENIA TILCÁRICA}

Los procesos de deformación, metamorfismo y plutonismo asociado a la Cuenca de Puncoviscana, tiene lugar en el Cámbrico inferior a medio y se activan con el cierre de la cuenca, relacionada probablemente con la colisión del terreno Arequipa-Antofalla con el margen oeste de Gondwana y la actividad de la placa paleo-Pacífica.

En la secuencia meta-sedimentaria deformada se desarrollan pliegues abiertos y clivaje de plano axial en los niveles pelíticos, con metamorfismo de Facies Esquistos Verdes. Asimismo, en el basamento en el noreste de Tucumán, el desarrollo del metamorfismo es esencialmente sin-cinemático y los eventos térmicos son particularmente evidentes en las proximidades de los plutones graníticos. El metamorfismo generalmente desarrolla re-cristalización de la matriz y la orientación preferencial de las micas. En algunas áreas del basamento se alcanzan las zonas de la clorita, biotita, granate, estaurolita y sillimanita, en las sierras de Quilmes, Ancasti y Cumbres Calchaquíes. En estas localidades no es fácil determinar donde los eventos metamórficos corresponden a la orogenia Tilcárica, o a eventos orogénicos y metamórficos posteriores acaecidos en tiempos ordovícicos (Ciclo Famatiniano, sensu Aceñolaza y Toselli, 1976).

Es importante tener en cuenta que la orogenia Tilcárica, acaecida entre los 540 y 520 Ma, es más antigua que el Grupo Mesón de edad Cámbrica media a superior, que se deposita discordantemente sobre la Formación Puncoviscana, especialmente en las provincias de Jujuy, Salta, Catamarca y Tucumán.

\section{METAMORFISMO}

Sobre la base de la propuesta original de Willner y Miller (1986) y Willner (1990), de división en zonas tectono-metamórficas, se consideran dos tipos de agrupaciones: a) Unidades en las que se reconocen sus caracteres sedimentarios (Zonas I y II); y b) Unidades con metamorfismo donde ya se han borrado los caracteres sedimentarios (Zona III).

\section{ZONA I}

Corresponde a la típica Formación Puncoviscana de las provincias de Salta y Jujuy, donde las rocas silico-clásticas psamíticas están constituidas por granos de cuarzoplagioclasa-feldespato potásico-clorita-micas blancas-fragmentos líticos, opacos y minerales pesados, que varían de sub-angulares a sub-redondeados y se interpretan como depositados en un ambiente marino somero (Ježek, 1990). Los colores varían generalmente de grises a verdes y sólo localmente tienen colores rojizos, especialmente en las rocas pelíticas. El conjunto pertenece a un piso tectónico somero, donde las características sedimentarias y la microfábrica original son visibles. Las rocas muestran un solo plegamiento penetrativo, aunque existen deformaciones sin-sedimentarias. El clivaje $S_{1}$ se desarrolló solo en pelitas, mientras que las psamitas presentan un débil bandeado como clivaje de plano axial.

El cambio desde la Zona I a la Zona II, es acompañado por el incremento del metamor- 
fismo sin-cinemático de muy bajo a bajo grado, con mayor desarrollo de illita - biotita y re-cristalización de la matriz.

\section{ZONA II}

De muy bajo a bajo grado de metamorfismo. Comprende el NE de las Cumbres Calchaquíes y las sierras del NE de Tucumán. Se
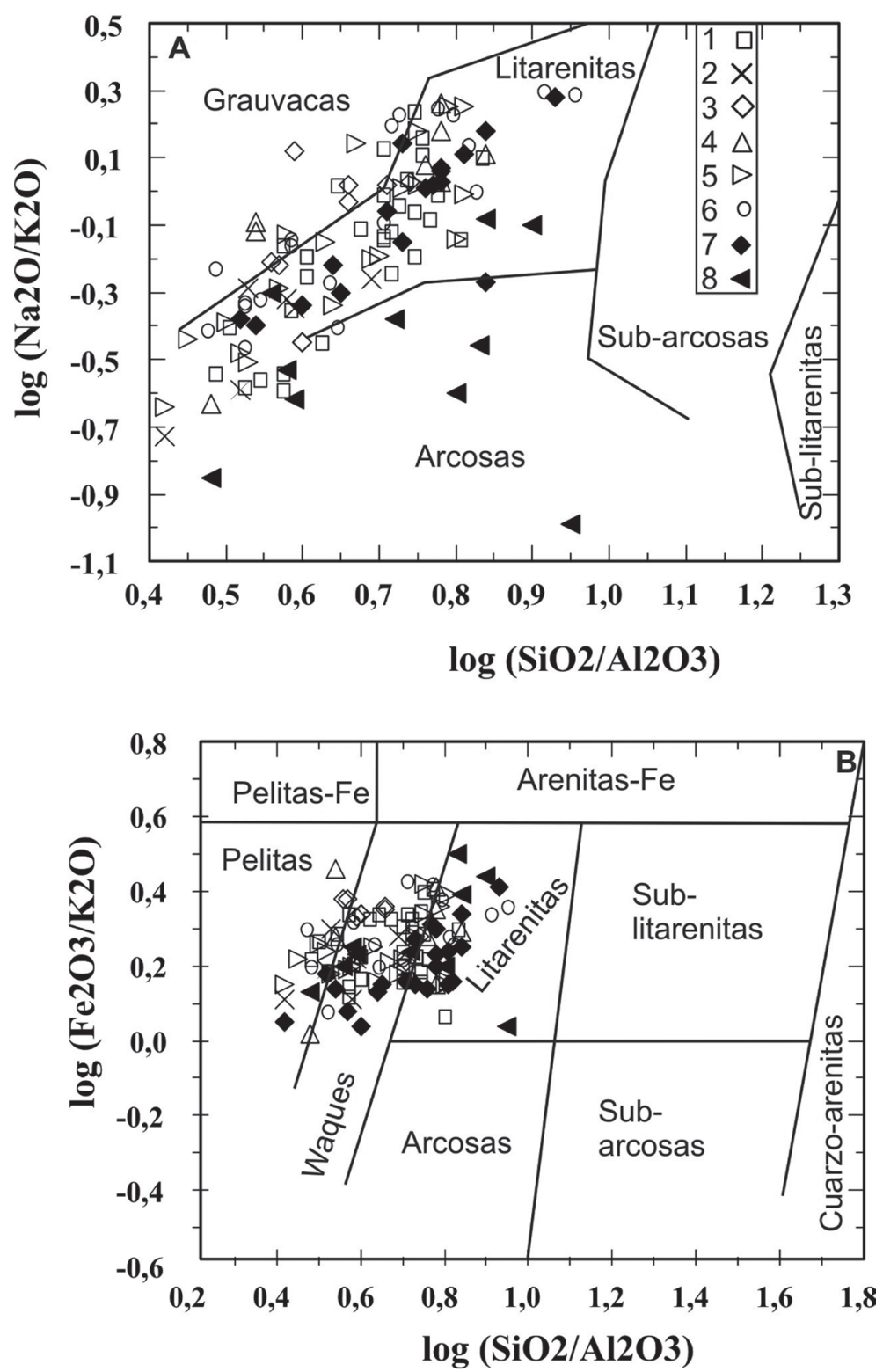

Figura 4. Diagramas de clasificación log/log de psamitas y pelitas de Pettijhon et al. (1972), con los campos modificados por Herron (1988) A: En el diagrama de Pettijohn et al. (1972) las muestras se concentran en los campos de litarenitas y en menor concentración, en grauvacas y arcosas. B: En el diagrama de Herron (1988) las muestras se concentran en los campos de waques y litarenitas y en menor proporción en el de las pelitas. Símbolos: 1: Sa. Ancasti. 2: Qda. La Cébila. 3: Sa. El Campo. 4: Sa. Guasayán. 5: Cumbres Calchaquíes y Sa. Quilmes. 6: Sa. San Javier. 7: Qda. Humahuaca. 8: Sa. Famatina. 
caracteriza por una mayor deformación con un bandeado tectónico penetrativo en rocas meta-psamíticas como un clivaje de plano axial $\left(\mathrm{S}_{1}\right)$ con pliegues $\mathrm{D}_{1}$ desde acostados a sub-verticales, con dirección NE-SO y pliegues coaxiales $\mathrm{D}_{2}$ de arrastre. La estructura $\mathrm{S}_{2}$ se presenta como clivaje de crenulación en las metapelitas y como clivaje de fractura en las metapsamitas.

\section{ZONA III}

Se desarrolla en la zona central de las Cumbres Calchaquíes, en la sierras de Ancasti, Aconquija y E de Quilmes. Está constituida por esquistos listados o micacitas finas bandeadas, que muestran un bandeado de 2 a 3 $\mathrm{mm}$, con alternancia de bandas claras ricas en cuarzo y oscuras con abundante biotita, cuya asociación típica es de: cuarzo-biotitamoscovita-clorita-albita (andalucita - granate - estaurolita). Muestra un progresivo cambio en la fábrica con desarrollo de pliegues cerrados, con transposición del bandeado $\mathrm{S}_{1}$, como resultado del apilamiento de los planos S anteriores. Esta zona ha sufrido diversos eventos metamórficos y deformativos (Toselli y Rossi de Toselli, 1973, 1982, 1984; Toselli et al., 1984) y el evento $\mathrm{D}_{1}$ se asocia al metamorfismo $\mathrm{M}_{1} \mathrm{y}$ produce la esquistosidad $\mathrm{S}_{1}$, con desarrollo de cuarzo, clorita, moscovita, biotita y granate. El evento $\mathrm{D}_{2}$, se relaciona a $\mathrm{M}_{2}$, produce pliegues isoclinales y segregaciones de cuarzo paralelos al bandeado, así como el desarrollo del clivaje $\mathrm{S}_{2}$. Esta zona se caracteriza por la orientación variable de los ejes de los pliegues $\mathrm{D}_{2}$.

\section{MAGMATISMO}

El magmatismo del Ciclo Pampeano, clásicamente están desarrolladas en las provincias de Jujuy y Salta. Aunque también se han identificado en las sierras de Fiambalá, Ancasti, Ambargasta y Chica, de las provincias de Catamarca, Santiago del Estero y Córdoba. Al mismo, lo podemos separar en dos grupos no bien definidos, aunque cada uno tiene significado tectónico particular. El vulcanismo efusivo intercalado en la Formación Puncoviscana tiene edades entre $\sim 580$ y 540 Ma; y el plutónico-volcánico relacionado con la orogenia Tilcárica, está entre los 540 y $520 \mathrm{Ma}$, que marca el inicio del Ciclo Famatiniano.

Coladas de basaltos toleíticos y alcalinos, además de ultrabásicas ocupan áreas restringidas, que se asocian con los fenómenos distensivos que permitió la deposición de la Formación Puncoviscana. Los mismos fueron descritos en la Cordillera Oriental y Puna por Chayle y Coira (1987), Manca et al. (1987), Coira et al. (1990). Asimismo, en la Cordillera Oriental, Escayola et al. (2011) identifican intercalaciones de delgados niveles tobáceos, con edades de 537 Ma.

Por otra parte, en las Sierras Pampeanas Orientales de las provincias de Santiago del Estero y Córdoba se describen dacitas y riolitas intruidas como domos y diques en estadios tardíos de intrusión de los granitos, con edades $\mathrm{U} / \mathrm{Pb}$ convencional de $584+/-22 /$ $14 \mathrm{Ma}$, los cuales se encuentran intercalados con los meta-conglomerados de la Formación La Lidia (Llambías et al., 2003). Rocas de esta edad, también han sido descritas en la Sierra de Fiambalá (Grisson et al., 1998) que reconocen un evento ígneo-metamórfico de 550 y 540 Ma, en Facies Esquistos Verdes y Anfibolitas, relacionado con la intrusión de un gabro-norita con caracteres calco-alcalinos.

El segundo grupo magmático incluye a los plutones descritos en el norte de Argentina, Cañaní, Tipayoc, Santa Rosa de Tastil y Mojotoro, todos los cuales son de carácter post-tectónico y relacionados con la fase orogénica diastrófica Tilcárica (Omarini et al., 1987a, b). Las rocas son principalmente tonalitas, granodioritas hornbléndicas y granitos biotíticos, todas ellas con caracteres calco-alcalinos y meta- a per-aluminosos (Omarini et al., 1999a; Hauser, 2011).

Rocas de esta edad, también han sido descritas en diferentes localidades de las Sierras Pampeanas, como en la Sierra de Ancasti (Albigasta e Icaño) por Bassi (1952) y Schalamuk et al. (1983) con edades K/Ar entre 512 y 468 Ma. Asimismo, en las Sierras Pampeanas Orientales de las provincias de Santiago del Estero y Córdoba se describen rocas 
graníticas con edades entre 567 y $500 \mathrm{Ma}$ (Koukharsky et al., 2003; Castellote, 1989) que intruyen en un basamento constituido por esquistos, gneises, anfibolitas y migmatitas. También Miró et al. (2004), Rapela et al. (1991) y Ianizzotto et al. (2013), y von Gosen (2014) identifican rocas graníticas con edades de 537 y 519 Ma. La presencia de conglomerados conteniendo rodados de riolitas e ignimbritas, en la sierra de La Ovejería, han sido citados por Durand (1988) y datados por Toselli et al. (2015), con edades $\mathrm{U}-\mathrm{Pb}$ en circones en $525 \mathrm{Ma}$.

\section{MÉTODOS GEOQUÍMICOS}

Los análisis químicos utilizados para este trabajo incluyen datos propios y también los obtenidos de los trabajos publicados por Willner et al. (1983); Ježek y Miller (1986) y Rossi et al. (1997) con referencias obligadas a las publicaciones realizadas por von Gosen et al. (2009); Zimmermann (2005); Keppie y Balhburg (1999), los que en muchos casos son utilizados como patrones de comparación.

Los análisis químicos sobre roca total de los elementos mayores, menores y trazas fueron realizados por Actlabs Laboratory (Canadá), utilizando un método estandarizado que es una combinación de fusión del polvo de roca con metaborato/tetraborato de litio y determinaciones de alta precisión por INAA, ICP-WRA y ICP/MS, utilizando para la calibración estándares externos de materiales naturales y sintéticos (más detalles sobre las metodologías utilizadas se encuentran en www.actlabs.com).

Las muestras con bajo metamorfismo, obtenidas por los autores, corresponden preferentemente a la fracción original psamítica fina de las rocas clásticas silicáticas, aunque en algunos sectores se utilizó la fracción pelítica. Se trabajó con 121 muestras de elementos mayores y 38 muestras de elementos trazas, entre los que se incluyeron algunos análisis publicados por Willner et al. (1983); Rossi et al. (1997); von Gosen (2009), Löttner (1986). Estos resultados están expresados en las Tablas 1 y 2, en que las muestras están ordenadas según las localidades geográficas de procedencia.

\section{ÁREAS DE MUESTREO}

Las zonas muestreadas corresponden a localidades típicas de la Formación Puncoviscana, en la quebrada de Humahuaca sobre el río Guasamayo (Tilcara) y en Chucalesna. También se muestrearon localidades representativas de las Sierras Pampeanas: Esquistos bandeados en Facies Esquistos Verdes en las sierras del Campo, Guasayán, San Javier, Ambato (La Cébila) Sierra de Famatina (Negro Peinado). En Facies Anfibolitas (esquistos bandeados) en las Cumbres Calchaquíes y sierras de Ancasti y Quilmes.

\section{INTERPRETACIÓN DE LOS ANÁLISIS QUIMMICOS Y CLASIFICACIONES}

Los análisis químicos de las rocas fueron interpretados sobre la base de diagramas discriminantes publicados, que utilizan tanto a los elementos mayores y menores, como así también, a los elementos trazas, tierras raras y relaciones entre elementos.

Ante las dificultades planteadas para la determinación de las rocas, utilizando métodos petrográficos microscópicos clásicos, se las clasificó utilizando el diagrama de Pettijohn et al. (1972), que usa las relaciones entre $\log \left(\mathrm{Na}_{2} \mathrm{O} / \mathrm{K}_{2} \mathrm{O}\right)$ versus $\log \left(\mathrm{SiO}_{2} / \mathrm{Al}_{2} \mathrm{O}_{3}\right)$, en los que también se incluyen los valores promedio de los tipos de rocas (ver Tabla 1). En la mayoría de las muestras de las localidades estudiadas: sierras de Famatina, San Javier, Nogalito, del Campo, Ancasti, Choromoro, Cumbres Calchaquíes, quebradas de Humahuaca, del Toro, de Purmamarca y de La Cébila, se proyectan esencialmente en los campos de las litarenitas, seguidas por las grauvacas, mientras que unas pocas, de la sierra de Famatina, lo hacen en el campo de las arcosas (Fig. 4A). En el diagrama de Herron (1988) que se aplica a las psamitas y pelitas, usando los parámetros $\log \left(\mathrm{Fe}_{2} \mathrm{O}_{3} /\right.$ $\mathrm{K}_{2} \mathrm{O}$ ) versus $\log \left(\mathrm{SiO}_{2} / \mathrm{Al}_{2} \mathrm{O}_{3}\right)$ (ver Tabla 1 ) evidencia que la mayoría de las muestras corresponden a litarenitas y waques, que gradan a pelitas (Fig. 4B). 
Tabla 1. Datos analíticos de los componentes mayores (peso \%) del basamento.

\begin{tabular}{|c|c|c|c|c|c|c|c|c|c|c|c|c|}
\hline & \multicolumn{12}{|c|}{ SIERRA DE ANCASTI } \\
\hline Muestra & An103 & An144 & An351 & An365 & An366 & An367 & An369 & An387 & An388 & An400 & An401 & An402 \\
\hline $\mathrm{SiO} 2$ & 70,44 & 71,58 & 69,59 & 67,37 & 71.86 & 59.02 & 72.58 & 71,31 & 62.80 & 70,78 & 75,34 & 64.20 \\
\hline $\mathrm{TiO} 2$ & 0,83 & 0,77 & 0,77 & 0,83 & 0,86 & 0,93 & 0,73 & 0,99 & 0,95 & 0,16 & 0,74 & 0,92 \\
\hline $\mathrm{Al} 2 \mathrm{O} 3$ & 13,61 & 12,96 & 13,64 & 15,83 & 12,76 & 19,0 & 12,68 & 12,71 & 16,43 & 11,77 & 11,61 & 16,98 \\
\hline $\mathrm{Fe}_{2} \mathrm{O}_{3} \mathrm{~T}$ & 4,94 & 4,35 & 4,89 & 6,49 & 4,75 & 8,07 & 4,19 & 5,18 & 7,20 & 6,42 & 4,15 & 7,38 \\
\hline $\mathrm{Fe} 2 \mathrm{O} 3$ & 2,61 & 2,27 & 2,62 & 4,16 & 2,39 & 5,64 & 1,96 & 2,69 & 4,75 & 4,76 & 1,91 & 4,96 \\
\hline $\mathrm{FeO}$ & 2,33 & 2,08 & 2,27 & 2,33 & 2,36 & 2,43 & 2,23 & 2,49 & 2,45 & 1,66 & 2,24 & 2,42 \\
\hline $\mathrm{MnO}$ & 0,11 & 0,11 & 0,11 & 0,07 & 0,09 & 0,11 & 0,07 & 0,08 & 0,09 & 0,10 & 0,06 & 0,09 \\
\hline $\mathrm{MgO}$ & 2,08 & 1,98 & 1,96 & 2,70 & 1,92 & 3,84 & 1,69 & 1,80 & 3,19 & 1,78 & 1,40 & 2,94 \\
\hline $\mathrm{CaO}$ & 2,07 & 1,34 & 2,13 & 0,31 & 1,32 & 0,71 & 1,81 & 1,46 & 0,81 & 2,19 & 1,11 & 0,63 \\
\hline $\mathrm{Na} 2 \mathrm{O}$ & 2,78 & 2,82 & 3,24 & 1,10 & 2,70 & 1,40 & 3,08 & 2,32 & 1,46 & 2,44 & 2,56 & 1,44 \\
\hline $\mathrm{K} 2 \mathrm{O}$ & 2,88 & 2,64 & 2,44 & 3,14 & 3,14 & 5,02 & 2,20 & 3,66 & 5,22 & 2,58 & 3,60 & 5,72 \\
\hline P2O5 & 0,22 & 0,19 & 0,19 & 0,10 & 0,20 & 0,17 & 0,18 & 0,26 & 0,19 & 0,28 & 0,19 & 0,11 \\
\hline LOI & 0,73 & 0,62 & 0,34 & 1,00 & 0,54 & 2,94 & 0,58 & 0,48 & 1,17 & 0,45 & 0,37 & 0,87 \\
\hline Total & 100,69 & 99,36 & 99,30 & 98,94 & 100,14 & 101,21 & 99,79 & 100,25 & 99,51 & 98,95 & 101,13 & 101,28 \\
\hline $\mathrm{CIA}$ & 63,78 & 65,59 & 63,59 & 77,67 & 64,06 & 72,71 & 64,14 & 63,08 & 68,69 & 62,01 & 61,49 & 68,55 \\
\hline $\log N / K$ & $-0,02$ & 0,03 & 0,12 & $-0,46$ & $-0,07$ & $-0,55$ & 0,15 & $-0,2$ & $-0,55$ & $-0,02$ & $-0,15$ & $-0,6$ \\
\hline $\log K / N$ & 0,02 & $-0,03$ & $-0,12$ & 0,46 & 0,07 & 0,55 & $-0,15$ & 0,2 & 0,55 & 0,02 & 0,15 & 0,6 \\
\hline $\log F / K$ & 0,23 & 0,22 & 0,3 & 0,32 & 0,18 & 0,21 & 0,28 & 0,15 & 0,14 & 0,4 & 0,06 & 0,11 \\
\hline $\log S / A$ & 0,71 & 0,74 & 0,71 & 0,63 & 0,75 & 0,49 & 0,76 & 0,75 & 0,58 & 0,78 & 0,81 & 0,58 \\
\hline B-F1 & 0,16 & $-0,15$ & 0,35 & $-3,69$ & $-0,19$ & $-1,63$ & 0,26 & $-0,15$ & $-1,42$ & 0,29 & 0,27 & $-2,21$ \\
\hline B-F2 & $-0,73$ & 0,40 & $-0,06$ & $-3,23$ & $-0,92$ & $-1,66$ & $-0,13$ & $-1,44$ & $-2,35$ & $-0,69$ & $-0,2$ & $-4,91$ \\
\hline RK-F3 & 2,0 & 2,18 & 1,10 & $-0,81$ & 3,37 & 1,51 & 1,28 & 4,32 & 3,63 & $-1,44$ & 5,60 & 4,04 \\
\hline RK-F4 & 1,57 & 1,62 & 0,54 & 1,71 & 2,10 & 3,03 & 0,50 & 2,66 & 3,65 & $-3,07$ & 1,80 & 3,07 \\
\hline RK-F1 & $-2,5$ & $-3,22$ & $-1,42$ & $-3,16$ & $-3,80$ & $-3,88$ & $-2,05$ & $-4,29$ & $-5,26$ & $-0,59$ & $-4,72$ & $-5,10$ \\
\hline RK-F2 & $-0,78$ & $-1,16$ & $-0,53$ & $-4,82$ & $-0,61$ & $-3,34$ & $-0,76$ & $-0,25$ & $-1,92$ & $-1,65$ & 0,54 & $-0,96$ \\
\hline
\end{tabular}

\begin{tabular}{|c|c|c|c|c|c|c|c|c|c|c|c|c|}
\hline & \multicolumn{12}{|c|}{ SIERRA DE ANCASTI } \\
\hline Muestra & An8125 & An8126 & An8127 & An103b & An104 & An110 & An113 & An114 & An115 & An116 & An129 & An371 \\
\hline $\mathrm{SiO} 2$ & 61,84 & 75,45 & 66,89 & 69,27 & 68,00 & 73,24 & 70,01 & 68,89 & 69,90 & 71,95 & 66,60 & 63,42 \\
\hline $\mathrm{TiO} 2$ & 0,835 & 0,682 & 0,794 & 0,89 & 1,03 & 0,69 & 1,09 & 0,65 & 0,69 & 0,92 & 1,07 & 0,97 \\
\hline $\mathrm{Al} 2 \mathrm{O} 3$ & 16,28 & 10,95 & 13,98 & 12,98 & 13,10 & 12,96 & 12,26 & 13,54 & 13,78 & 12,29 & 14,93 & 16,46 \\
\hline $\mathrm{Fe}_{2} \mathrm{O}_{3} \mathrm{~T}$ & 6,94 & 3,77 & 5,82 & 5,50 & 6,13 & 3,67 & 5,35 & 4,81 & 5,18 & 4,81 & 6,12 & 6,83 \\
\hline $\mathrm{Fe} 2 \mathrm{O} 3$ & 4,61 & 1,59 & 3,53 & 3,11 & 3,60 & 1,48 & 2,76 & 2,66 & 2,99 & 2,39 & 3,55 & 4,36 \\
\hline $\mathrm{FeO}$ & 2,34 & 2,18 & 2,29 & 2,39 & 2,53 & 2,19 & 2,59 & 2,15 & 2,19 & 2,42 & 2,57 & 2,47 \\
\hline $\mathrm{MnO}$ & 0,093 & 0,055 & 0,088 & 0,10 & 0,12 & 0,08 & 0,10 & 0,06 & 0,08 & 0,09 & 0,14 & 0,10 \\
\hline $\mathrm{MgO}$ & 3,39 & 1,46 & 2,79 & 2,29 & 2,44 & 1,58 & 1,90 & 2,36 & 2,05 & 1,67 & 2,77 & 3,11 \\
\hline $\mathrm{CaO}$ & 1,75 & 1,20 & 1,83 & 2,24 & 2,38 & 2,48 & 1,89 & 1,29 & 1,25 & 1,23 & 2,34 & 1,22 \\
\hline $\mathrm{Na} 2 \mathrm{O}$ & 2,20 & 2,41 & 2,09 & 2,34 & 2,14 & 2,83 & 2,74 & 2,42 & 2,40 & 2,37 & 2,92 & 1,90 \\
\hline $\mathrm{K} 2 \mathrm{O}$ & 3,22 & 7,94 & 2,76 & 2,65 & 2,86 & 1,68 & 2,17 & 3,42 & 3,32 & 2,94 & 2,86 & 4,32 \\
\hline P2O5 & 0,19 & 0,21 & 0,21 & 0,19 & 0,37 & 0,19 & 0,23 & 0,18 & 0,18 & 0,21 & 0,25 & 0,21 \\
\hline LOI & 1,93 & 0,91 & 1,06 & 1,07 & 0,90 & 0,92 & 0,86 & 1,23 & 1,22 & 0,96 & 0,79 & 0,48 \\
\hline Total & 98,67 & 99,05 & 98,30 & 99,52 & 99,47 & 100,32 & 98,60 & 98,85 & 100,05 & 99,44 & 100,79 & 99,02 \\
\hline CIA & 69,42 & 66,36 & 67,67 & 64,23 & \begin{tabular}{|l|}
63,96 \\
\end{tabular} & 64,96 & 64,32 & 65,51 & 66,41 & 65,27 & 64,77 & 68,87 \\
\hline $\log N / K$ & $-0,17$ & 0,09 & $-0,12$ & $-0,05$ & $-0,13$ & 0,23 & 0,1 & $-0,15$ & $-0,14$ & $-0,09$ & 0,01 & $-0,36$ \\
\hline $\log K / N$ & 0,17 & $-0,09$ & 0,12 & 0,05 & 0,13 & $-0,23$ & $-0,1$ & 0,15 & 0,14 & 0,09 & $-0,01$ & 0,36 \\
\hline $\log \mathrm{F} / \mathrm{K}$ & 0,33 & 0,29 & 0,32 & 0,32 & 0,33 & 0,34 & 0,39 & 0,15 & 0,19 & 0,21 & 0,33 & 0,20 \\
\hline $\log S / A$ & 0,58 & 0,84 & 0,68 & 0,73 & $\begin{array}{l}0,72 \\
\end{array}$ & 0,75 & 0,76 & 0,71 & 0,71 & 0,77 & 0,65 & 0,59 \\
\hline B-F1 & $-0,45$ & $-0,1$ & $-0,35$ & $-0,41$ & 0,59 & 0,39 & $-0,03$ & $-0,18$ & $-0,47$ & $-0,46$ & 0,29 & $-0,82$ \\
\hline B-F2 & 1,04 & 0,89 & 1,11 & 0,13 & 1,4 & 0,09 & 1,54 & $-0,53$ & $-1,25$ & $-0,28$ & 0,44 & $-1,10$ \\
\hline RK-F3 & 0 & 1,11 & 0,39 & 1,09 & 1,22 & $-0,19$ & 0,96 & 3,0 & 2,15 & 2,79 & 1,17 & 2,28 \\
\hline RK-F4 & 2,27 & 0,78 & 2,34 & 2,12 & 2,76 & 0,06 & 1,93 & 2,18 & 1,18 & 1,89 & 2,50 & 3,05 \\
\hline RK-F1 & $-2,24$ & $-3,39$ & $-2,96$ & $-2,72$ & $-2,91$ & $-1,12$ & $-2,46$ & $-4,07$ & $-3,16$ & $-3,75$ & $-2,00$ & $-3,86$ \\
\hline RK-F2 & $-3,57$ & $-2,08$ & $-3,35$ & $-2,15$ & $-2,40$ & $-1,28$ & $-1,74$ & $-1,36$ & $-1,14$ & $-1,07$ & $-1,61$ & $-2,15$ \\
\hline
\end{tabular}


Tabla 1 (cont.). Datos analíticos de los componentes mayores (peso \%) del basamento.

\begin{tabular}{|l|l|l|l|l|l|l|l|}
\hline & \multicolumn{7}{|c|}{ SIERRA DE ANCASTI (cont.) } \\
\hline Muestra & An390 & An403 & Anj371b & An43 & An49 & An72 & An79 \\
\hline $\mathrm{SiO2}$ & 70,94 & 65,43 & 63,42 & 59,70 & 63,98 & 59,48 & 58,42 \\
\hline $\mathrm{TiO} 2$ & 0,78 & 0,93 & 0,97 & 1,21 & 1,11 & 1,10 & 0,97 \\
\hline $\mathrm{Al2O} 3$ & 13,67 & 16,00 & 16,46 & 16,90 & 15,88 & 17,36 & 18,04 \\
\hline $\mathrm{Fe}_{2} \mathrm{O}_{3} \mathrm{~T}$ & 5,29 & 6,01 & 6,83 & 8,90 & 7,33 & 8,11 & 8,46 \\
\hline $\mathrm{Fe} 2 \mathrm{O} 3$ & 3,01 & 3,58 & 4,36 & 6,19 & 4,72 & 5,51 & 5,99 \\
\hline $\mathrm{FeO}$ & 2,28 & 2,43 & 2,47 & 2,71 & 2,61 & 2,60 & 2,47 \\
\hline $\mathrm{MnO}$ & 0,08 & 0,12 & 0,10 & 0,14 & 0,10 & 0,12 & 0,14 \\
\hline $\mathrm{MgO}$ & 2,17 & 3,00 & 3,11 & 4,33 & 3,52 & 3,94 & 4,07 \\
\hline $\mathrm{CaO}$ & 0,82 & 1,79 & 1,22 & 1,05 & 1,73 & 0,86 & 1,08 \\
\hline $\mathrm{Na2O}$ & 2,10 & 2,62 & 1,90 & 1,28 & 2,42 & 1,38 & 1,78 \\
\hline $\mathrm{K} 2 \mathrm{O}$ & 3,70 & 4,12 & 4,32 & 4,72 & 4,42 & 5,38 & 4,60 \\
\hline $\mathrm{P} 2 \mathrm{O} 5$ & 0,19 & 0,20 & 0,21 & 0,20 & 0,17 & 0,18 & 0,16 \\
\hline $\mathrm{LOI}$ & 1,42 & 0,96 & 0,48 & 1,65 & 0,7 & 2,62 & 1,97 \\
\hline $\mathrm{Total}$ & 101,16 & 101,21 & 99,02 & 100,08 & 101,36 & 100,53 & 99,69 \\
\hline $\mathrm{CIA}$ & 67,37 & 65,23 & 68,87 & 70,56 & 64,95 & 69,50 & 70,75 \\
\hline logN/K & $-0,25$ & $-0,2$ & $-0,36$ & $-0,57$ & $-0,26$ & $-0,59$ & $-0,41$ \\
\hline logK/N & 0,25 & 0,2 & 0,36 & 0,57 & 0,26 & 0,59 & 0,41 \\
\hline logF/K & 0,16 & 0,16 & 0,20 & 0,28 & 0,22 & 0,18 & 0,26 \\
\hline logS/A & 0,72 & 0,61 & 0,59 & 0,55 & 0,61 & 0,53 & 0,51 \\
\hline $\mathrm{B}-\mathrm{F} 1$ & $-0,81$ & $-0,2$ & $-0,82$ & $-1,84$ & $-0,83$ & $-1,70$ & $-1,50$ \\
\hline $\mathrm{B}-\mathrm{F} 2$ & $-1,68$ & $-1,69$ & $-1,10$ & $-0,04$ & $-1,84$ & $-1,46$ & $-0,5$ \\
\hline $\mathrm{RK}-\mathrm{F} 3$ & 3,11 & 3,15 & 2,28 & 1,88 & 3,28 & 3,29 & 1,25 \\
\hline $\mathrm{RK}-\mathrm{F} 4$ & 2,20 & 3,07 & 3,05 & 5,03 & 4,15 & 4,63 & 3,31 \\
\hline $\mathrm{RK}-\mathrm{F} 1$ & $-4,36$ & $-3,57$ & $-5,19$ & $-4,24$ & $-5,60$ & $-3,59$ & $-2,70$ \\
\hline $\mathrm{RK}-\mathrm{F} 2$ & $-1,40$ & $-0,81$ & $-4,78$ & $-1,74$ & $-3,01$ & $-3,73$ & $-4,62$ \\
\hline & & & & & & & \\
\hline
\end{tabular}

\begin{tabular}{|l|l|l|l|l|l|l|l|l|}
\hline & \multicolumn{7}{|c|}{ SIERRAS DEL CAMPO Y DEL CAJON } \\
\hline Muestra & $\mathrm{C} 8156$ & $\mathrm{C} 8157$ & $\mathrm{C} 8158$ & $\mathrm{C} 8161$ & $\mathrm{C} 8157 \mathrm{~b}$ & $\mathrm{C} 8159$ & $\mathrm{C} 8160$ & $\mathrm{C} 8161 \mathrm{~b}$ \\
\hline $\mathrm{SiO} 2$ & 60,88 & 68,99 & 60,29 & 64,98 & 63,21 & 70,56 & 69,70 & 65,85 \\
\hline $\mathrm{TiO} 2$ & 0,975 & 0,832 & 0,946 & 0,727 & 0,851 & 0,557 & 0,738 & 0,77 \\
\hline $\mathrm{A}$ 2O3 & 16,73 & 13,65 & 16,33 & 14,18 & 15,77 & 13,84 & 12,80 & 14,49 \\
\hline $\mathrm{Fe}_{2} \mathrm{O}_{3} \mathrm{~T}$ & 8,13 & 4,93 & 8,03 & 6,14 & 8,17 & 4,61 & 4,86 & 6,41 \\
\hline $\mathrm{Fe} 2 \mathrm{O} 3$ & 5,65 & 2,60 & 5,58 & 3,91 & 5,82 & 2,55 & 2,62 & 4,14 \\
\hline $\mathrm{FeO}$ & 2,48 & 2,33 & 2,45 & 2,23 & 2,35 & 2,06 & 2,24 & 2,27 \\
\hline $\mathrm{MnO}$ & 0,121 & 0,066 & 0,118 & 0,111 & 0,092 & 0,057 & 0,051 & 0,095 \\
\hline $\mathrm{MgO}$ & 3,63 & 1,99 & 3,53 & 2,61 & 3,01 & 1,87 & 2,24 & 2,71 \\
\hline $\mathrm{CaO}$ & 0,49 & 0,63 & 0,69 & 1,50 & 0,59 & 0,38 & 1,05 & 0,75 \\
\hline $\mathrm{Na} 2 \mathrm{O}$ & 2,09 & 2,74 & 2,01 & 2,51 & 1,32 & 2,98 & 2,69 & 2,73 \\
\hline $\mathrm{K} 2 \mathrm{O}$ & 3,38 & 2,68 & 3,35 & 2,69 & 3,73 & 2,86 & 2,53 & 2,85 \\
\hline $\mathrm{P} 2 \mathrm{O} 5$ & 0,14 & 0,23 & 0,15 & 0,18 & 0,15 & 0,14 & 0,21 & 0,19 \\
\hline $\mathrm{LOI}$ & 3,83 & 2,60 & 4,03 & 3,30 & 3,90 & 2,40 & 2,81 & 2,83 \\
\hline $\mathrm{Total}$ & 100,40 & 99,34 & 99,46 & 98,95 & 100,80 & 100,30 & 99,68 & 99,69 \\
\hline $\mathrm{ClA}$ & 73,73 & 69,29 & 72,97 & 67,91 & 73,66 & 68,99 & 67,12 & 69,60 \\
\hline logN/K & $-0,21$ & $-0,45$ & $-0,22$ & $-0,03$ & $-0,45$ & 0,02 & 0,03 & 0,02 \\
\hline logK/N & 0,21 & 0,45 & 0,22 & 0,03 & 0,45 & $-0,02$ & $-0,03$ & $-0,02$ \\
\hline logF/K & 0,38 & 0,34 & 0,38 & 0,36 & 0,34 & 0,21 & 0,28 & 0,35 \\
\hline logS/A & 0,56 & 0,60 & 0,57 & 0,66 & 0,60 & 0,71 & 0,74 & 0,66 \\
\hline $\mathrm{B}-\mathrm{F} 1$ & $-1,55$ & 0,12 & $-1,43$ & $-0,39$ & $-2,08$ & $-0,27$ & 0,13 & $-0,37$ \\
\hline $\mathrm{B}-\mathrm{F} 2$ & 1,48 & 1,43 & 1,83 & 1,61 & $-0,28$ & $-0,35$ & 1,46 & 1,44 \\
\hline $\mathrm{RK}-\mathrm{F} 3$ & $-0,45$ & 1,39 & $-0,45$ & $-0,05$ & $-0,45$ & 1,57 & 1,43 & 0,30 \\
\hline $\mathrm{RK}-\mathrm{F} 4$ & 2,39 & 1,22 & 2,32 & 1,13 & 1,59 & 0,06 & 1,70 & 1,24 \\
\hline $\mathrm{RK}-\mathrm{F} 1$ & $-2,70$ & $-3,02$ & $-2,70$ & $-2,11$ & $-2,86$ & $-2,73$ & $-3,38$ & $-2,49$ \\
\hline $\mathrm{RK}-\mathrm{F} 2$ & $-4,62$ & $-1,61$ & $-4,56$ & $-2,80$ & $-4,41$ & $-0,94$ & $-2,18$ & $-2,75$ \\
\hline
\end{tabular}


Tabla 1 [cont.]. Datos analíticos de los componentes mayores (peso \%) del basamento.

\begin{tabular}{|c|c|c|c|c|c|c|c|c|c|}
\hline & \multicolumn{6}{|c|}{ QDA. LA CEBILA } & \multicolumn{3}{|c|}{ SIERRA DE QUILMES } \\
\hline Muestra & Ceb6941 & Ceb7244 & Ceb7252 & Ceb7901 & Ceb7904 & Ceb7912 & quil8138 & Quil7151 & Quil727 \\
\hline $\mathrm{SiO} 2$ & 57,20 & 64,57 & 66,06 & 61,48 & 70,98 & 59,48 & 75,07 & 61,97 & 68,43 \\
\hline $\mathrm{TiO} 2$ & 0.87 & 0,87 & 0,71 & 0,91 & 0,68 & 1,15 & 0,649 & 0,84 & 0,82 \\
\hline $\mathrm{Al} 2 \mathrm{O} 3$ & 21.92 & 16.77 & 17,29 & 18,35 & 14,42 & 17,85 & 11,60 & 16,64 & 15,21 \\
\hline $\mathrm{Fe}_{2} \mathrm{O}_{3} \mathrm{~T}$ & 6,45 & 6,74 & 5,24 & 6,97 & 4,81 & 8,38 & 3,81 & 7,82 & 6,06 \\
\hline $\mathrm{Fe} 2 \mathrm{O} 3$ & 4,08 & 4,37 & 3,03 & 4,56 & 2,63 & 5,73 & 1,66 & 5,48 & 3,94 \\
\hline $\mathrm{FeO}$ & 2,37 & 2,37 & 2,21 & 2,41 & 2,18 & 2,65 & 2,15 & 2,34 & 2,32 \\
\hline $\mathrm{MnO}$ & 0,07 & 0,11 & 0,05 & 0,09 & 0,07 & 0,13 & 0,08 & 0,12 & 0,083 \\
\hline $\mathrm{MgO}$ & 2,45 & 2,07 & 1,95 & 2,53 & 1,79 & 2,40 & 1,11 & 2,45 & 2,46 \\
\hline $\mathrm{CaO}$ & 0,18 & 0,28 & 0,35 & 0,77 & 0,69 & 0,54 & 1,37 & 0,39 & 0,92 \\
\hline $\mathrm{Na} 2 \mathrm{O}$ & 0,93 & 1,80 & 1,95 & 1,79 & 1,40 & 1,41 & 2,60 & 1,46 & 1,18 \\
\hline $\mathrm{K} 2 \mathrm{O}$ & 5,05 & 4,06 & 4,10 & 3,47 & 2,54 & 5,47 & 2,64 & 5,23 & 4,37 \\
\hline P2O5 & 0,13 & 0,09 & 0,20 & 0,08 & 0,15 & 0,10 & 0,649 & 0,21 & 0,18 \\
\hline LOI & 4,73 & 2,60 & 2,35 & 2,42 & 2,24 & 2,72 & 1,67 & 1,70 & 1,39 \\
\hline Total & 99,98 & 99,94 & 100,25 & 98,85 & 99,76 & 99,63 & 100,80 & 98,97 & 101,17 \\
\hline $\mathrm{CIA}$ & 78,06 & 73,20 & 72,98 & 75,27 & 75,70 & 70,64 & 63,70 & 70,15 & 70,16 \\
\hline $\log N / K$ & $-0,73$ & $-0,35$ & $-0,32$ & $-0,29$ & $-0,26$ & $-0,59$ & $-0,01$ & $-0,55$ & $-0,57$ \\
\hline $\log K / N$ & 0,73 & 0,35 & 0,32 & 0,29 & 0,26 & 0,59 & 0,01 & 0,55 & 0,57 \\
\hline $\log F / K$ & 0,11 & 0,22 & 0,11 & 0,30 & 0,28 & 0,19 & 0,16 & 0,17 & 0,14 \\
\hline $\log S / A$ & 0,42 & 0,59 & 0,58 & 0,53 & 0,69 & 0,52 & 0,81 & 0,57 & 0,65 \\
\hline B-F1 & $-1,87$ & $-2,12$ & $-0,59$ & $-1,90$ & $-1,44$ & $-2,68$ & 3,25 & $-1,62$ & $-1,54$ \\
\hline B-F2 & $-2,70$ & $-2,20$ & $-2,06$ & $-0,90$ & $-0,20$ & $-3,61$ & 2,11 & $-2,62$ & $-2,41$ \\
\hline RK-F3 & 0,63 & 0,93 & 1,65 & $-0,75$ & $-0,81$ & 2,49 & 1,46 & 2,53 & 2,56 \\
\hline RK-F4 & 0,93 & 0,59 & 0,64 & 0,61 & 0,41 & 1,77 & 0,59 & 1,41 & 2,59 \\
\hline RK-F1 & $-1,70$ & $-2,32$ & $-2,61$ & $-0,92$ & $-2,54$ & $-3,17$ & $-9,09$ & $-3,63$ & $-4,58$ \\
\hline RK-F2 & $-1,58$ & $-1,52$ & $-0,69$ & $-2,78$ & $-3,45$ & $-0,68$ & $-0,18$ & $-1,17$ & $-2,26$ \\
\hline
\end{tabular}

\begin{tabular}{|l|l|l|l|l|l|l|l|l|l|l|}
\hline & \multicolumn{9}{|c|}{ SIERRA DE FAMATINA } \\
\hline Muestra & Fam5617 & Fam5629 & Fam2513 & Fam2514 & Fam5644 & Fam5648 & Fam2501 & Fam2504 & Fam4091 & Fam4094 \\
\hline $\mathrm{SiO2}$ & 64,50 & 76,00 & 65,73 & 77,11 & 77,75 & 68,50 & 76,24 & 66,15 & 77,10 & 62,59 \\
\hline $\mathrm{TiO} 2$ & 0,93 & 0,66 & 0,87 & 0,69 & 0,67 & 1,02 & 0,59 & 0,88 & 0,59 & 1,00 \\
\hline $\mathrm{Al} 2 \mathrm{O} 3$ & 16,81 & 9,50 & 17,01 & 11,03 & 8,77 & 13,15 & 11,33 & 18,18 & 12,36 & 20,77 \\
\hline $\mathrm{Fe}_{2} \mathrm{O}_{3} \mathrm{~T}$ & 7,29 & 5,57 & 7,30 & 4,74 & 4,25 & 6,88 & 6,68 & 5,53 & 4,53 & 6,54 \\
\hline $\mathrm{Fe} 2 \mathrm{O} 3$ & 4,86 & 3,41 & 4,93 & 2,55 & 2,08 & 4,36 & 4,59 & 3,15 & 2,44 & 4,04 \\
\hline $\mathrm{FeO}$ & 2,43 & 2,16 & 2,37 & 2,19 & 2,17 & 2,52 & 2,09 & 2,38 & 2,09 & 2,50 \\
\hline $\mathrm{MnO}$ & 0,02 & 0,02 & 0,09 & 0,10 & 0,03 & 0,04 & 0,07 & 0,04 & 0,08 & 0,08 \\
\hline $\mathrm{MgO}$ & 1,13 & 0,72 & 2,25 & 1,47 & 0,52 & 1,10 & 2,14 & 2,23 & 1,36 & 1,99 \\
\hline $\mathrm{CaO}$ & 0,22 & 0,76 & 0,26 & 0,67 & 0,02 & 0,28 & 0,19 & 0,57 & 0,22 & 0,27 \\
\hline $\mathrm{Na2O}$ & 1,20 & 1,60 & 1,03 & 1,58 & 0,40 & 1,65 & 0,72 & 1,74 & 0,71 & 0,69 \\
\hline $\mathrm{K} 2 \mathrm{O}$ & 4,10 & 2,00 & 4,26 & 1,92 & 3,90 & 4,00 & 2,10 & 3,47 & 2,84 & 4,84 \\
\hline $\mathrm{P} 2 \mathrm{O} 5$ & 0,08 & 0,16 & 0,12 & 0,17 & 0,24 & 0,24 & 0,15 & 0,14 & 0,13 & 0,18 \\
\hline $\mathrm{LOI}$ & 3,33 & 2,90 & 3,32 & 1,50 & 3,42 & 3,07 & 2,80 & 3,57 & 3,07 & 4,51 \\
\hline Total & 96,98 & 96,99 & 98,93 & 99,47 & 96,55 & 96,86 & 100,20 & 98,95 & 99,91 & 98,45 \\
\hline $\mathrm{CIA}$ & 75,28 & 68,54 & 75,40 & 72,57 & 67,00 & 68,92 & 79,01 & 75,88 & 76,63 & 78,17 \\
\hline logN/K & $-0,53$ & $-0,10$ & $-0,62$ & $-0,08$ & $-0,99$ & $-0,38$ & $-0,46$ & $-0,30$ & $-0,60$ & $-0,85$ \\
\hline logK/N & 0,53 & 0,10 & 0,62 & 0,08 & 0,99 & 0,38 & 0,46 & 0,30 & 0,60 & 0,85 \\
\hline logF/K & 0,25 & 0,44 & 0,23 & 0,39 & 0,04 & 0,24 & 0,50 & 0,20 & 0,20 & 0,13 \\
\hline logS/A & 0,58 & 0,90 & 0,59 & 0,84 & 0,95 & 0,72 & 0,83 & 0,56 & 0,80 & 0,48 \\
\hline $\mathrm{B}-\mathrm{F1}$ & $-2,67$ & $-1,65$ & $-2,57$ & $-1,57$ & $-1,91$ & $-1,34$ & $-2,68$ & $-1,22$ & $-2,45$ & $-2,08$ \\
\hline $\mathrm{B}-\mathrm{F} 2$ & $-3,49$ & $-0,27$ & $-3,01$ & 0,12 & $-2,07$ & $-1,71$ & $-0,21$ & $-1,78$ & $-2,12$ & $-3,97$ \\
\hline $\mathrm{RK}-\mathrm{F3}$ & $-0,14$ & 6,25 & 0,37 & $-0,99$ & 6,61 & 2,32 & $-3,47$ & 0,09 & 0,12 & 0,50 \\
\hline $\mathrm{RK}-\mathrm{F} 4$ & $-1,08$ & $-0,12$ & 0,87 & 0,24 & 1,68 & 0,09 & 0,19 & 0,93 & 0,46 & 0,77 \\
\hline $\mathrm{RK}-\mathrm{F} 1$ & $-0,96$ & $-2,51$ & $-2,66$ & $-3,35$ & $-7,06$ & $-3,22$ & $-3,48$ & $-1,77$ & $-4,21$ & $-1,68$ \\
\hline $\mathrm{RK}-\mathrm{F} 2$ & $-1,07$ & $-2,83$ & $-2,78$ & $-3,81$ & $-1,63$ & $-0,60$ & $-6,55$ & $-2,16$ & $-3,71$ & $-1,54$ \\
\hline
\end{tabular}


Tabla 1 (cont.). Datos analíticos de los componentes mayores (peso \%) del basamento.

\begin{tabular}{|l|l|l|l|l|l|l|l|l|l|l|}
\hline & \multicolumn{9}{|c|}{ SIERRA DE FAMATINA (cont.) } \\
\hline Muestra & Sanog11 & Sanog13 & Sanog14 & Sanog15 & Sanog16 & Sanog18 & Sanog19 & Sanog2 & Sanog21 & Sanog222 \\
\hline $\mathrm{SiO} 2$ & 71,62 & 66,46 & 66,40 & 73,27 & 70,58 & 74,30 & 59,28 & 58,14 & 78,13 & 69,07 \\
\hline $\mathrm{TiO} 2$ & 0,67 & 0,75 & 0,74 & 0,71 & 0,62 & 0,38 & 0,86 & 0,99 & 0,57 & 0,82 \\
\hline $\mathrm{Al} 2 \mathrm{O} 3$ & 10,58 & 15,18 & 15,03 & 11,57 & 13,31 & 8,11 & 17,48 & 18,81 & 9,44 & 13,54 \\
\hline $\mathrm{Fe}_{2} \mathrm{O}_{3} \mathrm{~T}$ & 3,88 & 6,34 & 6,35 & 4,34 & 5,65 & 2,70 & 7,41 & 7,01 & 3,12 & 4,62 \\
\hline $\mathrm{Fe} 2 \mathrm{O} 3$ & 1,71 & 4,09 & 4,11 & 2,13 & 3,53 & 0,82 & 5,05 & 4,52 & 1,05 & 2,30 \\
\hline $\mathrm{FeO}$ & 2,17 & 2,25 & 2,24 & 2,21 & 2,12 & 1,88 & 2,36 & 2,49 & 2,07 & 2,32 \\
\hline $\mathrm{MnO}$ & 0,08 & 0,09 & 0,06 & 0,06 & 0,09 & 0,11 & 0,10 & 0,10 & 0,05 & 0,07 \\
\hline $\mathrm{MgO}$ & 1,20 & 2,95 & 2,37 & 1,53 & 2,02 & 1,31 & 2,85 & 2,92 & 1,17 & 2,02 \\
\hline $\mathrm{CaO}$ & 3,14 & 0,51 & 0,29 & 1,59 & 0,74 & 4,76 & 0,74 & 0,26 & 0,62 & 0,68 \\
\hline $\mathrm{Na2O}$ & 2,13 & 1,84 & 1,61 & 3,06 & 3,33 & 2,31 & 1,68 & 2,58 & 2,82 & 2,26 \\
\hline $\mathrm{K} 2 \mathrm{O}$ & 2,20 & 3,53 & 4,11 & 1,85 & 2,15 & 1,22 & 4,95 & 4,50 & 1,45 & 2,87 \\
\hline $\mathrm{P} 2 \mathrm{O} 5$ & 0,19 & 0,19 & 0,14 & 0,20 & 0,15 & 0,13 & 0,17 & 0,14 & 0,15 & 0,24 \\
\hline $\mathrm{LOI}$ & 4,03 & 3,26 & 3,03 & 2,53 & 2,37 & 5,25 & 3,59 & 3,69 & 1,77 & 2,88 \\
\hline Total & 99,72 & 101,10 & 100,13 & 100,71 & 101,01 & 100,58 & 99,11 & 99,24 & 99,29 & 99,07 \\
\hline $\mathrm{CIA}$ & 58,61 & 72,08 & 71,44 & 64,03 & 68,15 & 49,45 & 70,34 & 71,93 & 65,88 & 69,97 \\
\hline logN/K & $-0,01$ & $-0,28$ & $-0,41$ & 0,22 & 0,19 & 0,28 & $-0,47$ & $-0,24$ & 0,29 & $-0,10$ \\
\hline logK/N & 0,01 & 0,28 & 0,41 & $-0,22$ & $-0,19$ & $-0,28$ & 0,47 & 0,24 & $-0,29$ & 0,10 \\
\hline logF/K & 0,25 & 0,25 & 0,19 & 0,37 & 0,42 & 0,35 & 0,18 & 0,19 & 0,33 & 0,21 \\
\hline logS/A & 0,83 & 0,64 & 0,65 & 0,80 & 0,72 & 0,96 & 0,53 & 0,49 & 0,92 & 0,71 \\
\hline $\mathrm{B}-\mathrm{F} 1$ & $-0,05$ & $-1,03$ & $-1,61$ & 0,3 & $-0,25$ & 0,22 & $-1,34$ & $-0,88$ & $-0,28$ & $-0,07$ \\
\hline $\mathrm{B}-\mathrm{F} 2$ & 0,13 & 0,16 & $-1,54$ & 0,89 & 0,62 & 0,72 & $-1,52$ & $-0,45$ & 1,46 & 1,41 \\
\hline $\mathrm{RK}-\mathrm{F} 3$ & 1,57 & 1,97 & 1,95 & 0,61 & $-0,44$ & 0,81 & 2,19 & 1,81 & 1,26 & 1,8 \\
\hline $\mathrm{RK}-\mathrm{F} 4$ & 0,42 & 1,66 & 1,62 & $-0,07$ & $-0,75$ & 0,26 & 1,94 & 1,74 & $-0,15$ & 1,88 \\
\hline $\mathrm{RK}-\mathrm{F} 1$ & $-2,38$ & $-3,88$ & $-4,04$ & $-2,05$ & $-1,33$ & $-2,14$ & $-3,40$ & $-2,51$ & $-3,71$ & $-3,79$ \\
\hline $\mathrm{RK}-\mathrm{F} 2$ & $-0,31$ & $-3,50$ & $-2,26$ & $-1,27$ & $-1,79$ & $-1,53$ & $-1,52$ & $-0,90$ & $-1,98$ & $-2,01$ \\
\hline
\end{tabular}

\begin{tabular}{|l|l|l|l|l|l|l|l|l|l|}
\hline & \multicolumn{9}{|c|}{ SIERRA DE FAMATINA (cont.) } \\
\hline Muestra & Sanog285 & Sanog286 & Sanog4 & Sanog49 & Sanog51 & Sanog54 & Sanog56 & Sanog6 & Sanog7 \\
\hline $\mathrm{SiO2}$ & 57,71 & 71,95 & 75,63 & 61,06 & 62,66 & 72,76 & 59,39 & 60,01 & 66,08 \\
\hline $\mathrm{TiO} 2$ & 0,80 & 0,67 & 0,51 & 0,86 & 0,82 & 0,78 & 0,78 & 0,85 & 0,85 \\
\hline $\mathrm{Al2O} 3$ & 18,91 & 13,29 & 11,34 & 17,94 & 16,05 & 11,95 & 17,73 & 16,94 & 16,87 \\
\hline $\mathrm{Fe} \mathrm{O}_{3} \mathrm{~T}$ & 8,32 & 3,92 & 3,82 & 5,10 & 6,65 & 4,30 & 7,47 & 7,18 & 6,93 \\
\hline $\mathrm{Fe} 2 \mathrm{O} 3$ & 6,02 & 1,75 & 1,81 & 2,74 & 4,33 & 2,02 & 5,19 & 4,83 & 4,58 \\
\hline $\mathrm{FeO}$ & 2,30 & 2,17 & 2,01 & 2,36 & 2,32 & 2,28 & 2,28 & 2,35 & 2,35 \\
\hline $\mathrm{MnO}$ & 0,10 & 0,06 & 0,08 & 0,09 & 0,10 & 0,08 & 0,09 & 0,10 & 0,15 \\
\hline $\mathrm{MgO}$ & 3,99 & 1,05 & 1,14 & 3,35 & 3,24 & 1,72 & 2,77 & 3,38 & 3,31 \\
\hline $\mathrm{CaO}$ & 0,40 & 0,31 & 1,01 & 0,38 & 0,36 & 1,03 & 0,37 & 0,53 & 0,90 \\
\hline $\mathrm{Na2O}$ & 1,60 & 3,20 & 2,81 & 1,96 & 2,63 & 2,93 & 2,22 & 1,91 & 2,39 \\
\hline $\mathrm{K} 2 \mathrm{O}$ & 4,25 & 1,95 & 2,07 & 4,33 & 3,87 & 1,69 & 5,01 & 4,08 & 3,39 \\
\hline $\mathrm{P} 2 \mathrm{O} 5$ & 0,19 & 0,19 & 0,17 & 0,21 & 0,14 & 0,22 & 0,11 & 0,20 & 0,20 \\
\hline $\mathrm{LOI}$ & 4,21 & 2,78 & 2,39 & 4,09 & 3,11 & 1,73 & 3,40 & 3,94 & 3,46 \\
\hline $\mathrm{Total}$ & 100,48 & 99,37 & 100,97 & 99,37 & 99,63 & 99,19 & 99,34 & 99,12 & 98,53 \\
\hline $\mathrm{CIA}$ & 75,16 & 70,88 & 65,82 & 72,90 & 70,06 & 67,90 & 70,00 & 72,21 & 71,63 \\
\hline logN/K & $-0,42$ & 0,22 & 0,13 & $-0,34$ & $-0,17$ & 0,24 & $-0,35$ & $-0,33$ & $-0,15$ \\
\hline logK/N & 0,42 & $-0,22$ & $-0,13$ & 0,34 & 0,17 & $-0,24$ & 0,35 & 0,33 & 0,15 \\
\hline logF/K & 0,29 & 0,30 & 0,27 & 0,07 & 0,24 & 0,41 & 0,17 & 0,25 & 0,31 \\
\hline logS/A & 0,48 & 0,73 & 0,82 & 0,53 & 0,59 & 0,78 & 0,53 & 0,55 & 0,59 \\
\hline $\mathrm{B}-\mathrm{F} 1$ & $-1,26$ & 0,21 & $-0,21$ & $-0,25$ & $-0,81$ & 0,22 & $-1,44$ & $-0,86$ & $-0,79$ \\
\hline $\mathrm{B}$-F2 & 0,60 & 1,19 & $-0,22$ & 0,89 & 0,48 & 2,18 & $-2,20$ & 1,01 & $-0,44$ \\
\hline $\mathrm{RK}-\mathrm{F} 3$ & $-0,08$ & 0,13 & 0,95 & 2,75 & 1,97 & 0,12 & 2,34 & 1,19 & 0,27 \\
\hline $\mathrm{RK}-\mathrm{F} 4$ & 2,27 & $-1,48$ & $-1,22$ & 3,58 & 2,52 & 0,57 & 1,30 & 2,56 & 2,01 \\
\hline $\mathrm{RK}-\mathrm{F} 1$ & $-2,83$ & $-1,37$ & $-2,40$ & $-4,94$ & $-3,78$ & $-2,47$ & $-2,96$ & $-3,62$ & $-2,43$ \\
\hline $\mathrm{RK}-\mathrm{F} 2$ & $-4,65$ & $-0,55$ & $-0,97$ & $-2,29$ & $-2,34$ & $-2,15$ & $-0,71$ & $-4,04$ & $-3,25$ \\
\hline
\end{tabular}


Tabla 1 [cont.). Datos analíticos de los componentes mayores (peso \%) del basamento.

\begin{tabular}{|c|c|c|c|c|c|c|c|c|c|c|c|c|c|}
\hline & \multicolumn{13}{|c|}{ CUMBRES CALCHAQUIES } \\
\hline Muestra & T17 & T20 & T26 & T29 & T30 & T31 & T466 & T467 & T468 & T469 & T470 & T471 & T8 \\
\hline $\mathrm{SiO} 2$ & 58,71 & 68,60 & 70,36 & 54,87 & 69,58 & 60,34 & 71,26 & 62,32 & 61,74 & 75,32 & 73,91 & 68,35 & 74,86 \\
\hline TiO2 & 90 & 0,70 & 0,79 & 0,93 & 0,67 & 0,85 & 0,72 & 0,83 & 0,84 & 0,66 & 0,64 & 0,83 & 0,60 \\
\hline $\mathrm{Al} 2 \mathrm{O} 3$ & 8,75 & 4,11 & 12,44 & 19,60 & 13,88 & 18,02 & 13,26 & 16,45 & 18,10 & 11,57 & 12,02 & 14,68 & 11,83 \\
\hline $\mathrm{Fe}_{2} \mathrm{O}_{3} \mathrm{~T}$ & 80 & 5,17 & 5,30 & 8,27 & 4,90 & 8,12 & 4,62 & 6,44 & 7,77 & 4,01 & 4,15 & 5,27 & 3,89 \\
\hline $\mathrm{Fe} 2 \mathrm{O} 3$ & 40 & 2,97 & 3,01 & 5,84 & 2,73 & 5,77 & 2,40 & 4,11 & 5,43 & 1,85 & 2,01 & 2,94 & 1,79 \\
\hline $\mathrm{FeO}$ & 40 & 2,20 & 2,29 & 2,43 & 2,17 & 2,35 & 2,22 & 2,33 & 2,34 & 2,16 & 2,14 & 2,33 & 2,40 \\
\hline $\mathrm{MnO}$ & 12 & 0,06 & 0,08 & 0,11 & 0,07 & 0,13 & 0,04 & 0,13 & 0,09 & 0,05 & 0,07 & 0,09 & 0,06 \\
\hline $\mathrm{MgO}$ & 06 & 2,02 & 1,84 & 3,75 & 1,96 & 3,08 & 1,88 & 3,06 & 3,18 & 1,36 & 1,74 & 2,22 & 1,51 \\
\hline $\mathrm{CaO}$ & 60 & 1,01 & 1,32 & 0,86 & 0,88 & 0,54 & 1,33 & 1,43 & 0,43 & 1,58 & 1,58 & 1,75 & 1,10 \\
\hline $\mathrm{Na} 2 \mathrm{O}$ & 1,74 & 2,18 & 2,52 & 1,78 & 1,89 & 1,53 & 2,50 & 3,00 & 1,56 & 2,94 & 3,26 & 2,31 & 1,98 \\
\hline K2O & 25 & 3,44 & 2,41 & 4,93 & 2,92 & 4,63 & 2,45 & 4,02 & 5,10 & 1,65 & 1,82 & 3,22 & 2,73 \\
\hline P2O5 & 13 & 0,16 & 0,20 & 0,15 & 0,18 & 0,12 & 0,16 & 0,24 & 0,13 & 0,17 & 0,15 & 0,21 & 0,15 \\
\hline LOI & 06 & 1,71 & 1,24 & 3,77 & 1,95 & 3,10 & 0,92 & 0,95 & 2,33 & 0,65 & 0,56 & 0,95 & 1,20 \\
\hline Total & 9,12 & 99,16 & 98,50 & 99,02 & 98,88 & 100,46 & 99,14 & 98,87 & 101,27 & 99,96 & 99,90 & 99,88 & 99,91 \\
\hline $\mathrm{CIA}$ & 73,99 & 68,03 & 66,56 & 72,14 & 70,92 & 72,90 & 67,86 & 66,06 & 71,85 & 65,22 & 64,35 & 66,85 & 67,06 \\
\hline $\log N / K$ & $-0,39$ & $-0,20$ & 0,02 & $-0,44$ & $-0,19$ & $-0,48$ & 0,01 & $-0,13$ & $-0,51$ & 0,25 & 0,25 & $-0,14$ & $-0,14$ \\
\hline $\log K / N$ & 0,39 & 0,20 & $-0,02$ & 0,44 & 0,19 & 0,48 & $-0,01$ & 0,13 & 0,51 & $-0,25$ & $-0,25$ & 0,14 & 0,14 \\
\hline $\log F / K$ & 26 & 0,18 & 0,34 & 0,22 & 0,22 & 0,24 & 0,28 & 0,20 & 0,18 & 0,39 & 0,36 & 0,21 & 0,15 \\
\hline $\log S / A$ & 0,50 & 0,69 & 0,75 & 0,45 & 0,70 & 0,52 & 0,73 & 0,58 & 0,53 & 0,81 & 0,79 & 0,67 & 0,80 \\
\hline B-F1 & $-1,72$ & $-0,71$ & $-0,33$ & $-1,35$ & $-0,78$ & $-2,14$ & $-0,34$ & 0,37 & $-1,91$ & 0,02 & 0,13 & $-0,23$ & $-0,87$ \\
\hline B-F2 &, 77 & 1,05 & 0,84 & 0,60 & 0,03 & $-1,93$ & $-0,10$ & $-0,12$ & $-3,09$ & 0,17 & 0,30 & $-0,85$ & $-1,13$ \\
\hline RK-F3 & 21 & 2,08 & 0,60 & 1,18 & 0,79 & 0,78 & 0,76 & 2,46 & 1,96 & $-0,01$ & 0,6 & 1,61 & 2,17 \\
\hline RK-F4 & 35 & 1,22 & 0,69 & 2,41 & 0,96 & 1,55 & 0,80 & 2,18 & 2,15 & $-0,6$ & 0,05 & 1,66 & 1,0 \\
\hline RK-F1 & ,91 & $-3,35$ & $-2,53$ & $-2,78$ & $-3,05$ & $-2,66$ & $-2,55$ & $-2,78$ & $-3,64$ & $-1,78$ & $-1,98$ & $-2,66$ & $-3,94$ \\
\hline RK-F2 & $-2,80$ & $-1,32$ & $-1,99$ & $-2,74$ & $-2,33$ & $-2,78$ & $-1,82$ & $-0,76$ & $-2,17$ & $-1,42$ & $-1,29$ & $-1,35$ & $-1,71$ \\
\hline
\end{tabular}

\begin{tabular}{|c|c|c|c|c|c|c|c|c|c|c|c|c|c|}
\hline & \multicolumn{6}{|c|}{ CUMBRES CALCHAQUIES (cont.) } & \multicolumn{7}{|c|}{ QDA. DE HUMAHUACA } \\
\hline Muestra & T8133 & T8134 & $\mathrm{T} 8135$ & T8136 & T8137 & T8153 & Top10 & Top12 & Top24 & Top460 & Top461 & Top462 & Top463 \\
\hline $\mathrm{SiO} 2$ & 56,25 & 67,04 & 65,07 & 71,72 & 63,55 & 72,39 & 64,63 & 71,57 & 71,90 & 50,25 & 61,98 & 75,68 & 74,30 \\
\hline $\mathrm{TiO} 2$ & 0,972 & 0,784 & 0,865 & 0,921 & 0,814 & 0,786 & 0,67 & 0,62 & 0,56 & 0,85 & 0,83 & 0,54 & 0,54 \\
\hline $\mathrm{Al} 2 \mathrm{O} 3$ & 21,32 & 15,19 & 15,41 & 12,66 & 17,17 & 11,91 & 14,93 & 13,35 & 12,46 & 19,09 & 17,79 & 11,76 & 12,30 \\
\hline $\mathrm{Fe}_{2} \mathrm{O}_{3} \mathrm{~T}$ & 8,72 & 5,80 & 6,21 & 5,20 & 6,70 & 4,94 & 5,21 & 4,30 & 3,66 & 6,58 & 6,47 & 3,70 & 3,62 \\
\hline $\mathrm{Fe} 2 \mathrm{O} 3$ & 6,25 & 3,52 & 3,85 & 2,78 & 4,39 & 2,65 & 3,04 & 2,18 & 1,60 & 4,23 & 4,14 & 1,66 & 1,58 \\
\hline $\mathrm{FeO}$ & 2,47 & 2,28 & 2,37 & 2,42 & 2,31 & 2,29 & 2,17 & 2,12 & 2,06 & 2,35 & 2,33 & 2,04 & 2,04 \\
\hline $\mathrm{MnO}$ & 0,135 & 0,082 & 0,087 & 0,094 & 0,071 & 0,056 & 0,09 & 0,08 & 0,05 & 0,13 & 0,08 & 0,07 & 0,05 \\
\hline $\mathrm{MgO}$ & 2,34 & 2,55 & 2,77 & 1,94 & 2,27 & 1,60 & 1,81 & 1,36 & 1,52 & 2,51 & 2,83 & 1,17 & 1,24 \\
\hline $\mathrm{CaO}$ & 0,84 & 1,13 & 1,78 & 2,42 & 0,30 & 0,87 & 1,28 & 1,13 & 0,63 & 1,76 & 0,55 & 1,23 & 0,75 \\
\hline $\mathrm{Na} 2 \mathrm{O}$ & 1,44 & 1,81 & 2,48 & 2,98 & 2,22 & 2,63 & 2,35 & 3,19 & 2,73 & 1,23 & 1,84 & 2,76 & 2,65 \\
\hline K2O & 6,22 & 3,97 & 3,50 & 1,98 & 4,30 & 2,48 & 3,87 & 2,31 & 2,66 & 5,84 & 4,67 & 2,12 & 2,26 \\
\hline P2O5 & 0,17 & 0,20 & 0,16 & 0,24 & 0,16 & 0,21 & 0,19 & 0,19 & 0,16 & 0,16 & 0,18 & 0,16 & 0,17 \\
\hline LOI & 2,43 & 1,52 & 1,45 & 3,32 & 3,32 & 2,43 & 3,83 & 2,98 & 2,90 & 5,11 & 3,83 & 2,56 & 2,22 \\
\hline Total & 100,80 & 100,10 & 99,78 & 100,90 & 100,90 & 100,30 & 98,86 & 101,06 & 99,23 & 99,51 & 101,05 & 101,74 & 100,10 \\
\hline $\mathrm{ClA}$ & 71,50 & 68,73 & 66,51 & 63,17 & 71,57 & 66,57 & 66,56 & 66,82 & 65,27 & 68,37 & 71,59 & 65,81 & 68,49 \\
\hline $\log N / K$ & $-0,64$ & $-0,34$ & $-0,15$ & 0,18 & $-0,29$ & 0,03 & $-0,22$ & 0,14 & 0,01 & $-0,68$ & $-0,4$ & 0,11 & 0,07 \\
\hline $\log K / N$ & 0,64 & 0,34 & 0,15 & $-0,18$ & 0,29 & $-0,03$ & 0,22 & $-0,14$ & $-0,01$ & 0,68 & 0,4 & $-0,11$ & $-0,07$ \\
\hline $\log F / K$ & 0,15 & 0,16 & 0,25 & 0,42 & 0,19 & 0,30 & 0,13 & 0,27 & 0,14 & 0,05 & 0,14 & 0,24 & 0,20 \\
\hline $\log S / A$ & 0,42 & 0,64 & 0,63 & 0,75 & 0,57 & 0,78 & 0,64 & 0,73 & 0,76 & 0,42 & 0,54 & 0,81 & 0,78 \\
\hline B-F1 & $-1,95$ & $-0,80$ & $-0,52$ & 0,40 & $-1,07$ & $-0,22$ & $-0,26$ & 0,28 & $-0,09$ & $-1,06$ & $-0,97$ & $-0,22$ & $-0,17$ \\
\hline B-F2 & $-5,62$ & $-1,43$ & $-0,80$ & 0,46 & $-1,96$ & 0,51 & $-0,81$ & $-0,01$ & 0,35 & $-0,89$ & $-1,67$ & $-0,73$ & $-0,11$ \\
\hline RK-F3 & 1,83 & 2,33 & 1,58 & 0,19 & 1,57 & 1,45 & 2,58 & 0,75 & 2,40 & 3,23 & 2,19 & 1,01 & 1,11 \\
\hline RK-F4 & 0,50 & 2,32 & 2,10 & 0,95 & 0,71 & 0,59 & 0,62 & $-0,99$ & 0,41 & 1,99 & 2,06 & $-0,91$ & $-0,62$ \\
\hline RK-F1 & $-1,12$ & $-3,92$ & $-2,63$ & $-1,41$ & $-2,37$ & $-3,06$ & $-2,72$ & $-1,37$ & $-3,50$ & $-3,21$ & $-3,53$ & $-2,28$ & $-2,65$ \\
\hline RK-F2 & 0,74 & $-1,90$ & $-1,68$ & $-1,50$ & $-0,84$ & $-1,52$ & 0,01 & $-0,27$ & $-0,84$ & 0,36 & $\begin{array}{l}-1,49 \\
\end{array}$ & $-0,84$ & $-1,06$ \\
\hline
\end{tabular}


Tabla 1 (cont.). Datos analíticos de los componentes mayores (peso \%) del basamento.

\begin{tabular}{|l|l|l|l|l|l|l|l|l|l|}
\hline & \multicolumn{10}{|c|}{ QDA. DE HUMAHUACA (cont.) } \\
\hline Muestra & Top464 & Top465 & Top47 & Top48 & Top50 & Top52 & Top53 & Top55 & Top9 \\
\hline $\mathrm{SiO} 2$ & 73,26 & 65,18 & 67,49 & 74,32 & 76,17 & 70,72 & 59,67 & 71,76 & 68,07 \\
\hline $\mathrm{TiO} 2$ & 0,59 & 0,76 & 0,74 & 0,45 & 0,37 & 0,55 & 0,81 & 0,59 & 0,58 \\
\hline $\mathrm{Al2O} 3$ & 12,09 & 16,38 & 15,26 & 10,70 & 8,95 & 13,24 & 18,07 & 12,29 & 13,22 \\
\hline $\mathrm{Fe}_{2} \mathrm{O}_{3} \mathrm{~T}$ & 3,95 & 5,35 & 5,56 & 3,75 & 2,99 & 4,19 & 6,94 & 4,53 & 4,43 \\
\hline $\mathrm{Fe} 2 \mathrm{O} 3$ & 1,86 & 3,09 & 3,32 & 1,80 & 1,12 & 4,19 & 4,63 & 2,44 & 2,35 \\
\hline $\mathrm{FeO}$ & 2,09 & 2,26 & 2,24 & 1,95 & 1,87 & & 2,31 & 2,09 & 2,08 \\
\hline $\mathrm{MnO}$ & 0,07 & 0,06 & 0,07 & 0,13 & 0,14 & 0,04 & 0,06 & 0,08 & 0,08 \\
\hline $\mathrm{MgO}$ & 1,24 & 2,15 & 2,03 & 1,29 & 1,19 & 1,59 & 2,75 & 1,78 & 1,92 \\
\hline $\mathrm{CaO}$ & 1,28 & 0,66 & 0,91 & 1,97 & 2,20 & 0,71 & 0,35 & 0,55 & 0,90 \\
\hline $\mathrm{Na} 2 \mathrm{O}$ & 2,66 & 2,23 & 1,96 & 2,60 & 2,22 & 2,12 & 1,89 & 2,34 & 2,64 \\
\hline $\mathrm{K} 2 \mathrm{O}$ & 2,34 & 4,83 & 3,95 & 1,72 & 1,16 & 2,98 & 4,55 & 2,22 & 3,05 \\
\hline $\mathrm{P} 2 \mathrm{O} 5$ & 0,18 & 0,18 & 0,21 & 0,18 & 0,16 & 0,19 & 0,17 & 0,18 & 0,17 \\
\hline $\mathrm{LOI}$ & 2,87 & 3,33 & 3,14 & 2,63 & 3,06 & 2,32 & 3,63 & 2,20 & 3,67 \\
\hline $\mathrm{Total}$ & 100,53 & 101,11 & 101,31 & 99,74 & 98,61 & 98,65 & 98,89 & 98,52 & 98,73 \\
\hline $\mathrm{CIA}$ & 65,81 & 67,97 & 69,11 & 62,98 & 61,60 & 69,50 & 72,69 & 70,63 & 66,73 \\
\hline logN/K & 0,06 & $-0,34$ & $-0,30$ & 0,18 & 0,28 & $-0,15$ & $-0,38$ & 0,02 & $-0,06$ \\
\hline logK/N & $-0,06$ & 0,34 & 0,30 & $-0,18$ & $-0,28$ & 0,15 & 0,38 & $-0,02$ & 0,06 \\
\hline logF/K & 0,23 & 0,04 & 0,15 & 0,34 & 0,41 & 0,15 & 0,18 & 0,31 & 0,16 \\
\hline logS/A & 0,78 & 0,60 & 0,65 & 0,84 & 0,93 & 0,73 & 0,52 & 0,77 & 0,71 \\
\hline $\mathrm{B}-\mathrm{F} 1$ & $-0,11$ & $-0,53$ & $-0,63$ & $-0,12$ & $-0,38$ & $-0,34$ & $-1,0$ & $-0,52$ & $-0,14$ \\
\hline $\mathrm{B}-\mathrm{F} 2$ & $-0,20$ & $-2,84$ & $-1,77$ & 0,80 & 1,97 & $-0,17$ & $-0,92$ & 1,45 & 0,80 \\
\hline $\mathrm{RK}-\mathrm{F} 3$ & 1,27 & 3,98 & 2,22 & 0,01 & $-0,76$ & 1,70 & 1,46 & 0,21 & 2,39 \\
\hline $\mathrm{RK}-\mathrm{F} 4$ & $-0,56$ & 1,77 & 1,18 & $-1,13$ & $-0,98$ & 0,36 & 1,40 & 0,26 & 0,91 \\
\hline $\mathrm{RK}-\mathrm{F} 1$ & $-2,38$ & $-4,02$ & $-3,24$ & $-2,05$ & $-2,76$ & $-3,36$ & $-2,80$ & $-3,09$ & $-3,44$ \\
\hline $\mathrm{RK}-\mathrm{F} 2$ & $-0,79$ & 0,53 & $-0,98$ & $-1,63$ & $-2,71$ & $-1,43$ & $-1,67$ & $-2,68$ & $-1,03$ \\
\hline
\end{tabular}

\begin{tabular}{|c|c|c|c|c|c|c|c|c|c|c|c|}
\hline & \multicolumn{9}{|c|}{ SIERRA DE GUASAYAN } & \multicolumn{2}{|c|}{ patrones } \\
\hline Muestra & Gua8150 & Guacb1-1 & Guasb1-2 & Guacb14 & Guab2 & Guacb25 & Guacb30 & Guacb6-1 & Guacb6-2 & $U C C^{*}$ & UCC\# \\
\hline $\mathrm{SiO} 2$ & 53,67 & 72,20 & 68,70 & 71,94 & 73,50 & 74,70 & 54,00 & 60,20 & 71,50 & 66,00 & 66,60 \\
\hline $\mathrm{TiO} 2$ & 1,079 & 0,50 & 0,88 & 0,85 & 0,59 & 0,85 & 0,96 & 0,90 & 0,72 & 0,50 & 0,64 \\
\hline $\mathrm{Al} 2 \mathrm{O} 3$ & 15,35 & 12,00 & 13,41 & 11,96 & 12,25 & 10,79 & 18,00 & 17,56 & 12,56 & 15,20 & 15,40 \\
\hline $\mathrm{Fe}_{2} \mathrm{O}_{3} \mathrm{~T}$ & 8,21 & 4,63 & 4,62 & 4,45 & 3,66 & 4,15 & 8,71 & 6,96 & 4,73 & 5,00 & 5,04 \\
\hline $\mathrm{Fe} 2 \mathrm{O} 3$ & 5,63 & 2,63 & 2,24 & 2,10 & 1,57 & 1,80 & 6,25 & 4,56 & 2,51 & --- & $-\ldots$ \\
\hline $\mathrm{FeO}$ & 2,58 & 2,00 & 2,38 & 2,35 & 2,09 & 2,35 & 2,46 & 2,40 & 2,22 & -- & ---- \\
\hline $\mathrm{MnO}$ & 0,122 & 0,06 & 0,06 & 0,05 & 0,04 & 0,06 & 0,09 & 0,11 & 0,07 & -- & 0,10 \\
\hline $\mathrm{MgO}$ & 3,91 & 2,27 & 2,55 & 1,87 & 1,50 & 1,65 & 4,23 & 3,29 & 1,81 & 2,20 & 2,48 \\
\hline $\mathrm{CaO}$ & 6,23 & 0,52 & 0,64 & 1,52 & 0,34 & 1,36 & 1,30 & 0,71 & 0,82 & 4,20 & 3,59 \\
\hline $\mathrm{Na} 2 \mathrm{O}$ & 2,28 & 3,26 & 2,76 & 3,03 & 2,80 & 2,70 & 1,97 & 2,80 & 3,03 & 3,90 & 3,27 \\
\hline K2O & 2,83 & 1,79 & 2,75 & 1,99 & 2,60 & 2,11 & 8,35 & 3,66 & 2,51 & 3,40 & 2,80 \\
\hline P2O5 & 0,17 & 0,02 & 0,01 & 0,01 & 0,01 & 0,01 & 0,01 & 0,02 & 0,01 & -- & 0,15 \\
\hline LOI & 6,01 & 2,37 & 2,78 & 1,20 & 2,13 & 0,68 & 1,64 & 2,96 & 1,68 & -- & ---- \\
\hline Total & 99,86 & 99,80 & 90,01 & 99,01 & 99,81 & 99,21 & 99,51 & 99,32 & 99,61 & -- & ----- \\
\hline $\mathrm{ClA}$ & 57,51 & 68,30 & 68,56 & 64,65 & 68,09 & 63,62 & 60,77 & 71,01 & 66,38 & 56,93 & 61,45 \\
\hline $\log N / K$ & $-0,09$ & 0,26 & 0 & 0,18 & 0,03 & 0,11 & $\begin{array}{l}-0,63 \\
\end{array}$ & $-0,12$ & 0,08 & 0,06 & 0,07 \\
\hline $\log K / N$ & 0,09 & $-0,26$ & 0 & $-0,18$ & $-0,03$ & $-0,11$ & 0,63 & 0,12 & $-0,08$ & $-0,06$ & $-0,07$ \\
\hline $\log F / K$ & 0,46 & 0,41 & 0,23 & 0,35 & 0,15 & 0,29 & 0,02 & 0,28 & 0,28 & 0,17 & 0,26 \\
\hline $\log S / A$ & 0,54 & 0,78 & 0,71 & 0,78 & 0,78 & 0,84 & 0,48 & 0,54 & 0,76 & 0,64 & 0,64 \\
\hline B-F1 & 0,22 & $-1,08$ & $-1,43$ & $-1,19$ & $-1,36$ & $-1,58$ & $-2,34$ & $-1,68$ & $-1,41$ & 0,43 & 0,63 \\
\hline B-F2 & 1,54 & 1,01 & 0,56 & $-0,03$ & $-1,03$ & $-0,62$ & $-7,05$ & $-0,27$ & $-0,78$ & $-4,91$ & $-1,78$ \\
\hline RK-F3 & $-0,76$ & $-0,01$ & 2,44 & 0,21 & 2,51 & 2,26 & 8,65 & 0,89 & 1,68 & $-2,57$ & 0,96 \\
\hline RK-F4 & 3,37 & 0,30 & 3,11 & 1,38 & 0,48 & 1,92 & 5,68 & 1,93 & 0,62 & $-0,04$ & 0,74 \\
\hline RK-F1 & 0,22 & $-2,79$ & $-4,39$ & $-2,72$ & $-3,72$ & $-3,74$ & $-8,01$ & $-2,29$ & $-2,89$ & 0,16 & 2,32 \\
\hline RK-F2 & $-3,10$ & $-2,77$ & $-2,24$ & $-1,59$ & $-0,92$ & $-1,65$ & 1,69 & $-2,25$ & $-1,15$ & $-0,32$ & $-0,09$ \\
\hline
\end{tabular}

UCC $^{*}$ - Promedio corteza continental superior (Taylor y McLennan, 1985).

UCC \# - Average upper continental crust (Rudnick y Gao, 2003).

B-F1, F2 - Funciones discriminantes 1 y 2 (Bhatia, 1985

RK-F1, 2, 3, 4 - Funciones discriminantes 1, 2, 3 y 4 (Roser y Korsch 1986, 1988).

$\mathrm{ClA}$ - índice de alteración - (relación molar $\left[\left(\mathrm{Al}_{2} \mathrm{O}_{3} / \mathrm{Al}_{2} \mathrm{O}_{3}+\mathrm{CaO}+\mathrm{Na}_{2} \mathrm{O}+\mathrm{K}_{2} \mathrm{O}\right)\right.$ * 100$]$

$\log \mathrm{K} / \mathrm{N}-\log \mathrm{K}_{2} \mathrm{O} / \mathrm{Na}_{2} \mathrm{O}$

$\log \mathrm{K} / \mathrm{N}-\log \mathrm{Na}_{2} \mathrm{O} / \mathrm{K}_{2} \mathrm{O}$

$\log \mathrm{S} / \mathrm{A}-\log \mathrm{SiO}_{2} / \mathrm{Al}_{2} \mathrm{O}_{3}$

$\log \mathrm{F} / \mathrm{K}-\log \mathrm{Fe}_{2} \mathrm{O}_{3} / \mathrm{K}_{2} \mathrm{O}$ 


\section{PROVENIENCIA}

La interpretación de la proveniencia de los materiales que constituyen a las rocas sedimentarias, permite interpretar la evolución geológica y las áreas fuente, así como el ambiente tectónico del desarrollo de la cuenca de Puncoviscana. Para ello se utiliza la información geológica, geoquímica, además de la mineralógica y petrográfica. Las rocas reflejan la composición de las áreas de aporte, que son poco afectadas por factores tales como, selección del material, alteración y metamorfismo.

Los estudios de edad de circones detríticos contenidos en las diferentes secuencias de la Formación Puncoviscana y equivalentes realizadas entre otros por Miller et al. (2010); Adams et al. (2008a, b, 2009); Aceñolaza et al. (2011), establecen que los mismos proceden de rocas del Paleo-Proterozoico, Meso-Proterozoico y Neo-Proterozoico, que se correlacionan con los terrenos aflorantes en Brasil, Paraguay y también del borde del cratón del Río de la Plata, tomando como evidencia que las paleo-corrientes indican proveniencias esencialmente desde el $\mathrm{E}$ y NE, pero sin descartar proveniencias desde el oeste como lo determina Ježek (1990). Las fracciones de zircón más jóvenes indican incluso edades del cámbrico inferior, que podrían estar indicando que la erosión afectó los niveles más antiguos de la Formación Puncoviscana, que van colmatando la cuenca y quedan expuestos. Estos datos radiométricos son coherentes con las composiciones de dichos terrenos que son típicos de corteza continental superior, que los podemos asimilar a gneises, migmatitas y granitos, a los que se suman aportes de material volcánico, tanto intra- como extracuencal (sierras de La Ovejería y Norte de Córdoba).

En razón que las rocas presentan cierta alteración de los minerales constituyentes, se cuantificó la misma mediante el «Índice de alteración química» (CIA = relación molar $\left[\left(\mathrm{Al}_{2} \mathrm{O}_{3} / \mathrm{Al}_{2} \mathrm{O}_{3}+\mathrm{CaO}+\mathrm{Na}_{2} \mathrm{O}+\mathrm{K}_{2} \mathrm{O}\right) * 100\right] \mathrm{de}$ Nesbitt y Young (1982). En el histograma CIA, más del $90 \%$ de las muestras dan valores entre $60 \%$ y $80 \%$ con un máximo en $68 \%$
(Fig. 5 A) (ver Tabla 1). Este índice valora la alteración de feldespatos y vidrio volcánico a minerales arcillosos, aunque está muy condicionado por las condiciones climáticas durante el transporte.

La alteración también es evaluada en el diagrama triangular $\mathrm{Al}_{2} \mathrm{O}_{3}-\mathrm{CaO}+\mathrm{Na}_{2} \mathrm{O}$ $-\mathrm{K}_{2} \mathrm{O}$ (Fig. 5 B) de Nesbitt y Young (1984, 1989), que integra al índice CIA. Las rocas de la Formación Puncoviscana se alinean según una tendencia que se desvía de la correspondiente a la alteración de las rocas ácidas de la corteza, que causa el incremento de potasio durante la diagénesis, transformando a los minerales aluminosos, en illita. Diferentes desviaciones de las tendencias ideales, que son paralelas al lado $\left(\mathrm{Al}_{2} \mathrm{O}_{3}-\mathrm{CaO}+\right.$ $\mathrm{Na}_{2} \mathrm{O}$ ), estaría indicando mezcla de diferentes fuentes, afectadas diferencialmente por la alteración y la movilización de álcalis. Este diagrama también apoya la hipótesis que los sedimentos provienen de rocas que se corresponden con la con las composiciones de la corteza continental superior, lo que permite interpretar que los sedimentos de la Formación Puncoviscana han tenido un transporte sedimentario relativamente breve sin procesos mayores de reciclaje, que no permitió la maduración del material, ni la alteración avanzada, que es coherente con las condiciones de una cuenca de antepaís. Los clastos de feldespatos frescos, o con débil alteración, avalan esta interpretación. Esta aparente contradicción con los datos de proveniencia que dan las edades de los circones detríticos, indica que los materiales lábiles correspondientes a fuentes más distantes son degradados granulométricamente con el transporte y sólo los materiales provenientes de áreas relativamente próximas son los que sobreviven para formar las rocas estudiadas.

Por las características sedimentológicas y petrográficas de las rocas de la Formación Puncoviscana, se considera que fueron transportadas principalmente por corrientes de turbidez, con rápido soterramiento y sólo localmente fueron re-trabajadas. Estas características corresponden a una cuenca poco profunda, como lo evidencias las trazas fósi- 

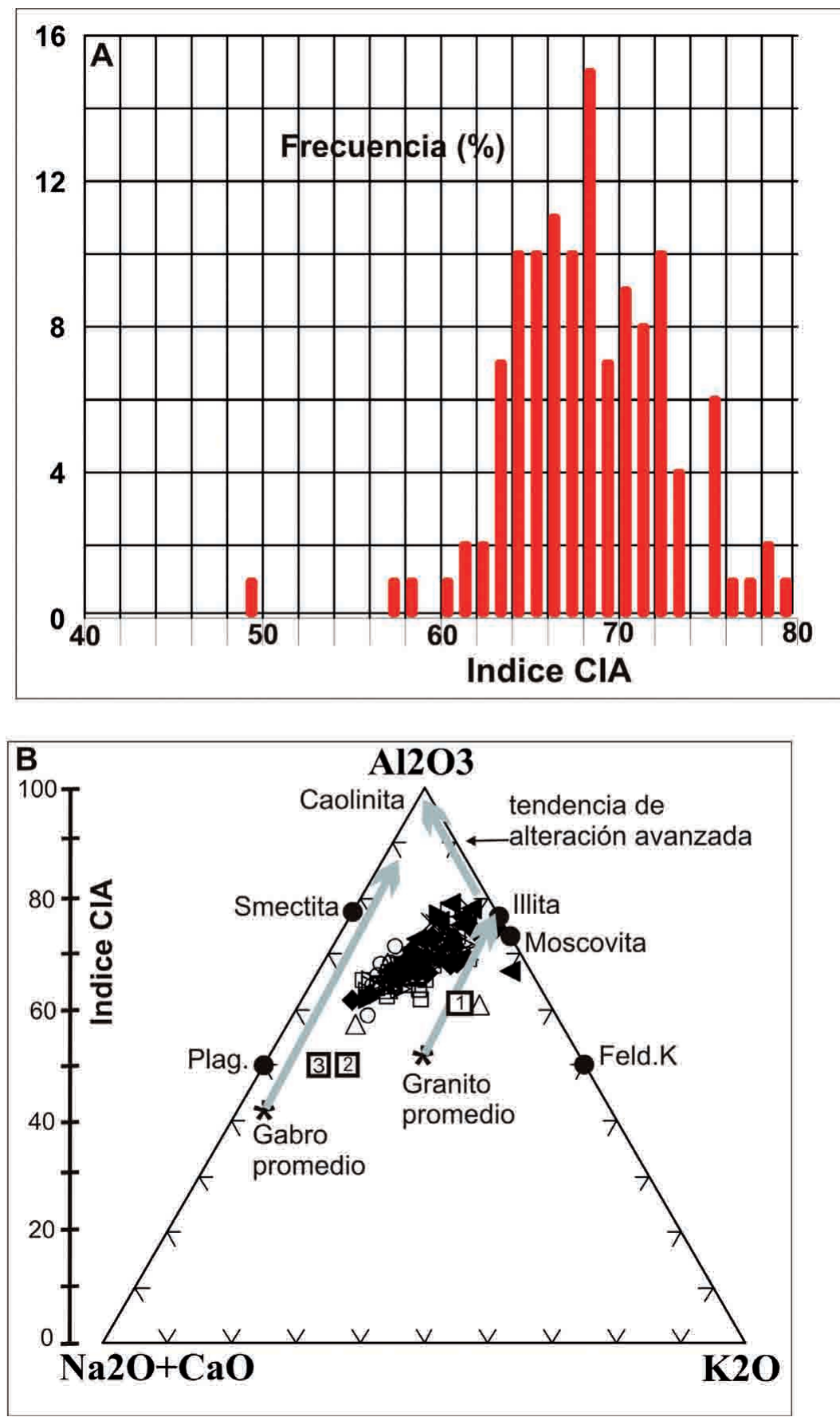

Figura 5. A: Índice de Alteración Química (CIA) vs. Frecuencia (Nesbitt y Young, 1984). Las rocas estudiadas se proyectan con valores entre el 60 y 80 y un máximo de 68. B: En el diagrama triangular $\left(\mathrm{Na}_{2} \mathrm{O}+\mathrm{CaO}\right)-\mathrm{Al}_{2} \mathrm{O}_{3}-\mathrm{K}_{2} \mathrm{O}$ (expresado en proporciones moleculares) de Nesbitt y Young (1989), las muestras proyectadas muestran la tendencia evolutiva de alteración hacia la illita, desde las composiciones de grauvaca promedio (2) y corteza superior (3) (Rudnick y Gao 2003), lo que sería típico para la Formación Puncoviscana. Símbolos: estrellas: gabro promedio y granito promedio; números: 1: Arcosa promedio. 2: Grauvaca promedio. 3: Corteza Continental Superior. Símbolos de las muestras como en Figura 4A. 

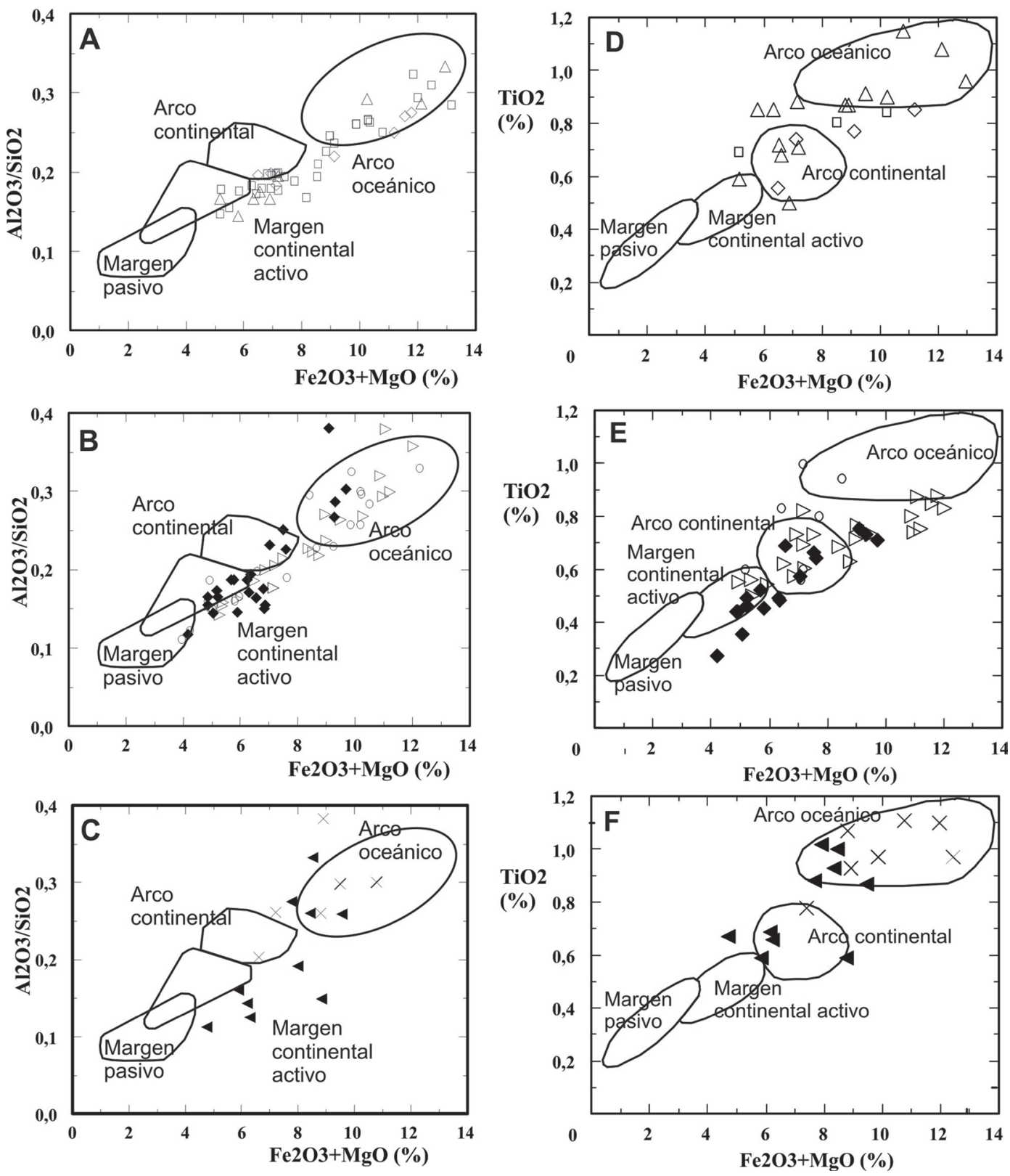

Figura 6. Diagramas de discriminación para arenicas de Bhatia, (1983): A, B y C, Relaciones $\mathrm{Al}_{2} \mathrm{O}_{3} / \mathrm{SiO}_{2}$ versus $\mathrm{Fe}_{2} \mathrm{O}_{3}+\mathrm{MgO} \%$. Para evitar superposiciones, se muestra el mismo diagrama en tres partes. $\mathrm{D}, \mathrm{E}$ y $\mathrm{F}$ : Relaciones $\mathrm{TiO}_{2} \%-\mathrm{Fe}_{2} \mathrm{O}_{3}+\mathrm{MgO} \%$. Las muestras de las sierras de Guasayán, Ancasti, del Campo, Cumbres Calchaquíes, Quilmes y San Javier, se proyectan en los campos de "Arco Oceánico, Arco Continental y Margen Continental Activo", mientras que las provenientes de la quebrada de La Cébila y Sierra de Famatina lo hacen en el campo de "Arco Oceánico". Símbolos como en Figura 4A. 
les y las estructuras sedimentarias encontradas (López de Azarevich et al., 2012). Una característica particular de las rocas, es la homogeneidad mineralógica y textural en toda su extensión, que es típica de cuencas pericratónicas de carácter extensivo.

\section{ELEMENTOS MAYORES}

Bhatia (1983) utiliza diagramas ortogonales para interpretar la composición de las rocas sedimentarias que resultan de la mezcla de diferentes mineralogías, como resultado de la dinámica de los procesos sedimentarios. Los diagramas de la Fig. 6, que se agrupan en tres figuras por razones de claridad. La primera correspondiente a las sierras de Ancasti, del Campo y Guasayán; la segunda a las localidades de la quebrada de Humahuaca, Cumbres Calchaquíes y sierra de San Javier; y la tercera a la sierra de Famatina y quebrada La Cébila (Fig. 2). En general muestran que con el aumento de la madurez mineralógica, evidenciado por el enriquecimiento en cuarzo, se produce la disminución de fragmentos líticos, feldespatos y micas (illita, clorita, biotita).
Cuando se proyectan las relaciones $\mathrm{Fe}_{2} \mathrm{O}_{3}$ $+\mathrm{MgO}$ versus $\mathrm{Al}_{2} \mathrm{O}_{3} / \mathrm{SiO}_{2}$, (Fig. $6 \mathrm{~A}, \mathrm{~B}$ ) la correlación es positiva, indicando el mayor contenido de minerales lábiles con la mayor relación $\mathrm{Al}_{2} \mathrm{O}_{3} / \mathrm{SiO}_{2}$ (Bhatia, 1985) y permite clasificar a las rocas de las sierras de Guasayán, Ancasti, del Campo, Cumbres Calchaquíes, Quilmes y San Javier, en los campos de «Arco Oceánico» a «Arco Continental» $\mathrm{y}$ «Margen Continental Activo», mientras que las rocas de la quebrada de La Cébila y Sierra de Famatina los hacen en el campo de «Arco Oceánico» (Bhatia, 1983), que los tomó de las turbiditas de Australia. Asimismo, en el diagrama $\mathrm{TiO}_{2}$ versus $\mathrm{Fe}_{2} \mathrm{O}_{3}$ $+\mathrm{MgO}$, muestran que las rocas de las sierras de Guasayán, San Javier, Nogalito, Choromoro, La Cébila y Famatina, se proyectan en los campos que corresponden a: Arco Oceánico y Arco Continental y Margen Continental Activo; mientras que las muestras que provienen de las sierras de Cumbres Calchaquíes, Quilmes, Quebrada del Toro y de Humahuaca y Famatina, se proyectan esencialmente en los campos de Arco Continental y Margen Continental Activo, quedando claramente excluida la pertenencia de las rocas estudia-

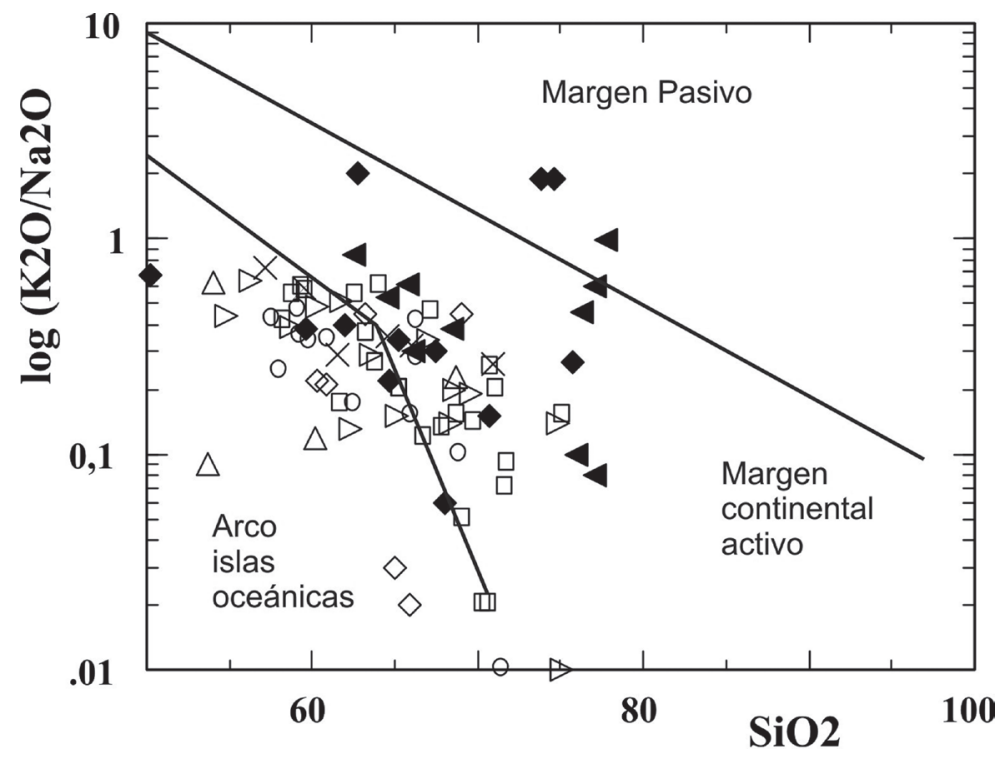

Figura 7. Diagrama de discriminación log ( $\mathrm{K}_{2} \mathrm{O} / \mathrm{Na}_{2} \mathrm{O}$ ) versus $\mathrm{SiO}_{2}$ (Roser y Korsch 1986), para suites de areniscas y lutitas. Las rocas se proyectan entre los campos de "Arco de Islas Oceánicas y Margen Continental Activo". Símbolos como en Figura 4A. 
das a un Margen Pasivo (Bhatia, 1985, Fig. 6 C, D, E).

Con relación al ambiente tectónico de deposición, en el diagrama de Roser y Korsch (1986), que utiliza las relaciones logarítmicas de $\mathrm{K}_{2} \mathrm{O} / \mathrm{Na}_{2} \mathrm{O}$ versus el \% de $\mathrm{SiO}_{2}$ (Fig. 7), los datos analíticos se proyectan dominantemente alrededor de la línea que marca el límite entre los campos de arco de islas oceánicas a margen continental activo, con predominancia de éste último.

Para establecer las litologías de las áreas de proveniencia de los sedimentos se utilizó el diagrama ortogonal de Roser y Korsch (1988) combinando la «función discriminante $3=\left(30,638 \mathrm{TiO}_{2} / \mathrm{Al}_{2} \mathrm{O}_{3}-12,541\right.$ $\mathrm{Fe}_{2} \mathrm{O}_{3}$ (total) $/ \mathrm{Al}_{2} \mathrm{O}_{3}+7,329 \mathrm{MgO} / \mathrm{Al}_{2} \mathrm{O}_{3}+$ $12,031 \mathrm{Na}_{2} \mathrm{O} / \mathrm{Al}_{2} \mathrm{O}_{3}+35,402 \mathrm{~K}_{2} \mathrm{O} / \mathrm{Al}_{2} \mathrm{O}_{3}-$ $6,382)$, versus el discriminante $4=(56,500$ $\mathrm{TiO}_{2} / \mathrm{Al}_{2} \mathrm{O}_{3}-10,879 \mathrm{Fe}_{2} \mathrm{O}_{3}$ (total) $/ \mathrm{Al}_{2} \mathrm{O}_{3}+$ $30,875 \mathrm{Mg} / \mathrm{Al}_{2} \mathrm{O}_{3}-5,404 \mathrm{Na}_{2} \mathrm{O} / \mathrm{Al}_{2} \mathrm{O}_{3}+$ $\left.11,112 \mathrm{~K}_{2} \mathrm{O} / \mathrm{Al}_{2} \mathrm{O}_{3}-3,89\right)$ ). Estos permiten establecer que las psamitas y pelitas provendrían, en su mayoría, de sedimentos cuarzosos, con una contribución menor de rocas ígneas intermedias y félsicas, en que las muestras de las localidades de las sierras de Ancasti, del Campo, Guasayán, Quilmes, Cumbres Calchaquíes y San Javier, se proyectan en los campos de Arco de Islas Continentales, Margen Continental Activo y en menor cantidad en Margen Pasivo; mientras que las muestras de las localidades de la Quebrada de La Cébila y de la Sierra de Famatina lo hacen esencialmente en Arco de Islas Continentales y Margen Continental Activo (Fig. $8 \mathrm{~A} \mathrm{y} \mathrm{B).}$

Estos resultados son parcialmente concordantes con los parámetros propuestos por Bhatia (1983) mediante la «función discriminante $1=\left(-0,0447 \mathrm{SiO}_{2}-0,972 \mathrm{TiO}_{2}\right.$ $+0,008 \mathrm{Al}_{2} \mathrm{O}_{3}-0,267 \mathrm{Fe}_{2} \mathrm{O}_{3}+0,208 \mathrm{FeO}$ $-3,082 \mathrm{MnO}+0,140 \mathrm{MgO}+0,195 \mathrm{CaO}+$ $0,719 \mathrm{Na}_{2} \mathrm{O}-0,032 \mathrm{~K}_{2} \mathrm{O}+7,510 \mathrm{P}_{2} \mathrm{O}_{5}+$ $0,303)$ versus el discriminante $2=(-0,421$ $\mathrm{SiO}_{2}+1,988 \mathrm{TiO}_{2}-0,526 \mathrm{Al}_{2} \mathrm{O}_{3}-0,551$ $\mathrm{Fe}_{2} \mathrm{O}_{3}-1,610 \mathrm{FeO}+2,720 \mathrm{MnO}+0,881$ $\mathrm{MgO}-0,907 \mathrm{CaO}-0,177 \mathrm{Na}_{2} \mathrm{O}-1,840 \mathrm{~K}_{2} \mathrm{O}$ $\left.+7,244 \mathrm{P}_{2} \mathrm{O}_{5}+43,57\right)$ ». Estos permiten interpretar que las muestras de las localidades de las sierras de Ancasti, del Campo, Guasayán, Quilmes, Cumbres Calchaquíes y San Javier, se proyectan en los campos de Arco de Islas Continentales, Margen Continental Activo y en menor cantidad en Margen Pasivo; mientras que las muestras de las localidades de La Quebrada de La Cébila y de la Sierra de Famatina lo hacen esencialmente
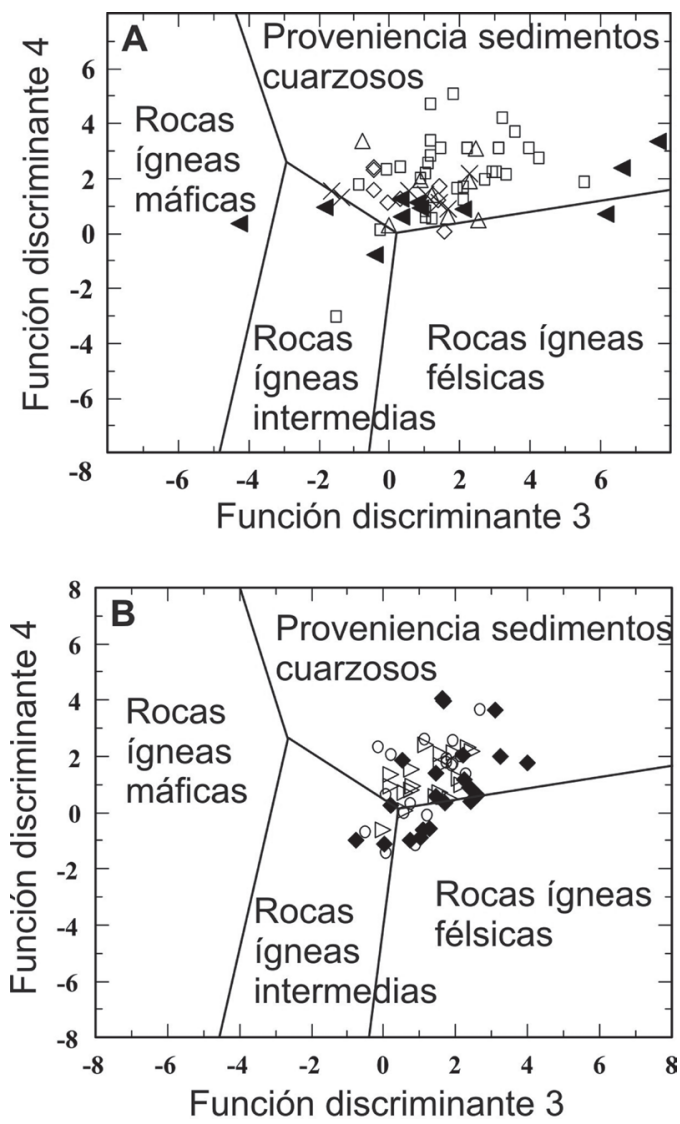

Figura 8. Diagramas discriminantes que permiten establecer la proveniencia de areniscas y lutitas, utilizando las relaciones de elementos mayores 3 y 4 de Roser y Korsch (1988).

A: En las localidades de las sierras de Ancasti, Campo, Guasayán, Famatina y la quebrada de La Cébila, las rocas se proyectan en el campo de sedimentos cuarzosos. B: En las localidades de las sierras de Quilmes, Cumbres Calchaquíes, San Javier y Quebrada de Humahuaca, las proveniencias se distribuyen entre sedimentos cuarzosos y rocas ígneas félsicas e intermedias. (Ver en el texto las explicaciones para las funciones discriminantes.) Símbolos como en Figura 4A. 
en Arco de Islas Continentales y Margen Continental Activo (Figs. 9, A, B).

\section{ELEMENTOS TRAZAS}

Los elementos trazas están presentes en las rocas en concentraciones $<0,1 \%$ peso. Los elementos Th, Sc, Th, Hf, Zr y Tierras Raras, son muy útiles en los análisis de proveniencia debido a que son insolubles y normalmente se comportan como inmóviles en las condiciones de sedimentación, por lo que preservan las características de la roca fuente.
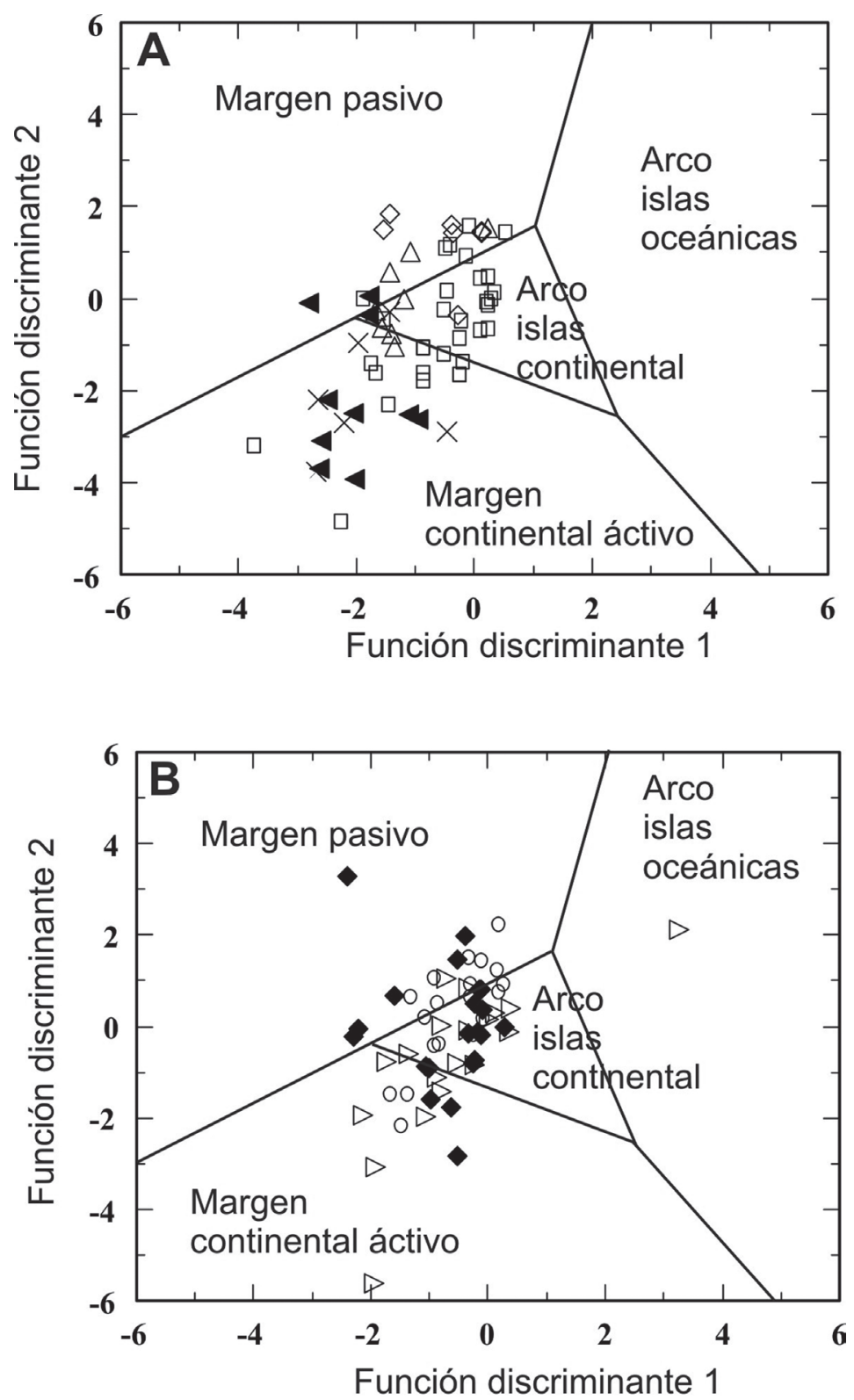

Figura 9. Diagrama de discriminantes 1 y 2 para areniscas (Bhatia 1983), mostrando los diferentes campos de areniscas. Las muestras se proyectan casi todas en los campos correspondientes a "Margen Continental Activo y Arcos de Islas Continentales". (Ver en el texto las explicaciones para las funciones discriminantes]. Símbolos como en Figura 4A. 
En los diagramas ternarios La-Th-Sc y ThSc-Zr/10 que Bhatia y Crook (1986) aplican a las psamitas (Figs. 10 A y B), la gran mayoría de las rocas se proyectan en el campo B correspondiente a «arco de islas continentales». Estos resultados son comparables con los parámetros establecidos por las funciones discriminantes combinando elementos mayores (Bhatia 1983), en que las muestras de las localidades de las sierras de Ancasti, del Campo, Guasayán, Quilmes, Cumbres Calchaquíes y San Javier, se proyectan en los campos de Arco de islas continentales, margen continental activo y en margen pasivo;

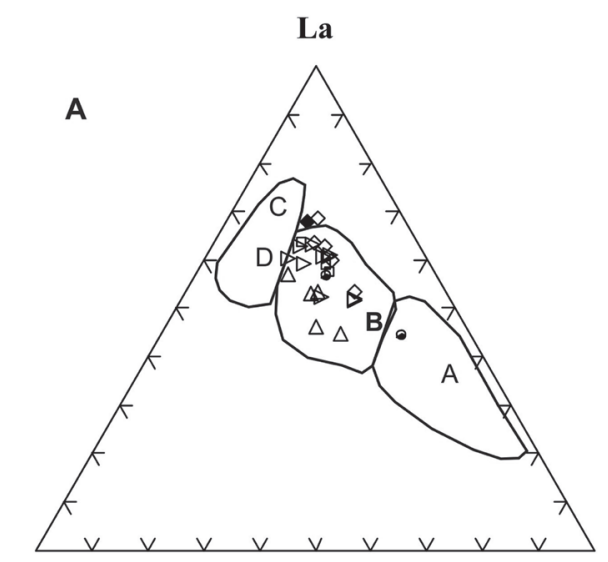

Th

Sc

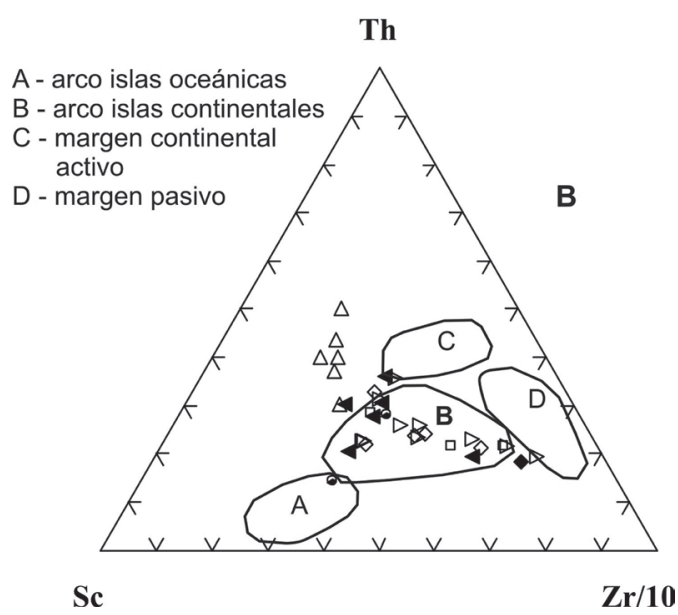

Figura 10. Diagramas discriminantes para grauvacas de Bhatia y Crook (1986). A: La-Th-Sc; y B: Th-Sc-Zr/10. Las muestras dominantemente se proyectan en el campo B [Arco de Islas Continentales]. Símbolos como en Figura 4A. mientras que las muestras de las localidades de La Quebrada de La Cébila y de la Sierra de Famatina lo hacen en los campos de arco de islas continental y margen continental activo (Figs. 10 A y B).

El Sc es un excelente trazador para establecer una fuente de rocas máficas y en especial cuando se lo compara con el Th, con el cual es incompatible, con lo cual el Th está más enriquecido en las rocas félsicas de la corteza superior. Como ambos elementos se comportan como inmóviles en condiciones de superficie, preservan las relaciones de la fuente. Así, la relación Th/Sc da buena información de la procedencia, siendo su valor promedio para la corteza superior de 0,79 (McLennan, 2001; Taylor y McLennan, 1985; McLennan et al., 1990). Usando las relaciones Th/Sc vs. Zr/Sc propuesta por McLennan et al. (1993) se encuentra que en las rocas de la Formación Puncoviscana las relaciones $\mathrm{Zr} / \mathrm{Sc}$ están comprendidas entre los valores de 4,86 y 58 , que no serían afectados por las variaciones granulométricas (Fig. 11). Las muestras de la Formación Puncoviscana se proyectan en el límite entre las relaciones de manto y de corteza continental, con relaciones Th/Sc entre 0,28 y 1,58. La relación $\mathrm{Zr} / \mathrm{Sc}$ se usa como medida del grado de reciclaje que es controlado con la concentración de zircones en los depósitos (McLennan et al., 1990, 1993).

En el diagrama de las relaciones $\mathrm{La} / \mathrm{Th}$ vs. Hf (ppm), las rocas muestran valores restringidos de la relación $\mathrm{La} / \mathrm{Th}$ entre 3,90 y 0,83 , que muestran aproximación a los valores de fuentes de arco ácido, corteza superior y margen pasivo, que es controlado por la dispersión de los valores de Hf entre 3 y 12 ppm. Los valores obtenidos, descartan proveniencias de arco magmático andesítico o de corteza inferior (Fig. 12).

\section{TIERRAS RARAS}

Las tierras raras están entre los elementos trazas menos solubles y son relativamente inmóviles durante el bajo grado de metamorfismo, la alteración e hidrotermalismo, aunque deben tenerse precauciones en su interpretación en las rocas metamorfizadas, en 


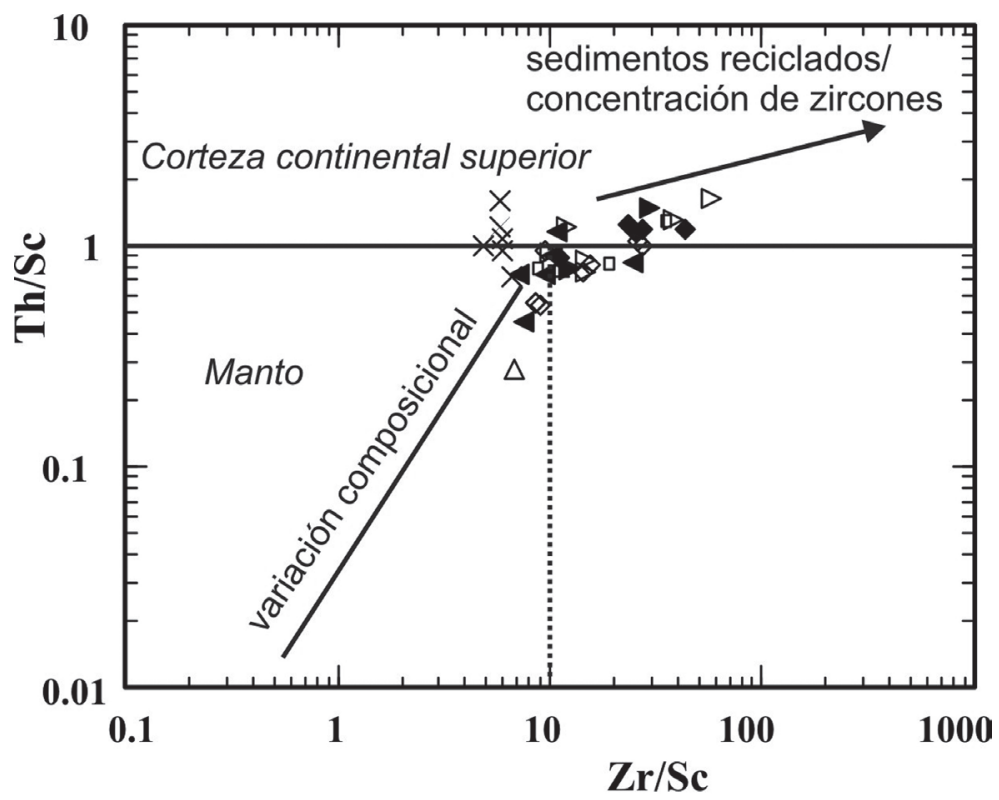

Figura 11. El diagrama Th/Sc vs. Zr/Sc de McLennan et al. $(1990,1993)$ muestra que las rocas de la Formación Puncoviscana y equivalentes se proyectan en la transición entre "Manto y Corteza Continental Superior", estas últimas controladas por la concentración de circones reciclados presentes en los sedimentos. Símbolos como en Figura 4A.

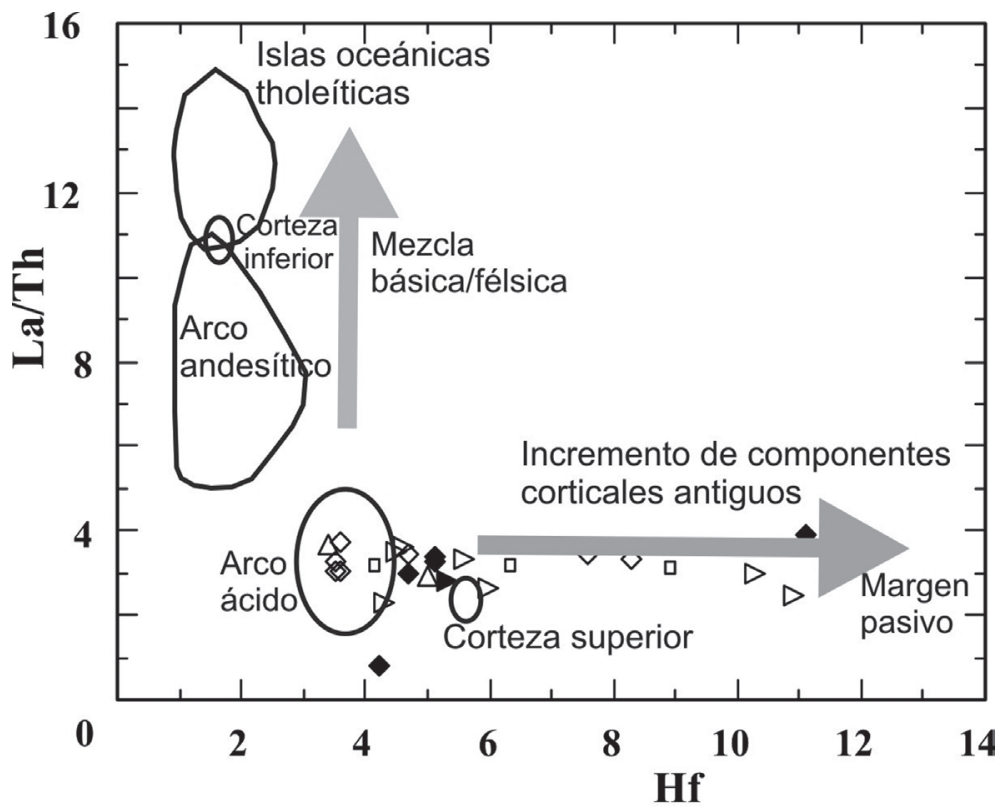

Figura 12. Diagrama La/Th vs. Hf (Floyd y Leveridge 1987). Las muestras dan valores uniformes de la relación La/Th entre 3,90 y 0,83, que se relacionan a diferentes fuentes. La mayoría de las muestras apuntan a la composición de "Corteza Continental Superior". Las muestras tienen bajo contenido de $\mathrm{Hf}$ y las metagrauvacas de la misma área apuntan a rocas fuente que corresponden a un "Arco ácido". Símbolos como en Figura 4A. 
general representan la composición original de las rocas no alteradas.

Como en las rocas clásticas las tierras raras son insolubles y están presentes en muy bajas concentraciones en el agua de mar, las tierras raras presentes en los sedimentos son transportados en las partículas minerales que reflejan la composición química de la fuente (McLennan, 1989). El alto contenido en cuarzo tiene un efecto de dilución de las concentraciones de las tierras raras, mientras que la presencia de minerales pesados, tales como circón, monacita y allanita, que las concentran, pueden dar lugar a efectos erráticos en el patrón de las tierras raras en muestras individuales.

En la Fig. 13 se presentan los diagramas de tierras raras normalizadas a Condrito C1 de Taylor y McLennan (1985), que presentan suave pendiente tanto de las tierras raras livianas, como pesadas, con débil anomalía negativa de Eu, que fue calculada como Eu/ $\mathrm{Eu}^{*}=\mathrm{Eu}_{\mathrm{N}} /\left(\left(\mathrm{Sm}_{\mathrm{N}}\right) \cdot\left(\mathrm{Gd}_{\mathrm{N}}\right)\right) 1 / 2$, en la que $\mathrm{N}$ es el valor de normalización correspondiente al condrito utilizado. Las relaciones $\mathrm{Eu} / \mathrm{Eu}^{*}$ son relativamente constantes con valores promedio entre 0,51 y 1,54 . Las muestras correspondientes a las localidades de sierras del Campo, Guasayán y Ancasti, junto a las correspondientes a la Quebrada de Humahuaca, sierra de Quilmes y Cumbres Calchaquíes, muestran suaves pendientes negativas de las tierras raras pesadas y livianas, con moderada anomalía negativa de Eu, con algunas excepciones de muy bajos valores de total de tierras raras y pendiente casi horizontal del patrón de las mismas. Por su parte las rocas correspondientes a la quebrada La Cébila muestran débil pendiente de las tierras raras pesadas, con una poco notable anomalía negativa de Eu y dispersión de las pendientes, correspondientes a las tierras raras livianas.

Las concentraciones en general van de 117 ppm y 291 pm, con alguna muestra de la sierra de Guasayán, con valor total de sólo 109 ppm. Aunque en todas las rocas muestran patrones típicos que se corresponden con las composiciones de Corteza Continental Superior (McLennan et al., 1990) (Fig. 13).
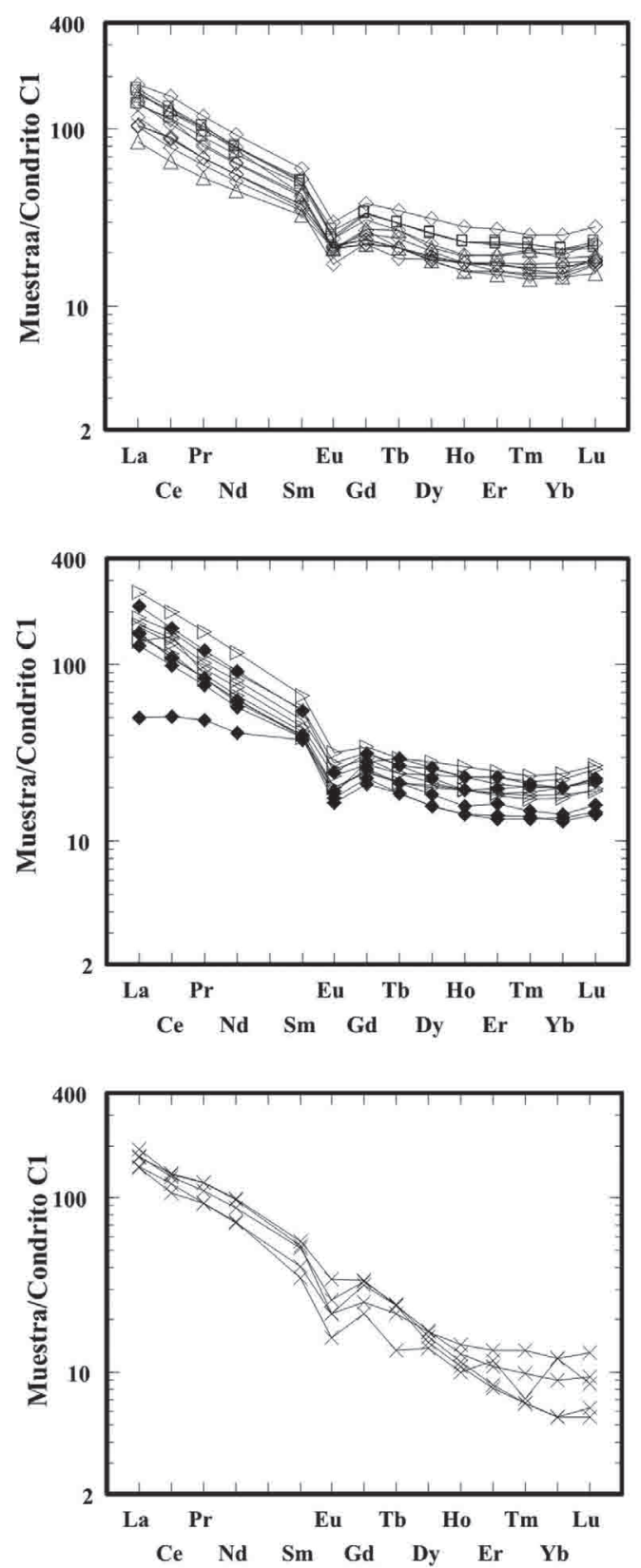

Figura 13. Diagramas de Tierras Raras normalizadas a Condrito C1 (Taylor y McLennan, 1985). Las muestras de la Formación Puncoviscana presentan un patrón uniforme de suave pendiente negativa de las tierras raras livianas y pesadas, con anomalía negativa de Eu, que es típica de patrones sedimentarios de "Corteza Continental Superior". Símbolos como en Figura 4A. 
INTERPRETACIÓN E IMPLICANCIAS REGIONALES

Los tipos de rocas sedimentarias, que varían de grauvacas a lita-arenitas y arcosas, con fases pelíticas importantes, en conjunto indican baja madurez y rápido transporte de los detritos desde la fuente, que permite la preservación de los componentes lábiles y poca selección granulométrica. Este tipo de sedimentos se depositan típicamente en cuencas de antepaís (foreland basin), con sedimentos provenientes de áreas continentales profundamente erosionadas, o bien desde arcos magmáticos. Estos depósitos clásticos pueden interpretarse como formados en ambientes de continua subsidencia.

Las rocas en general evidencian bajos contenidos en aportes volcánicos, que están presentes como coladas alcalinas básicas y ultrabásicas (Chayle y Coira, 1987; Manca et al., 1987), o como niveles tobáceos delgados sin-sedimentarios como los descritos por Escayola et al. (2011) o en clastos de riolitas e ignimbritas contenidos en manifestaciones psefíticas de la sierra de la Ovejería, descritas por Durand (1990) y Toselli et al. (2015).

Las relaciones isotópicas de plomo en zircones, realizados por Lucassen et al. (2000, 2002) sugieren que el terreno Arequipa-Antofalla estuvo relacionado a Gondwana antes de su desmembramiento, como ya lo había sostenido Tosdal (1996) que relaciona al basamento de Arequipa-Antofalla con el cratón Amazónico, ambos con edades de 1,1 y 1,5 Ma.

Esta separación de Arequipa-Antofalla del Cratón Amazónico, la consideramos la base sustentación del inicio del desarrollo de la cuenca extensiva, que permitió la formación de secuencias sedimentarias monótonas, entre el final del Ciclo Sunsás y el comienzo del Ciclo Pampeano. Esta interpretación sirve de fundamento para que no se haya producido una distribución granulométrica más gruesa al este y más fina al oeste, sino que es bastante homogénea en toda la cuenca y también soporta, como ya lo sostuviera Ježek (1990), que el aporte sedimentario también provenía desde el oeste lo que estaría apoyado por las edades de los circones detríticos. En esta etapa se produce el magmatismo básico alcalino y sub-alcalino descrito en Cordillera Oriental y Puna por Chayle y Coira (1987), y Coira et al. (1990), al que le asignamos una edad entre $580 \mathrm{y}$ 540 Ma. También en este período se produce la intrusión de rocas básicas en las Sierras Pampeanas.

Con la evolución de la cuenca, esta pasa a un régimen compresivo (cuenca foreland), con subducción al este y se genera un evento magmático ácido de tipo calco-alcalino y meta- a per-aluminoso, que se relaciona con el cierre de la cuenca y que conocemos como orogenia Tilcárica, que habría ocurrido entre los 540 y 520 Ma.

Los análisis de las rocas de las diferentes localidades tanto de la Formación Puncoviscana, como de los terrenos con mayor metamorfismo, en comparación con el promedio de análisis de (UCC) de la Corteza Continental Superior (McLennan, 2001), muestra que las rocas detríticas muestran valores similares de los elementos incompatibles $\mathrm{Th}$ y $\mathrm{Zr}$ y están enriquecidos en los elementos compatibles Cs, Sr y Ni, así como en las tierras raras. Asimismo la anomalía negativa de Eu y las bajas relaciones $\mathrm{Eu} / \mathrm{Eu}^{*}$, son también características para estas rocas.

Las secuencias sedimentarias con abundante matriz pelítica, junto a litoclastos y feldespatos se pueden reconocer que las rocas de la sierra de Ancasti y de Cumbres Calchaquíes tienen relaciones $\mathrm{Th} / \mathrm{U}$ mayores que las UCC; mientras que las correspondientes a las sierras del Campo, Famatina, Quilmes y las quebradas de Humahuaca y La Cébila tienen valores similares a las UCC (Tabla 2). Asimismo, las relaciones $\mathrm{Rb} / \mathrm{Sr}$ son en todos los casos mayores a las UCC (Tabla 2).

En el diagrama de la figura 5B, se observa que los estadios iniciales de alteración constituyen una tendencia paralela a lado $\left[\left(\mathrm{CaO}+\mathrm{Na}_{2} \mathrm{O}\right)-\mathrm{Al}_{2} \mathrm{O}_{3}\right]$ del triángulo, mientras que para la alteración más avanzada la pérdida de $\mathrm{K}_{2} \mathrm{O}$ es mayor y las composiciones se desplazan hacia el vértice de $\mathrm{Al}_{2} \mathrm{O}_{3}$. Esta distribución de las muestras sugiere un transporte sedimentario corto y rápido, sin mayores procesos de reciclaje. La intemperización de los minerales indica estadios 
Tabla 2. Datos analíticos de los elementos trazas (ppm) del basamento.

\begin{tabular}{|c|c|c|c|c|c|c|c|c|c|c|c|}
\hline & \multicolumn{3}{|c|}{ SIERRA DE ANCASTI } & \multicolumn{8}{|c|}{ SIERRAS DEL CAMPO Y DEL CAJON } \\
\hline Sample & An8125 & An8126 & An8127 & C8156 & C8157 & C8158 & C8161 & $\mathrm{C} 8157 \mathrm{~b}$ & C8159 & C8160 & $\mathrm{C} 8161 \mathrm{~b}$ \\
\hline $\mathrm{Ba}$ & 541 & 403 & 469 & 460 & 354 & 460 & 462 & 521 & 377 & 456 & 494 \\
\hline $\mathrm{Rb}$ & 139 & 89 & 123 & 162 & 133 & 162 & 99 & 180 & 134 & 118 & 132 \\
\hline $\mathrm{Sr}$ & 169 & 183 & 158 & 38 & 60 & 38 & 105 & 33 & 62 & 79 & 63 \\
\hline $\mathrm{Y}$ & 31 & 33 & 31 & 24 & 43 & 26 & 28 & 26 & 26 & 32 & 30 \\
\hline $\mathrm{Zr}$ & 159 & 369 & 261 & 130 & 307 & 129 & 175 & 125 & 141 & 299 & 184 \\
\hline $\mathrm{Nb}$ & 16 & 11 & 12 & 16 & 13 & 15 & 11 & 11 & 6 & 8 & 10 \\
\hline Th & 12,8 & 12,60 & 10,50 & 8,20 & 12,70 & 8,2 & 9,10 & 7,50 & 7,40 & 11,10 & 9,80 \\
\hline $\mathrm{Pb}$ & 29 & 17 & 24 & 70 & 11 & 33 & 10 & 9 & 0 & 6 & 7 \\
\hline $\mathrm{Ga}$ & 23 & 14 & 19 & 29 & 21 & 29 & 16 & 26 & 19 & 18 & 22 \\
\hline $\mathrm{Zn}$ & 110 & 50 & 100 & 190 & 100 & 190 & 100 & 150 & 80 & 120 & 110 \\
\hline $\mathrm{Cu}$ & 40 & 0 & 40 & 20 & 30 & 10 & 30 & 0 & 20 & 30 & 30 \\
\hline $\mathrm{Ni}$ & 40 & 0 & 0 & 50 & 0 & 40 & 30 & 60 & 30 & 40 & 50 \\
\hline V & 124 & 66 & 98 & 115 & 80 & 115 & 98 & 106 & 68 & 79 & 99 \\
\hline $\mathrm{Cr}$ & 130 & 60 & 70 & 90 & 60 & 90 & 60 & 80 & 50 & 50 & 70 \\
\hline $\mathrm{Hf}$ & 4,2 & 9 & 6,4 & 3,60 & 8,30 & 3,5 & 4,60 & 3,50 & 3,60 & 7,60 & 4,70 \\
\hline Cs & 8 & 6,20 & 8,10 & 7,90 & 6,70 & 7,9 & 7,40 & 9,70 & 6,90 & 5,30 & 6,70 \\
\hline Sc & 17 & 10 & 13 & 15 & 12 & 15 & 12 & 14 & 9 & 11 & 13 \\
\hline $\mathrm{Ta}$ & 1,9 & 2,10 & 2 & 1,10 & 1,70 & 1,3 & 1,30 & 2,60 & 1,30 & 1,60 & 1,60 \\
\hline Co & 30 & 24 & 30 & 32 & 25 & 35 & 19 & 45 & 25 & 21 & 24 \\
\hline $\mathrm{U}$ & 2,9 & 2 & 2,50 & 3,50 & 3,50 & 3,10 & 2,20 & 2 & 2 & 2,80 & 2,30 \\
\hline Sn & 6 & 4 & 5 & 6 & 4 & 6 & 3 & 5 & 3 & 3 & 4 \\
\hline La & 39,7 & 38,70 & 32,90 & 25,10 & 42,5 & 24,9 & 32,9 & 24,6 & 27,6 & 38,3 & 33,90 \\
\hline $\mathrm{Ce}$ & 80,7 & 76,50 & 70,10 & 55,40 & 93,7 & 54,1 & 68,90 & 48,4 & 53,40 & 76,3 & 65,40 \\
\hline $\mathrm{Pr}$ & 9,77 & 9,90 & 8,54 & 6,50 & 11,20 & 6,53 & 7,62 & 5,99 & 6,53 & 9,38 & 7,86 \\
\hline $\mathrm{Nd}$ & 36,6 & 37,4 & 33,70 & 26 & 43,40 & 26,10 & 29,80 & 23,60 & 26,10 & 36,8 & 30,10 \\
\hline $\mathrm{Sm}$ & 7,7 & 7,80 & 7,40 & 5,50 & 9,20 & 5,70 & 6,40 & 5,30 & 5,70 & 8,0 & 6,60 \\
\hline $\mathrm{Eu}$ & 1,55 & 1,45 & 1,39 & 1,22 & 1,74 & 1,28 & 1,19 & 1 & 1,25 & 1,41 & 1,24 \\
\hline Gd & 6,90 & 6,90 & 6,80 & 4,60 & 7,80 & 4,90 & 5,50 & 4,70 & 4,90 & 6,3 & 5,30 \\
\hline $\mathrm{Tb}$ & 1,10 & 1,10 & 1,10 & 0,70 & 1,30 & 0,80 & 0,80 & 0,80 & 0,80 & 1,0 & 0,90 \\
\hline Dy & 6,50 & 6,50 & 6,60 & 4,70 & 7,90 & 4,90 & 4,80 & 4,70 & 4,60 & 5,7 & 5,20 \\
\hline Ho & 1,30 & 1,30 & 1,30 & 1 & 1,60 & 1 & 1 & 1 & 0,90 & 1,1 & 1 \\
\hline $\mathrm{Er}$ & 3,7 & 3,70 & 3,80 & 2,60 & 4,50 & 2,8 & 2,8 & 2,90 & 2,60 & 3,2 & 2,90 \\
\hline $\mathrm{Tm}$ & 0,54 & 0,57 & 0,57 & 0,39 & 0,64 & 0,42 & 0,42 & 0,41 & 0,38 & 0,51 & 0,44 \\
\hline $\mathrm{Yb}$ & 3,50 & 3,60 & 3,60 & 2,60 & 4,30 & 2,8 & 2,80 & 2,60 & 2,50 & 3,3 & 3 \\
\hline Lu & 0,54 & 0,59 & 0,56 & 0,44 & 0,71 & 0,45 & 0,47 & 0,48 & 0,43 & 0,58 & 0,46 \\
\hline$=$ & 200,10 & 196,01 & 178,36 & 136,75 & 230,49 & 136,68 & 165,40 & 126,48 & 137,69 & 117,59 & 164,30 \\
\hline $\mathrm{Eu} / \mathrm{Eu}^{*}$ & 0,64 & 0,59 & 0,59 & 0,72 & 0,61 & 0,72 & 0,60 & 0,60 & 0,71 & 1,54 & 0,62 \\
\hline $\mathrm{Th} / \mathrm{Sc}$ & 0,75 & 1,26 & 0,81 & 0,55 & 1,06 & 0,55 & 0,76 & 0,95 & 0,54 & 0,82 & 1,01 \\
\hline $\mathrm{Zr} / \mathrm{Sc}$ & 9,35 & 36,9 & 20,1 & 8,67 & 25,58 & 8,6 & 14,58 & 8,93 & 15,67 & 27,18 & 14,15 \\
\hline $\mathrm{Ti} / \mathrm{Zr}$ & 31,48 & 11,08 & 18,24 & 44,96 & 40,81 & 43,96 & 25,09 & 40,81 & 23,68 & 14,80 & 25,09 \\
\hline $\mathrm{La}_{\mathrm{N}} / \mathrm{Sm}_{\mathrm{N}}$ & 3,33 & 3,20 & 2,87 & 2,95 & 2,98 & 2,82 & 3,32 & 3,00 & 3,13 & 3,09 & 3,32 \\
\hline $\mathrm{Gd}_{N} / \mathrm{Yb}_{N}$ & 1,53 & 1,49 & 1,47 & 1,38 & 1,41 & 1,36 & 1,53 & 1,41 & 1,53 & 1,49 & 1,38 \\
\hline $\mathrm{La}_{N} / \mathrm{Yb}_{\mathrm{N}}$ & 7,66 & 7,26 & 6,17 & 6,52 & 6,57 & 6,0 & 7,93 & 6,39 & 7,45 & 7,84 & 7,63 \\
\hline$T h / U$ & 4,41 & 6,3 & 4,2 & 2,34 & 3,63 & 2,65 & 4,14 & 3,75 & 3,7 & 3,96 & 4,26 \\
\hline $\mathrm{Rb} / \mathrm{Sr}$ & 0,82 & 0,49 & 0,78 & 4,26 & 2,22 & 4,26 & 0,94 & 5,45 & 2,16 & 1,49 & 2,10 \\
\hline $\mathrm{La} / \mathrm{Th}$ & 3,10 & 3,07 & 3,13 & 3,06 & 3,35 & 3,04 & 3,62 & 3,28 & 3,73 & 3,45 & 3,46 \\
\hline
\end{tabular}

iniciales de alteración ya que la alteración avanzada en ambientes sedimentarios recientes está fuertemente controlada por el ambiente ácido típico de condiciones tropicales húmedas. Dada la ausencia de vegetación en los continentes durante el Ediacarano-Terreneuviano, deducir condiciones climáticas análogas es difícil.

La variación que se obtiene usando los óxidos mayores en los diagramas de Bhatia (1983), Roser y Korsch $(1986,1988)$, presentados en las figuras 7 y 9 , que se pro- yectan en diferentes ambientes tectónicos, pueden ser explicados por la movilidad del potasio, sodio y calcio.

Los patrones de distribución de las tierras raras de las muestras de la Formación Puncoviscana son homogéneas, con independencia del tamaño de grano. En el diagrama normalizado a tierras raras se caracteriza por una clara anomalía negativa de Eu (Fig. 13), con un patrón de suave pendiente de las tierras raras livianas $\left(\mathrm{La}_{\mathrm{N}} / \mathrm{Sm}_{\mathrm{N}}=2-4\right)$ y para las tierras raras pesadas $\left(\mathrm{Gd}_{\mathrm{N}} / \mathrm{Yb}_{\mathrm{N}}=1-6\right) \mathrm{y}$ 
Tabla 2 (cont.). Datos analíticos de los elementos trazas (ppm) del basamento.

\begin{tabular}{|l|l|l|l|l|l|l|}
\hline \multicolumn{7}{|c|}{ QUEBRADA LA CEBILA } \\
\hline $\mathrm{Sample}$ & Ceb6941 & Ceb7244 & Ceb7252 & Ceb7901 & Ceb7904 & Ceb7912 \\
\hline $\mathrm{Ba}$ & 798 & 372 & 434 & 615 & 370 & 294 \\
\hline $\mathrm{Rb}$ & 190 & 264 & 206 & 138 & 104 & 249 \\
\hline $\mathrm{Sr}$ & 138 & 78 & 67 & 158 & 119 & 71 \\
\hline $\mathrm{Y}$ & 16 & 17 & 20 & 11 & 15 & 14 \\
\hline $\mathrm{Zr}$ & 102 & 119 & 90 & 194 & 69 & 104 \\
\hline $\mathrm{Nb}$ & 21 & 24 & 21 & 44 & 16 & 24 \\
\hline $\mathrm{Th}$ & 21 & 19 & 16 & 21 & 19 & 22 \\
\hline $\mathrm{Pb}$ & 26 & 10 & 23 & 47 & 24 & 16 \\
\hline $\mathrm{Ga}$ & 74 & 39 & 41 & 72 & 30 & 34 \\
\hline $\mathrm{Zn}$ & 63 & 135 & 93 & 201 & 114 & 150 \\
\hline $\mathrm{Cu}$ & 0 & 0 & 0 & 0 & 0 & 0 \\
\hline $\mathrm{Ni}$ & 5 & 43 & 53 & 93 & 37 & 12 \\
\hline $\mathrm{V}$ & 158 & 115 & 86 & 207 & 80 & 119 \\
\hline $\mathrm{Cr}$ & 143 & 180 & 137 & 193 & 75 & 95 \\
\hline $\mathrm{Hf}$ & 0 & 0 & 0 & 0 & 0 & 0 \\
\hline $\mathrm{Cs}$ & 14 & 34 & 28 & 4 & 7 & 29 \\
\hline $\mathrm{Sc}$ & 21 & 20 & 15 & 29 & 12 & 18 \\
\hline $\mathrm{Ta}$ & 5 & 3 & 4 & 5 & 2 & 2 \\
\hline $\mathrm{Co}$ & 11 & 23 & 22 & 56 & 33 & 12 \\
\hline $\mathrm{U}$ & 6 & 6 & 9 & 7 & 4 & 11 \\
\hline $\mathrm{Sn}$ & 0 & 0 & 0 & 0 & 0 & 0 \\
\hline $\mathrm{La}$ & 35,96 & 44,74 & 35,20 & 40,60 & 41,06 & ------ \\
\hline $\mathrm{Ce}$ & 73,78 & 83,03 & 65,70 & 84,44 & 80,31 & ---- \\
\hline $\mathrm{Pr}$ & 8,80 & 11,54 & 8,81 & 11,70 & 10,44 & ----- \\
\hline $\mathrm{Nd}$ & 34,26 & 45,20 & 33,39 & 46,33 & 40,79 & ----- \\
\hline $\mathrm{Sm}$ & 5,32 & 8,18 & 6,18 & 8,63 & 7,92 & ---- \\
\hline $\mathrm{Eu}$ & 0,91 & 1,25 & 1,25 & 1,98 & 1,51 & ----- \\
\hline $\mathrm{Gd}$ & 4,45 & 6,53 & 5,22 & 6,90 & 6,81 & ----- \\
\hline $\mathrm{Tb}$ & 0,50 & 0,90 & 0,81 & 0,90 & 0,92 & ----- \\
\hline $\mathrm{Dy}$ & 3,49 & 4,36 & 4,31 & 3,80 & 4,08 & ----- \\
\hline $\mathrm{Ho}$ & 0,57 & 0,72 & 0,82 & 0,61 & 0,65 & ----- \\
\hline $\mathrm{Er}$ & 1,92 & 1,79 & 2,22 & 1,34 & 1,40 & ----- \\
\hline $\mathrm{Tm}$ & 0,18 & 0,25 & 0,34 & 0,17 & 0,17 & ----- \\
\hline $\mathrm{Yb}$ & 2,03 & 1,53 & 2,05 & 0,94 & 0,94 & ---- \\
\hline $\mathrm{Lu}$ & 0,22 & 0,24 & 0,33 & 0,16 & 0,14 & ----- \\
\hline $\mathrm{NREE}$ & 172,39 & 210,26 & 166,63 & 208,50 & 197,14 & ----- \\
\hline $\mathrm{Eu} / \mathrm{Eu}{ }^{*}$ & 0,56 & 0,51 & 0,66 & 0,76 & 0,61 & ---- \\
\hline $\mathrm{Th} / \mathrm{Sc}$ & 0,75 & 1,0 & 0,95 & 1,07 & 1,58 & 1,22 \\
\hline $\mathrm{Zr} / \mathrm{Sc}$ & 4,86 & 5,95 & 6,0 & 6,69 & 5,75 & 5,78 \\
\hline $\mathrm{Ti} / \mathrm{Zr}$ & 51,13 & 43,83 & 47,29 & 28,12 & 59,08 & 66,29 \\
\hline $\mathrm{La} / \mathrm{Sm} \mathrm{N}$ & 3,68 & 3,53 & 3,68 & 3,04 & 3,35 & ----- \\
\hline $\mathrm{Gd} / \mathrm{Y} \mathrm{b}_{\mathrm{N}}$ & 1,71 & 3,32 & 1,98 & 5,72 & 5,64 & ----- \\
\hline $\mathrm{La} \mathrm{N}_{\mathrm{N}} / \mathrm{Yb} \mathrm{N}$ & 11,96 & 19,74 & 11,59 & 29,16 & 29,49 & ----- \\
\hline $\mathrm{Th} / \mathrm{U}$ & 3,5 & 3,17 & 1,78 & 3,0 & 4,75 & 2,0 \\
\hline $\mathrm{Rb} / \mathrm{Sr}$ & 1,38 & 3,38 & 3,07 & 0,37 & 0,87 & 3,51 \\
\hline $\mathrm{La} / \mathrm{Th}$ & 1,71 & 2,36 & 2,2 & 1,93 & 2,16 & ----- \\
\hline & & & & & & \\
\hline
\end{tabular}

pendiente de las relaciones totales de tierras raras $\left(\mathrm{La}_{\mathrm{N}} / \mathrm{Yb}_{\mathrm{N}}=5-29\right)$, que se corresponden con los de la corteza continental superior $(\mathrm{UCC}=9,21)$ (Tabla 2$)$. Las rocas muestran concentraciones de tierras raras $(« \mathrm{REE}=109$ - 291 ppm), el valor de las rocas de la UCC es 146 ppm. La relación $\mathrm{Eu} / \mathrm{Eu}^{*}$ tienen valores variables con valores promedio entre 0,56 y 1,54 (valor de la UCC $=0,65$ ), estos valores reflejan la riqueza de plagioclasa en la fuente (McLennan, 1989).

Las relaciones geológicas y los diferentes diagramas geoquímicos, con la distribución de los elementos mayores y trazas, provee bue- na información sobre la variedad litológica de las rocas fuentes, ígneas y sedimentarios, que también reflejan el ambiente tectónico. La geoquímica también evidencia que las rocas incluyen pelitas, grauvacas, lita-arenitas y arcosas (Figs. 4 A y B), que fueron depositadas en condiciones de aguas relativamente someras, aunque no afectadas por el tren de olas y rápidamente soterradas.

\section{CONCLUSIONES}

Consideramos que la Formación Puncoviscana se habría depositado entre los 580 
Tabla 2 (cont.). Datos analíticos de los elementos trazas (ppm) del basamento.

\begin{tabular}{|c|c|c|c|c|c|c|}
\hline & \multicolumn{6}{|c|}{ SIERRA DE FAMATINA } \\
\hline Sample & Fa2513 & Fa2514 & Fa2501 & Fa2504 & Fa4091 & Fa4094 \\
\hline $\mathrm{Ba}$ & 742 & 304 & 261 & 515 & 369 & 681 \\
\hline $\mathrm{Rb}$ & 197 & 94 & 82 & 136 & 126 & 194 \\
\hline $\mathrm{Sr}$ & 35 & 59 & 33 & 61 & 55 & 32 \\
\hline $\mathrm{Y}$ & 37 & 44 & 25 & 32 & 34 & 26 \\
\hline $\mathrm{Zr}$ & 176 & 317 & 152 & 217 & 113 & 160 \\
\hline $\mathrm{Nb}$ & 19,40 & 17,60 & 13,70 & 19,90 & 13,90 & 19,70 \\
\hline Th & 15,40 & 10,90 & 9,14 & 17,30 & 11,80 & 17,60 \\
\hline $\mathrm{Pb}$ & 73 & 87 & 45 & 73 & 29 & 60 \\
\hline $\mathrm{Ga}$ & 0 & 0 & 0 & 0 & 0 & 0 \\
\hline $\mathrm{Zn}$ & 190 & 85 & 58 & 44 & 40 & 85 \\
\hline $\mathrm{Cu}$ & 24 & 0 & 7 & 11 & 21 & 46 \\
\hline $\mathrm{Ni}$ & 34 & 38 & 27 & 24 & 19 & 16 \\
\hline $\mathrm{V}$ & 0 & 0 & 0 & 0 & 0 & 0 \\
\hline $\mathrm{Cr}$ & 78 & 53 & 49 & 85 & 68 & 89 \\
\hline $\mathrm{Hf}$ & 8,84 & 17,50 & 9,33 & 10,20 & 6,86 & 6,94 \\
\hline Cs & 0 & 0 & 0 & 0 & 0 & 0 \\
\hline Sc & 17 & 13 & 20 & 23 & 16 & 15 \\
\hline $\mathrm{Ta}$ & 0,95 & 0,74 & 0,67 & 1,20 & 0,94 & 1,41 \\
\hline Co & 11 & 14 & 16 & 12 & 10 & 10 \\
\hline$U$ & 1,56 & 1,90 & 1,54 & 3,06 & 1,87 & 4,85 \\
\hline Sn & 0 & 0 & 0 & 0 & 0 & 0 \\
\hline $\mathrm{La}$ & ------- & ----- & ----- & ----- & ---- & ---- \\
\hline $\mathrm{Ce}$ & ------ & ----- & ----- & ----- & ---- & ---- \\
\hline $\mathrm{Pr}$ & -------- & ------ & ------ & ------ & ----- & ----- \\
\hline $\mathrm{Nd}$ & ------ & ----- & ------ & ----- & ---- & ----- \\
\hline $\mathrm{Sm}$ & ------- & ----- & ------ & ------ & ----- & ----- \\
\hline $\mathrm{Eu}$ & |------ & ----- & ----- & ----- & ---- & ----- \\
\hline $\mathrm{Gd}$ & ------- & ----- & ------ & ----- & ----- & ----- \\
\hline $\mathrm{Tb}$ & ------ & ------ & ---.-- & ----- & --.- & --.-- \\
\hline Dy & -----.- & -.-.-. & --.-- & --..-- & --..- & -..- \\
\hline $\mathrm{Ho}$ & ------- & ----- & ----- & ----- & ---- & ----- \\
\hline $\mathrm{Er}$ & ------- & ------ & ----- & ----- & ---- & ---- \\
\hline $\mathrm{Tm}$ & ------- & ----- & ------ & ----- & ---- & ----- \\
\hline $\mathrm{Yb}$ & |------ & ----- & ----- & ----- & ---- & ---- \\
\hline Lu & ------- & ------ & ------ & ------ & ---- & ----- \\
\hline ¿REE & ------- & ------ & ----- & ----- & ----- & ----- \\
\hline $\mathrm{Eu} / \mathrm{Eu}^{*}$ & ------- & ------ & ----- & ----- & ---- & ----- \\
\hline $\mathrm{Th} / \mathrm{Sc}$ & 0,91 & 0,84 & 0,46 & 0,75 & 0,74 & 1,17 \\
\hline $\mathrm{Zr} / \mathrm{Sc}$ & 10,35 & 24,38 & 7,6 & 9,44 & 7,06 & 10,67 \\
\hline $\mathrm{Ti} / \mathrm{Zr}$ & 29,63 & 13,05 & 23,27 & 24,31 & 31,30 & 37,47 \\
\hline $\mathrm{La}_{\mathrm{N}} / \mathrm{Sm}_{\mathrm{N}}$ & ------ & ------ & ----- & ----- & ---- & ---- \\
\hline $\mathrm{Gd}_{N} / Y \mathrm{~b}_{\mathrm{N}}$ & |------ & ----- & ----- & ----- & ---- & ---- \\
\hline $\mathrm{La}_{\mathrm{N}} / \mathrm{Yb}_{\mathrm{N}}$ & ------- & ----- & ------ & ----- & ---- & ---- \\
\hline$T h / U$ & 9,87 & 5,74 & 5,94 & 5,65 & 6,31 & 3,63 \\
\hline $\mathrm{Rb} / \mathrm{Sr}$ & 5,63 & 1,59 & 2,48 & 2,23 & 2,29 & 6,06 \\
\hline $\mathrm{La} / \mathrm{Th}$ & -.---.- & -.---. & --.--- & -.---. & ---- & ----- \\
\hline
\end{tabular}

y $520 \mathrm{Ma}$. Su base estaría constituida, por sedimentos similares, depositados en la misma cuenca entre el final del Ciclo Sunsás y el comienzo del Ciclo Pampeano, al que denominamos Ciclo Ancajano, se habría desarrollado según los circones detríticos, entre los 850 y 600 Ma.

Los materiales que constituyen al Ciclo Ancajano, tiene características petrográficas similares a las rocas de la Formación Puncoviscana.

La cuenca de deposición habría iniciado con un período distensivo, avalado por las similitudes entre los basamentos de Arequi-
pa-Antofalla y Guaporé, junto a las manifestaciones magmáticas básicas alcalinas a tholeíticas y ultrabásicas. Seguido por un período compresivo, relacionado a una cuenca de antepaís (foreland basin), con subducción al este y generación de magmatismo volcánico plutónico ácido, típico de arco magmático.

La Formación Puncoviscana está constituida por lita-arenitas, grauvacas y pelitas, que constituyen los protolitos que dan lugar a las a pizarras, filitas y esquistos, de las regiones con mayor metamorfismo, mientras que las arcosas parecen estar restringidas 
Tabla 2 (cont.). Datos analíticos de los elementos trazas (ppm) del basamento.

\begin{tabular}{|c|c|c|c|c|c|c|c|c|}
\hline & \multicolumn{2}{|c|}{ SIERRA GUASAYAN } & Sa. QUILMES & \multicolumn{5}{|c|}{ QDA. DE HUMAHUACA } \\
\hline Sample & Gua8150 & Gua cb6-1 & Quil8138 & Top8153 & Top1 & Top1a & Top1b & Top2 \\
\hline $\mathrm{Ba}$ & 393 & 695,8 & 367 & 270 & 308 & 403 & 425 & 491 \\
\hline $\mathrm{Rb}$ & 119 & 166,2 & 127 & 111 & 89 & 112 & 110 & 192 \\
\hline $\mathrm{Sr}$ & 356 & 135,2 & 174 & 64 & 36 & 32 & 33 & 21 \\
\hline $\mathrm{Y}$ & 26 & 35,1 & 27 & 33 & 20 & 26 & 23 & 13 \\
\hline $\mathrm{Zr}$ & 137 & 176 & 464 & 472 & 189 & 246 & 230 & 175 \\
\hline $\mathrm{Nb}$ & 7 & 17,9 & 11 & 10 & 10 & 10 & 9 & 13 \\
\hline Th & 5,50 & 12,8 & 13 & 13,10 & 10,1 & 10,80 & 10,50 & 14,3 \\
\hline $\mathrm{Pb}$ & 9 & 4,4 & 29 & 12 & 16 & 15 & 16 & 20 \\
\hline $\mathrm{Ga}$ & 19 & 25,1 & 16 & 17 & 12 & 13 & 13 & 22 \\
\hline $\mathrm{Zn}$ & 90 & 130 & 90 & 80 & 80 & 100 & 100 & 110 \\
\hline $\mathrm{Cu}$ & 40 & 8,10 & 20 & 10 & 0 & 0 & 10 & 0 \\
\hline $\mathrm{Ni}$ & 50 & 49,3 & 0 & 40 & 20 & 30 & 30 & 40 \\
\hline $\mathrm{V}$ & 148 & 129 & 62 & 84 & 60 & 66 & 67 & 117 \\
\hline $\mathrm{Cr}$ & 30 & 0 & 50 & 60 & 40 & 40 & 40 & 70 \\
\hline $\mathrm{Hf}$ & 3,40 & 5 & 10,90 & 11,10 & 4,7 & 5,10 & 5,10 & 4,20 \\
\hline Cs & 8,70 & 5,6 & 5,60 & 5,5 & 7,6 & 9,90 & 10 & 12,20 \\
\hline Sc & 20 & 16 & 8 & 11 & 8 & 9 & 9 & 16 \\
\hline $\mathrm{Ta}$ & 1,40 & 1,6 & 2 & 2,5 & 1,3 & 1,3 & 1,3 & 1,5 \\
\hline Co & 35 & 51,9 & 26 & 29 & 19 & 20 & 20 & 20 \\
\hline$U$ & 1,90 & 5,3 & 3,40 & 3,2 & 2,3 & 2,90 & 2,8 & 3,8 \\
\hline Sn & 2 & 5 & 3 & 3 & 2 & 2 & 3 & 4 \\
\hline $\mathrm{La}$ & 20,10 & 37,20 & 32,10 & 51,10 & 30,40 & 35,50 & 35,70 & 11,80 \\
\hline $\mathrm{Ce}$ & 40,20 & 79,6 & 88,10 & 97,9 & 60,20 & 67,10 & 66,40 & 31,1 \\
\hline $\mathrm{Pr}$ & 5,08 & 9,58 & 8,32 & 11,4 & 7,31 & 7,97 & 7,97 & 4,61 \\
\hline $\mathrm{Nd}$ & 31 & 35,8 & 31,3 & 42,70 & 26,80 & 29,50 & 28,40 & 19,20 \\
\hline $\mathrm{Sm}$ & 5 & 6,57 & 6,4 & 8,40 & 5,90 & 6,10 & 6,10 & 5,70 \\
\hline Eu & 1,24 & 1,23 & 1,17 & 1,42 & 0,96 & 1,12 & 1,02 & 1,08 \\
\hline $\mathrm{Gd}$ & 4,60 & 5,56 & 5,10 & 6,4 & 4,30 & 5,30 & 4,70 & 5,80 \\
\hline $\mathrm{Tb}$ & 0,80 & 1,01 & 0,80 & 1 & 0,70 & 0,80 & 0,70 & 1,10 \\
\hline Dy & 4,60 & 5,46 & 5,30 & 5,8 & 4 & 4,70 & 4 & 6,60 \\
\hline Ho & 0,90 & 1,09 & 1,10 & 1,10 & 0,80 & 0,90 & 0,80 & 1,30 \\
\hline $\mathrm{Er}$ & 2,50 & 3,24 & 3,10 & 3,30 & 2,20 & 2,70 & 2,30 & 3,80 \\
\hline $\mathrm{Tm}$ & 0,36 & 0,53 & 0,48 & 0,52 & 0,34 & 0,38 & 0,35 & 0,54 \\
\hline $\mathrm{Yb}$ & 2,50 & 3,19 & 3,40 & 3,40 & 2,30 & 2,40 & 2,20 & 3,40 \\
\hline Lu & 0,39 & 0,49 & 0,57 & 0,58 & 0,37 & 0,41 & 0,36 & 0,55 \\
\hline$\sum \mathrm{REE}$ & 109,27 & 190,55 & 187,24 & 235,02 & 146,58 & 164,88 & 161,0 & 96,58 \\
\hline $\mathrm{Eu} / \mathrm{Eu}^{*}$ & 0,78 & 0,61 & 0,61 & 0,59 & 0,58 & 0,60 & 0,58 & 0,57 \\
\hline $\mathrm{Th} / \mathrm{Sc}$ & 0,28 & 0,8 & 1,63 & 1,19 & 1,03 & 1,00 & 1,00 & 1,11 \\
\hline $\mathrm{Zr} / \mathrm{Sc}$ & 6,85 & 11,0 & 58,0 & 42,9 & 23,6 & 27,3 & 25,6 & 10,9 \\
\hline $\mathrm{Ti} / \mathrm{Zr}$ & 47,22 & 30,66 & 8,39 & 9,98 & 17,54 & 14,33 & 15,51 & 29,70 \\
\hline $\mathrm{La}_{\mathrm{N}} / \mathrm{Sm}_{\mathrm{N}}$ & 2,60 & 3,66 & 3,24 & 3,83 & 3,24 & 3,66 & 3,68 & 1,30 \\
\hline $\mathrm{Gd}_{N} / Y \mathrm{~b}_{\mathrm{N}}$ & 1,43 & 1,36 & 1,17 & 1,53 & 1,52 & 1,79 & 1,73 & 1,38 \\
\hline$L a_{N} / Y b_{N}$ & 5,43 & 7,87 & 6,37 & 10,15 & 8,92 & 9,99 & 10,96 & 2,34 \\
\hline$T h / U$ & 2,89 & 2,42 & 3,82 & 4,09 & 4,39 & 3,72 & 3,75 & 3,76 \\
\hline $\mathrm{Rb} / \mathrm{Sr}$ & 0,33 & 1,23 & 0,73 & 1,73 & 2,47 & 3,5 & 3,33 & 9,14 \\
\hline $\mathrm{La} / \mathrm{Th}$ & 3,66 & 2,91 & 2,47 & 3,9 & 3,0 & 3,29 & 3,4 & 0,83 \\
\hline
\end{tabular}

sólo a sectores de la sierra de Famatina.

La pobre selección y la inmadurez de los sedimentos, indicarían débil alteración y relativamente corto transporte y rápido soterramiento, no estando afectadas por el tren de olas.

El comportamiento similar, en todas las localidades estudiadas, de las tierras raras aunque con variaciones en el contenido total, evidenciaría diferencias en las áreas de aporte. Estas, muestran suave pendiente negativa tanto de las tierras raras livianas como de las pesadas, con marcada anomalía negativa de Eu, que es característico para las rocas que derivan de la Corteza Continental Superior (UCC) (McLennan et al., 1990).

Sobre la base de las funciones discriminantes de elementos mayores de Roser y Korsch (1988) las rocas de las sierras de Ancasti, del Campo y Guasayán provienen de sedimentos cuarzosos; mientras que las de las quebradas de Humahuaca y de La Cébila, así como las de las sierras de Quilmes, Cumbres Calchaquíes, San Javier y Famatina, la proveniencia se distribuye entre sedimentos cuarzosos, rocas ígneas félsicas e interme- 
Tabla 2 (cont.). Datos analíticos de los elementos trazas (ppm) del basamento.

\begin{tabular}{|c|c|c|c|c|c|c|c|c|c|}
\hline & \multicolumn{7}{|c|}{ CUMBRES CALCHAQUIES } & \multicolumn{2}{|c|}{ patrones } \\
\hline Sample & T8133 & T8134 & $\mathrm{T} 8135$ & T8136 & T8137 & T8135 & T8136 & UCC $^{*}$ & UCC\# \\
\hline $\mathrm{Ba}$ & 837 & 652 & 643 & 430 & 300 & 643 & 430 & 550 & 628 \\
\hline $\mathrm{Rb}$ & 274 & 158 & 150 & 101 & 192 & 150 & 101 & 112 & 82 \\
\hline $\mathrm{Sr}$ & 110 & 128 & 174 & 179 & 48 & 174 & 179 & 350 & 320 \\
\hline $\mathrm{Y}$ & 34 & 28 & 34 & 37 & 27 & 34 & 37 & 22 & 21 \\
\hline $\mathrm{Zr}$ & 227 & 174 & 208 & 420 & 161 & 208 & 420 & 190 & 193 \\
\hline $\mathrm{Nb}$ & 22 & 14 & 15 & 15 & 16 & 15 & 15 & 25 & 12 \\
\hline Th & 23,10 & 11,1 & 12,10 & 14,5 & 14,7 & 12,10 & 14,5 & 10,7 & 10,5 \\
\hline $\mathrm{Pb}$ & 30 & 29 & 29 & 33 & 36 & 29 & 33 & 20 & 17 \\
\hline $\mathrm{Ga}$ & 34 & 24 & 24 & 18 & 27 & 24 & 18 & 17 & 17,5 \\
\hline $\mathrm{Zn}$ & 160 & 110 & 120 & 90 & 160 & 120 & 90 & 71 & 67 \\
\hline $\mathrm{Cu}$ & 0 & 0 & 0 & 120 & 0 & 0 & 120 & 25 & 28 \\
\hline $\mathrm{Ni}$ & 40 & 40 & 30 & 20 & 30 & 30 & 20 & 20 & 47 \\
\hline V & 129 & 108 & 111 & 90 & 116 & 111 & 90 & 60 & 97 \\
\hline $\mathrm{Cr}$ & 90 & 80 & 80 & 70 & 80 & 80 & 70 & -- & 92 \\
\hline $\mathrm{Hf}$ & 6 & 4,50 & 5,60 & 10,3 & 4,3 & 5,60 & 10,3 & 5,8 & 5,3 \\
\hline Cs & 16 & 9,6 & 8,4 & 6,4 & 9,4 & 8,4 & 6,4 & 3,5 & 4,9 \\
\hline Sc & 19 & 14 & 14 & 11 & 16 & 14 & 11 & - & 14 \\
\hline $\mathrm{Ta}$ & 2 & 1,70 & 2 & 2,5 & 1,3 & 2 & 2,5 & 2,20 & 0,9 \\
\hline Co & 31 & 33 & 32 & 34 & 22 & 32 & 34 & 10 & 17,3 \\
\hline $\mathrm{U}$ & 2,5 & 2,70 & 2,6 & 3,0 & 3,0 & 2,6 & 3,0 & 2,80 & 2,7 \\
\hline $\mathrm{Sn}$ & 6 & 4 & 5 & 3 & 4 & 5 & 3 & 5,50 & 2,1 \\
\hline $\mathrm{La}$ & 61,30 & 38,8 & 40 & 43,4 & 33,6 & 40 & 43,4 & 30 & 31 \\
\hline $\mathrm{Ce}$ & 122 & 81,2 & 86,2 & 94,10 & 70,6 & 86,2 & 94,10 & 64 & 63 \\
\hline $\mathrm{Pr}$ & 14,7 & 8,94 & 9,73 & 10,80 & 7,83 & 9,73 & 10,80 & 7,10 & 7,1 \\
\hline $\mathrm{Nd}$ & 54,8 & 34,60 & 37,7 & 41,40 & 29,7 & 37,7 & 41,40 & 26 & 27 \\
\hline $\mathrm{Sm}$ & 10,20 & 6,80 & 7,40 & 8,50 & 5,9 & 7,40 & 8,50 & 4,50 & 4,7 \\
\hline $\mathrm{Eu}$ & 1,83 & 1,35 & 1,49 & 1,60 & 1,17 & 1,49 & 1,60 & 0,88 & 1,0 \\
\hline $\mathrm{Gd}$ & 7 & 5,60 & 6 & 6,50 & 5 & 6 & 6,50 & 3,80 & 4,0 \\
\hline $\mathrm{Tb}$ & 1,1 & 0,90 & 0,9 & 1 & 0,8 & 0,9 & 1 & 0,64 & 0,7 \\
\hline Dy & 7,1 & 5,40 & 6 & 6,5 & 5,1 & 6 & 6,5 & 3,50 & 3,9 \\
\hline $\mathrm{Ho}$ & 1,5 & 1,10 & 1,3 & 1,3 & 1,1 & 1,3 & 1,3 & 0,80 & 0,83 \\
\hline $\mathrm{Er}$ & 4,1 & 3 & 3,5 & 3,8 & 3,1 & 3,5 & 3,8 & 2,30 & 2,3 \\
\hline $\mathrm{Tm}$ & 0,6 & 0,44 & 0,51 & 0,55 & 0,46 & 0,51 & 0,55 & 0,33 & 0,3 \\
\hline $\mathrm{Yb}$ & 4,1 & 3 & 3,40 & 3,8 & 3,1 & 3,40 & 3,8 & 2,20 & 2,0 \\
\hline Lu & 0,68 & 0,50 & 0,58 & 0,65 & 0,49 & 0,58 & 0,65 & 0,32 & 0,31 \\
\hline$\sum R E E$ & 291,01 & 191,63 & 204,71 & 223,90 & 167,95 & 204,71 & 223,90 & 146,37 & 148,14 \\
\hline $\mathrm{Eu} / \mathrm{Eu}^{*}$ & 0,63 & 0,65 & 0,66 & 0,63 & 0,64 & 0,66 & 0,63 & 0,65 & 0,72 \\
\hline $\mathrm{Th} / \mathrm{Sc}$ & 1,22 & 0,79 & 0,86 & 1,32 & 0,92 & 0,86 & 1,32 & -- & 0,75 \\
\hline $\mathrm{Zr} / \mathrm{Sc}$ & 11,95 & 12,43 & 14,86 & 38,18 & 10,06 & 14,86 & 38,18 & -- & 13,79 \\
\hline $\mathrm{Ti} / \mathrm{Zr}$ & 25,67 & 27,01 & 24,93 & 13,15 & 30,31 & 24,93 & 13,15 & 15,78 & 19,88 \\
\hline $\mathrm{La}_{\mathrm{N}} / \mathrm{Sm}_{\mathrm{N}}$ & 3,88 & 3,68 & 3,49 & 3,30 & 3,68 & 3,49 & 3,30 & 9,20 & 4,15 \\
\hline$G d_{N} / Y b_{N}$ & 1,33 & 1,45 & 1,37 & 1,33 & 1,26 & 1,37 & 1,33 & 1,40 & 1,60 \\
\hline $\mathrm{La}_{\mathrm{N}} / \mathrm{Yb}_{\mathrm{N}}$ & 10,09 & 8,73 & 7,94 & 7,71 & 7,32 & 7,94 & 7,71 & 9,21 & 10,47 \\
\hline Th/U & 9,24 & 4,11 & 9,24 & 4,11 & 4,65 & 9,24 & 4,11 & 4,83 & 3,8 \\
\hline $\mathrm{Rb} / \mathrm{Sr}$ & 2,49 & 1,23 & 0,86 & 0,56 & 4,0 & 0,86 & 0,56 & 0,32 & 0,26 \\
\hline $\mathrm{La} / \mathrm{Th}$ & 2,65 & 3,5 & 3,31 & 2,99 & 2,29 & 3,31 & 2,99 & 2,80 & 2,95 \\
\hline
\end{tabular}

dias, que habrían formado parte de la Corteza Continental Superior (UCC).

Con relación al ambiente tectónico de deposición, utilizando elementos mayores, en el diagrama de Roser y Korsch (1986), las rocas se distribuyen entre arco de islas oceánicas y margen continental activo. Mientras que en el diagrama de Bhatia y Crook (1986) los valores se corresponden con los campos de margen pasivo, margen activo y arco de islas continentales.

Un origen extensional, para el inicio de la cuenca de Puncoviscana parece el modelo más adecuado a la luz de las evidencias geológicas disponibles, en relación a las edades similares de los basamentos de ArequipaAntofalla y Amazonia; junto al magmatismo básico alcalino a sub-alcalino. Con posterioridad y en respuesta a un evento compresivo cambian los caracteres de la sedimentación que es controlada por las condiciones correspondientes a una cuenca de antepaís (foreland basin) que ocurre durante la orogenia Tilcárica, que genera una actividad magmática ácida con caracteres calco-alcalinos.

Las características de los depósitos de la 
Formación Puncoviscana se corresponden esencialmente con derivación de rocas de la Corteza Continental Superior de McLennan et al. (1990), mostrando enriquecimiento en Cs y está deprimida en $\mathrm{Sr}$ y Ni, por influencia de aportes de arco magmático ácido, en un margen pasivo.

Los datos de las diferentes edades de circones detríticos obtenidos por diferentes autores, avalan un origen multi-cíclico y multi-fuente de los sedimentos y permiten interpretar que la constitución mineralógica actual, respondería a la composición de las diferentes fuentes relativamente próximas a la zona de deposición, en una cuenca de antepaís, ya que las distantes habrían sido transformadas en fracciones granulométricas finas, sobreviviendo como psamitas sólo los materiales de procedencia relativamente cercana.

\section{TRABAJOS CITADOS}

Aceñolaza, F. G., Miller, H., y Toselli, A. J. 1988. The Puncoviscana Formation [Late Precambrian - Early Cambrian). Sedimentology, tectonometamorphic history and age of the oldest rocks of NW Argentina. In: Bahlburg, H., Breitkreutz, C., y Giese, P. (eds.). The Southern Central Andes. Contributions to Structure and Evolution of an Active Continental Margin. Berlin. Springer. Lecture Notes in Earth Sciences, 17: 25-37.

Aceñolaza, F. G., Toselli, A. J., Miller, H., Adams, C. 2010. Interpretación de las poblaciones de circones detríticos en unidades estratigráficas equivalentes del Ediacarano-Cámbrico de Argentina. En: El Ediacarano-Cámbrico en Gondwana Occidental I. Serie Correlación Geológica № 26: 49-64.

Aceñolaza, G. F., y Aceñolaza, F. G. 2001. Ichnofossils and microbial activity in the Precambrian/Cambrian transition of Northwestern Argentina. Palaeoworld 13: 241-244. Nanjing- China.

Aceñolaza, F. G., y Aceñolaza, G. 2005 La Formacion Puncoviscana y unidades estratigráficas equivalentes en el Neoproterozoico - Cámbrico Temprano del Noroeste Argentino. Latin American Journal of Sedimentology and Basin Analysis 12: 7-91

Aceñolaza, F. G., y Durand, F. 1986. Upper Precambrian-Lower Cambrian biota from northwest of Argentina. Geological Magazine 123: 367-375.

Aceñolaza, F. G., y Miller, H. 1982. Early Paleozoic orogeny in southern South America. Precambrian Research 17: 133-146.

Aceñolaza, F., Toselli, A., y Miller, H. 2002. Proterozoic-Early Paleozoic evolution in western South America - A discussion. Tectonophysics 354: 121-137

Aceñolaza, F. G., y Toselli, A. J., 1976. Consideraciones estratigráficas y tectónicas sobre el Paleozoico inferior del noroeste argentino. II Congreso Latino Americano de Geología Venezuela. 2: 741-754.

Adams, C., Miller, H., y Toselli, A. J. 2008a. Detrital zircon U-Pb ages of the Puncoviscana Formation, Late Neoproterozoic - Early Cambrian, of NW Argentina: provenance area and maximum age of deposition. (VI SSAGI) VI South American Symposium on Isotope Geology. Compilers Proceedings: Linares, E., Cabaleri, N.G., Do Campo, M. D., Duchos, E. I., Panarello, H. O. Trabajo CD Room. 4 pp.

Adams, C. J., Miller, H., y Toselli, A. J. 2005. Rb-Sr age of metasediments of the Puncoviscana Formation, northwest Argentina, and $\mathrm{U}-\mathrm{Pb}$ detrital zircon age evidence for their provenance. In: Pankhurst, R. J., and Veiga, G. D. [Eds.] Gondwana 12: Geological and Biological Heritage of Gondwana, Abstracts. Academia Nacional de Ciencias, Córdoba, Argentina, p. 35 .

Adams, Ch., Miller, H., Toselli, A. J., y Griffin, W. L. 2008b. The Puncoviscana Formation of northwest Argentina: U$\mathrm{Pb}$ geochronology of detrital zircons and $\mathrm{Rb}-\mathrm{Sr}$ metamorphic ages and their bearing on its stratigraphic age, sediment provenance and tectonic setting. Neues Jahrbuch Geologie und Paläontologie Abhandlungen, 247 (3): 341-352.

Adams, C., Miller, H., y Toselli, A. J. 2009. Detrital zircon U-Pb ages of the Puncoviscana Formation and its metamorphic equivalents in Catamarca and La Rioja, northwest Argentina. In: Wörner, G., Möller-McNett, S. [Eds.] Lateinamerika-Kolloquium 2009. Abstract and Program. Universitätsverlag Göttingen, 20-21 p.

Adams, C. J., Miller, H., Aceñolaza, F. G., Toselli, A. J., y Griffin, W. L. 2011. The Pacific Gondwana margin in the late Neoproterozoic - early Paleozoic: Detrital zircon $\mathrm{U}-\mathrm{Pb}$ ages from metasediments in northwest Argentina reveal 
their maximum age, provenance and tectonic setting. Gondwana Research, doi:10.1016/j.gr.2010.05.002.

Almeida, F. F. M. de, Hasui, Y., Neves, B. B. de, Fuck, R. A. 1981. Brazilian structural provinces: an introduction. EarthSciences Review, 17: 1-21.

Bahlburg, H. 1999. The geochemistry and provenance of Ordovician turbidites in the Argentine Puna. In: Pankhurst, R. J., y Rapela, C. W. (eds.). The ProtoAndean Margin of Gondwana. Geological Society, London, Special Publication 142: 127-142.

Bassi, H. G. L. 1952. Los depósitos de ilmenita y magnetita titanífera de la Mina Podestá (ex-Romay). Departamento El Alto (Catamarca). Boletín Dirección Nacional de Minería 77: 5-25.

Bhatia, M. R. 1983. Plate tectonics and geochemical composition of sandstones. Journal of Geology 91 (6): 611-627.

Bhatia , M. R. 1985. Composition and classification of Paleozoic flysh of eastern Australia: implication in provenance and tectonic setting interpretation. Sedimentary Geology 41 (2-4): 249-268.

Bhatia, M. R., y Crook, K. A. W. 1986. Trace element characteristics of greywackes and tectonic setting discrimination of sedimentary basins. Contributions to Mineralogy and Petrology 92 (2): 181 193.

Bock, B., Bahlburg, H., Wörner, G., y Zimmermann, U., 2000. Tracing crustal evolution in the Southern Central Andes from Late Precambrian to Permian with geochemical and $\mathrm{Nd}$ and $\mathrm{Pb}$ isotope data. Journal of Geology 108: 515-535.

Caminos, R. 1979. Sierras Pampeanas noroccidentales, Salta, Tucumán, Catamarca, La Rioja, San Juan. In: II Simposio Geología Regional Argentina. Academia Nacional de Ciencias en Córdoba, 1: 225-291.

Castellote, P. 1989. Estudio geológico y geocronológico del basamento cristalino del sector septentrional de la Sierra Norte de Córdoba. Acta Geológica Lilloana XVII (1): 61-66.

Colombo, C., Tassinari, G., y Macambia, M.J.B. 1999. Geochronological provinces of the Amazonian Craton. Episodes, 22: 174-182.

Chayle, W., y Coira, B. 1987. Vulcanitas básicas a ultrabásicas y mesosiliceas de la Formación Puncoviscana en el área del Cerro Alto de Las Minas, departamento Tilcara, Jujuy, Argentina. 10응
Congreso Geológico Argentino. Acta IV: 296-298.

Coira, B., Manca, N., y Chayle, W. 1990. Registros volcánicos en la Formación Puncoviscana. Serie Correlación Geológica 4: 53-60.

Do Campo, M., y Ribeiro Guevara, S. 2005 Provenance analysis and tectonic setting of late Neoproterozoic metasedimentary successions in NW Argentina. Journal of South American Earth Sciences 19: 143-153.

Durand, F. R. 1988. Los depósitos psefíticos del basamento metamórfico en el noroeste argentino. oo Congreso Geológico Chileno, Actas II: C105 - C119.

Durand, F. R. 1990. Los conglomerados del Ciclo Pampeano en el Noroeste Argentino. In: Aceñolaza, F.G., Miller, H., Toselli, A.J. (Eds.). El Ciclo Pampeano en el Noroeste Argentino. Serie Correlación Geológica 4: 61-69.

Durand, F. R., y Aceñolaza, F. G. 1990. Caracteres biofaunisticos, paleoecológicos y paleogeográficos de la Formación Puncoviscana (Precámbrico superior-Cámbrico inferior] del Noroeste Argentino. In: Aceñolaza, F. G., Miller, H., Toselli, A. J. [Eds.]. El Ciclo Pampeano en el Noroeste Argentino. Serie Correlación Geológica 4: 71-112.

Escayola, M. P., Pimentel, M. M., Amstrong, R. 2007. Neoproterozoic back-arc basin: sensitive high-resolution ion microprobe U-Pb and $\mathrm{Sm}-\mathrm{Nd}$ isotopic evidence from the Eastern Sierras Pampeanas, Argentina. Geology 35: 495-498.

Floyd, P.A., y Leveridge, B.E. 1987. Tectonic environment of the Devonian Gramscatho basin, south Cornwall: Framework mode and geochemical evidence from turbidite sandstones. Journal of the Geological Society, London, 144: 531-542.

Gaucher, C., Poiré, D., Gómez Peral, L., Chiglino, L. 2005. Litoestratigrafía, bioestratigrafía y correlaciones de las sucesiones sedimentarias del Neoproterozoico-Cámbrico del Cratón del Río de la Plata (Uruguay y Argentina). Latin American Journal of Sedimentology and Basin Análisis, 12 (2): 145-160.

Gaucher, C., Bossi, J., y Blanco, G. 2009. Paleogeography. Neoproterozoic - Cambrian evolution of the Río de la Plata palaeocontinent. In: Gaucher, C., Sial, A. N., Halverson, G. P., y Frimmel, H.E. (Eds.). Neoproterozoic - Cambrian tectonics, global change and evolution: a focus on southwestern Gondwana. Developments in Precambiran Geology, 16: 131-141. 
Gosen, W. von, McClelland, W. C., Martínez, J. C., Proxy, C. 2014. Geochronology pf igneous rocks in the Sierra Norte de Córdoba (ÇArgentina): Implications for the Pampean evolution at the western Gondwana margin. Geological Society of America, Lithosphere, 6:277-300

Gosen, W. von, Buggisch, W., y Prozzi, C. 2009. Provenance and geotectonic setting of Late Proterozoic-Early Cambrian metasediments in the Sierras de Córdoba and Guasayán (western Argentina): a geochemical approach. Neues Jahrbuch Geologie und Paläontologie Abhandlungen. 251/3: 257-284. Stuttgart.

Grissom, G. C., De Bari, y Snee, L. W. 1998. Geology of the Sierra de Fiambalá, northwest Argentina: implications for Early Palaeozoic Andean tectonics. In: Pankhurst, R.J. and Rapela, C. W. (Ed.), The Proto-Andean margin of Gondwana. Geological Society of London, Special Publication 142: 297-324.

Hauser, N. 2011. Petrología y geología isotópica de las rocas ígneas y estudios de proveniencia (U-Pb y Lu-Hf) de las rocas metasedimentarias del basamento del Paleozoico inferior en las áreas de Tastil, Niño Muerto, Río Blanco y Río Grande, Cordillera Oriental, Noroeste Argentino. Tesis Doctoral Universidad Nacional de Salta, 248 pp. (inédita).

Herron, M.M. 1988. Geochemical classification of terrigenous sands and shales from core of log data. Journal of Sedimentary Petrology 58: 820-829.

lannizzotto, N. F., Rapela, C. W., Baldo, E. G. A., Galindo, C., Fanning, C. M., Pakhurst, R.J. 2013. The Sierra NorteAmbargasta batholith: Late EdiacaranAerly Cambrian magmatism associated with Pampean transpressional tectonics. Journal of South American Earth Scienses, 42: 127-143.

Ježek, P., and Miller, H. 1986. Deposition and facies distribution of turbiditic sediments of the Puncovicana Formation (Upper Precambrian - Lower Cambrian] within the basement of the NW-Argentine Andes. Zentralblatt Geologie und Paläontologie. Teil I: 9-10: 1235-1244.

Ježek, P, A. P. Willner, A. P., Aceñolaza, F. G., y Miller, H. 1985. The Puncoviscana trough-a large basin of Late Precambrian to Early Cambrian age on the Pacific edge of the Brazilian shield. Geologische Rundschau 74: 573-584.

Ježek, P. 1990. Análisis sedimentológico de la Formación Puncoviscana entre Tucumán y Salta. In: Aceñolaza, F.G., Miller, H., y Toselli, A. J. (Eds). El Ciclo Pampeano en el Noroeste Argentino. Serie Correlación Geológica 4: 9-35.

Keppie, J. D., y Bahlburg, H. 1999. Puncoviscana Formation of northwestern and central Argentina: Passive margin or foreland basin deposits? In: LaurentiaGondwana connections before Pangaea (Eds V. A. Ramos and J. D. Keppie), Geological Society of America Special Publication: 336, 139-144.

Koukharsky, M., Brodtkorb, M. K., Kay, S. M., and Munizaga, F. 2003. La Formación Balbuena, integrante del arco magmático pampeano en la sierra de Ambargasta, provincia de Santiago del Estero. Revista de la Asociación Geológica Argentina 58 (4): 583-592.

Kraemer, P. E., Escayola, M. P., y Martino, R. D., 1995. Hipótesis sobre la evolución tectónica Neoproterozoica de las Sierras Pampeanas de Córdoba, Argentina. Revista de la Asociación Geológica Argentina 50: 47-59.

Kroner, A. 1981. Precambrian plate tectonics. In Kroner A. (editor) Development in Precambrian geology. Elsevier 4:57-90.

Leal, P. R., Hartmann, L. A., Santos, J. 0. S., Miró, R., y Ramos, V. A. 2003. Volcanismo posorogénicos en el extremo norte de las Sierras Pampeanas Orientales: Nuevos datos geocronológicos y sus implicancias tectónicas. Revista de la Asociación Geológica Argentina 58 (4): 593-607.

Litherland 1986. The Geology and mineral resources of the Bolivian Precambrian Shield. Overseas Memoir British Geological Survey 9: 1-153.

Llambías, E. J., Gregori, D., Basei, M. A., Varela, R., y Prozzi, C. 2003. Ignimbritas riolíticas neoproterozoicas en la Sierra Norte de Córdoba ¿evidencia de un arco magmático temprano en el ciclo Pampeano? Revista de la Asociación Geológica Argentina 58 (4): 572-582.

López de Azarevich, V., Aceñolaza, F. G., Aceñolaza, G. F., Omarini, R. H., Azarevich, M. 2012. La cuenca NeoproterozoicaEocámbrica en el NOA: sedimentología y ambientes de depósito de secuencias con icnofósiles, nuevas perspectivas. XIII Reunión Argentina de Sedimentología, Relatorio, 119-132. Salta.

Lottner, U. S. 1986. Strukturgebundene Magmenentwicklung im altpaläozoischen Grundgebirge NW-Argentiniens am Beispiel der Sierra de Ancasti (Provinz Catamarca). Münstersche Forschungen 
zur Geologie und Paläontologie 65: 1180. Münster.

Lucassen, F., Becchio, R., Wilke, H. G., Franz, G., Thirlwall, M. F., Viramonte, y Wemmer, K. 2000. Proterozoic-Paleozoic development of the basement of the Central Andes (18-265) - a mobile belt of the South American craton. Journal of South American Earth Sciences 13: 697-715.

Lucassen, F., Harmon, R., Franz, G., Becchio, R., Siebel, W. 2002. Lead evolution of the Pre-Mesozoic crust in the Central Andes $\left(18^{\circ}-27^{\circ}\right)$. Progresive homogenization of $\mathrm{Pb}$. Chemical Geology, 186 (34): 183-197.

Manca, N., Coira, B., Barber, E., y Pérez, A. 1987. Episodios magmáticos de los ciclos Pampeano y Famatiniano en el Río Yacoraite, Jujuy. Xo Congreso Geológico Argentino Actas, IV: 299-301. Tucumán.

McLennan, S. M. 1989. Rare earth elements in sedimentary rocks: influence of provenance and sedimentary processes. In: Lipin, B. R., y McKay, G. A. [Eds.]. Geochemistry and mineralogy of rare earth elements. Reviews in Mineralogy 21 : 169-200.

McLennan, S. M. 2001. Relationships between the trace element composition of sedimentary rocks and upper continental crust. Geochemistry, Geophysics, Geosystems, 2: 2000GC000109.

McLennan, S.M., Hemming, S., McDaniel, D. K., y Hanson, G. N. 1993. Geochemical approaches to sedimentation, provenance and tectonics. In: Johnson, M. J., y Basu, A. (eds.). Processes controlling the composition of clastic sediments. Geological Society of America Special Paper, 284: 21-40. Boulder.

McLennan, S. M., Taylor, S.R., McCulloch, M. T., y Maynard, J. B. 1990. Geochemical and $\mathrm{Nd}-\mathrm{Sr}$ isotopic composition of deep sea turbidites: crustal evolution and plate tectonic associations. Geochimical and Cosmochimical Acta 54: 2015-2050.

Miller, H., Adams, C., Aceñolaza, F.G., Toselli, A. J. 2010. Ways and wrong ways of interpreting detrital zircón ages. VII South American Symposium on Isotope Geology (VII-SSAGI). Brasilia. Publicación CD-9h3028.

Miró, R. C., Schwartz, J. L., y Gromet, P. 2004. Magmatismo calcoalcalino en la Sierra Norte de Córdoba, su extensión temporal. In: Aceñolaza, F. G., Aceñolaza, G. F., Hünicken, M., Rossi, J. N.,
Toselli, A.J. (ed.) Simposio Bodenbender. Serie Correlación Geológica 19: 199 210.

Mon, R., y Hong, F. D. 1991. The structure of the Precambrian and Lower Paleozoic basement of the Central Andes between $22^{\circ}$ and 32 ㅇ S Lat. Geologische Rundschau 80 (3): 745-758.

Nesbitt, H. W., y Young, G. M. 1984. Prediction of some weathering trends of plutonic and volcanic rocks based upon thermodynamic and kinetic considerations. Geochemical and Cosmochimical Acta 48: 1523-1534.

Nesbitt, H. W., y Young, G. M. 1989. Formation and diagenesis of weathering profiles. Journal Geology 97: 129-147.

Omarini, R., 1983. Caracterización litológica, diferenciación y génesis de la Formación Puncoviscana entre el Valle de Lerma y la Faja Eruptiva de la Puna. 202 pp. Thesis unpublished. Universidad Nacional de Salta.

Omarini, R. H., Sureda, R.,Toselli, A. J., y Rossi, J. N. 1999a. Magmatismo. En: Geología del Noroeste Argentino. Relatorio del XIV Congreso Geológico Argentino. Edit. González Bonorino, G., Omarini, R., and Viramonte, J. I: 29-40.

Omarini, R. H., Sureda, R. J., Götze, H. J., Seilacher, A., y Pflüger, F. 1999b. Puncoviscana folded belt in northwestern Argentina: testimony of Late Proterozoic Rodinia fragmentation and pre-Gondwana collisional episodes. International Journal Earth Sciences 88: 76-97.

Omarini, R., Aparicio Yague, A., Pichoviak, S., Viramonte, J., Damm, W., and García Cacho, L. 1987 a. Santa Rosa de Tastil Granitic Complex, Salta, Argentina: an unusual $\mathrm{S}$ type granite. $\mathrm{X}$ o Congreso Geológico Argentino Actas, 4: 119121.

Omarini, R., Aparicio Yague, A., y Viramonte, J. 1987 b. Cañaní granitic complex, Salta, Argentina. Geochemical and petrological approach. Xo Congreso Geológico Argentino Actas, 4: 122-124.

Pankhurst, R. J., Rapela, C. W., Saavedra, J., Baldo, E., Dahlquist, J., Pascua, I., y Fanning, C. M. 1998. The Famatinian magmatic arc in the central Sierras Pampeanas: an early to Mid-Ordovician continental arc on the Gondwana margin. In: Pankhurst, R. J., y Rapela, C. W. (Eds.). The protoandean margin of Gondwana. The Geological Society of London. Special Publication 142: 343367. 
Pankhurst, R., and Rapela, C. W. 1999. The proto-Andean margin of Gondwana: an introduction. In: Pankhurst, R., y Rapela, C.W. (Eds.). The proto-Andean margin of Gondwana. The Geological Society of London. Special Publication 142: 1-10.

Pettijohn, F. J., Potter, P. E., Siever, R. 1972. Sand and sandstones. Springer Verlag, New-York.

Porto, J. C., Fernández, R. I., Carrión, M. H. 1990. Calizas y dolomias de la Formación Puncoviscana s.I. In: Aceñolaza, F. G., Miller, H., y Toselli, A. J. (eds.). El Ciclo Pampeano en el Noroeste Argentina. Serie Correlación Geológica 4: 37-52.

Ramstein, G., Donnadieu, Y., Goddéris, Y. 2004. Les glaciations du Protérozoïque. Comptes Rendus Geoscience, 336: 639646.

Rapela, C. W., Pankhurst, R. J., y Bonalumi, A. A. 1991. Edad y geoquímica del pórfido granítico de Oncán, sierra Norte de Córdoba, Sierras Pampeanas, Argentina. 6ํㅡㄹ Congreso Geológico Chileno, Actas 1: 19-22.

Rapela, C. W., Pankhurst, R., Casquet, C., Baldo, E., Saavedra, J., Galindo, C., Fanning, C. M. 1998. The Pampean orogeny of the southern proto-Andes: Cambrian continental collision in the Sierras de Córdoba. In: Pankhurst, R., y Rapela, C. W. (Ed.) The Proto-Andean Margin of Gondwana. Geological Society of London. Special Publication № 142: 181-217. London.

Rapela, C. S., Pankhurst, R. J., Casquet, C., Fanning, C. M., Baldo, E.G., GonzálezCasado. J. M., Galindo, C., Dahlquist, J. 2007. The Río de la Plata craton the assembly of SW Gondwana. Earth-Science Reviews 83: 49-82.

Roser, B. P., y Korsch, R. J. 1986. Determination of tectonic setting of sandstonemudstone suites determined using $\mathrm{SiO} 2$ content amd $\mathrm{K} 20 / \mathrm{Na} 2 \mathrm{O}$ ratio. Journal Geology 94: 635-650.

Roser, B. P., y Korsch, R. J. 1988. Provenance signatures of sandstone-mudstone suites determined using discriminant function of major-element data. Chemical Geology 67: 119-139.

Rossi, J. N., Toselli, A. J., Durand, F. R. y Sardi, F. G. 1997. Aspectos estratigráficos y geoquímicos comparativos del basamento metamórfico de bajo grado del Sistema de Famatina, Argentina. Revista de la Asociación Geológica Argentina 52 (4): 469-480.
Rudnick, R. L., y Gao, S. 2003. The Crust. In: Davis, A. M., Holland, H. D., y Turekian, K. K. (eds.). Treatise on Geochemistry. Vol. 3: 569-659.

Schalamuk, I., Dalla Salda, L., Angelelli, V., Fernández, R., y Etcheverry, R. 1983. Rocas máficas y ultramáficas. Petrología y mineralización. In: Aceñolaza, F. G., Miller, H. y Toselli, A. J. (Edit.) La Geología de la Sierra de Ancasti. Münstersche Forschungen Geologie und Paläontologie 59: 31-78.

Schwartz, J. J., y Gromet, L. P. 2004. Provenance of a late Proterozoic-early Cambrian basin, Sierras de Córdoba. Precambrian Research 129: 1-21.

Simpson, C., Law, R.D., Gromet, P. L., Miró, R., Northrup, C. J. 2003. Paleozoic deformation in the Sierras de Córdoba, Easthern Sierras Pampeanas. Argentina. Journal of South American Earth Sciences, 15: 749-764.

Sims, J. P., T. R. Ireland, A. Camacho, P. Lyons, P. E. Pieters, R. G. Skirrow, P. G. Stuart-Smith, and R. Miró. 1998. U-Pb, $\mathrm{Th}-\mathrm{Pb}$ and $\mathrm{Ar}-\mathrm{Ar}$ geochronology from the Sierras Pampeanas, Argentina: Implications for the Palaeozoic tectonic evolution of the western Gondwana margin. In: Pankhurst, R. J., and C. W. Rapela (eds.): "The Proto-Andean Margin of Gondwana". 142: 259-281.

Suárez Soruco, R. 1989. Desarrollo tectonosedimentario del Paleozoico inferior de Bolivia. Información Geológica UAFT. Simposio Bodas de Oro de la Universidad Tomás Frías, Potosí. II: 1-11.

Suárez Soruco, R. 2000. Compendio de Geología de Bolivia. Revista Técnica de Yacimientos Petrolíferos Fiscales Bolivianos, 18 (1-2): 1-144.

Taylor, S. R., y McLennan, S. M. 1985. The continental crust: its composition and evolution. Blackwell, Oxford.

Tosdal, R. M. 1996. The Amazon-Laurentia connection as viewed from the Middle Proterozoic rocks in the central Andes, western Bolivia and northern Chile. Tectonics 15 (4): 827-842.

Toselli, A. y Rossi de Toselli, J. 1973. Metamorfismo de las Cumbres Calchaquíes: I Rasgos de deformación y blastésis en las rocas del faldeo suroccidental, entre La Angostura y Tafí del Valle, Tucumán, Argentina. Revista de la Asociación Geológica Argentina 28 (1): 454473.

Toselli, A. y Rossi de Toselli, J. N. 1984. Metamorfismo de las Cumbres Calchaquíes II: Petrología del basamento esquistoso entre La Angostura y Tafí del Valle. Re- 
vista de la Asociación Geológica Argentina XXXIX (3 4): 262275.

Toselli, A. y Rossi de Toselli, J. N. 1982. Metamorfismo de la Formación Puncoviscana en las provincias de Salta y Tucumán, Argentina. oo Congreso Latinoamericano de Geología, Acta II: 37 52, Argentina.

Toselli, A. J., Aceñolaza, G. F., Millar, H., Adams, C., Aceñolaza, F. G., Rossi, J. N. 2012. Basin evolution of the margino $f$ Gondwana at the Neoproterozoic/Cambrian transition: the Puncoviscana formation of Northwest Argentina. Neues Jahrbuch für Geologie und Paläontologie Abhandlungen. 265/1: 79-95.

Toselli, A. J., Aceñolaza, G. F., Basei, M. A., Aceñolaza, F. G., Rossi, J. N. 2015. Regional implications of U-Pb zircón ages from rhyolitic pebbles of Suncho Formation conglomerates, northern Sierras Pampeanas (NW Argentina). Neues Jahrbuch für Geologie und Paläontologie Abhandlungen. 275/1: 33-45.

Verdecchia, S. O., Murra, J. A., Baldo, E. G., Casquet, C., Pascua, I., Saavedra, J. 2014. Geoquímica de las rocas metasedimentarias del Cámbrico medio al Ordovícico temprano de la Sierra de Los Llanos (Sierras Pampeanas, Argentina): fuente de sedimentos, correlación y ambiente geotectónico, Andean Geology 41 (2): $380-400$

Willner, A. P., Toselli, A. J., Bazán, C., Vides de Bazán. 1983. Rocas Metamórficas. In: Aceñolaza, F. G., Miller, H., y Toselli, A. J. (eds.). La Geología de la Sierra de Ancasti. Münstersche Forschungen zur Geologie und Paläontologie 59: 31-78. Münster.

Willner, A. 1990. División tectonometamórfica del basamento del noroeste argentino. In: Aceñolaza, F., Miller, H., and Toselli, A. (Eds.) El Ciclo Pampeano en el Noroeste Argentino. Serie Correlación Geológica 4: 113-159.

Willner, A. and Miller, H. 1986. Structural division and evolution of the Lower Paleozoic basement in the NW-Argentina Andes. Zentralblatt Geologie und Paläontologie. Teil. I (9-10): 1245-1255. Sttutgart.

Zimmermann, U. 2005. Provenance studies of very low-to low-grade metasedimentary rocks of the Puncoviscana Complex, northwest Argentina. In: Vaughan, A., Leat, P., y Pankhurst, R. [Eds.] Geological Society of London. Special Publication 246: 381-416. 